I NTER NATIONAL MONETARY FUND

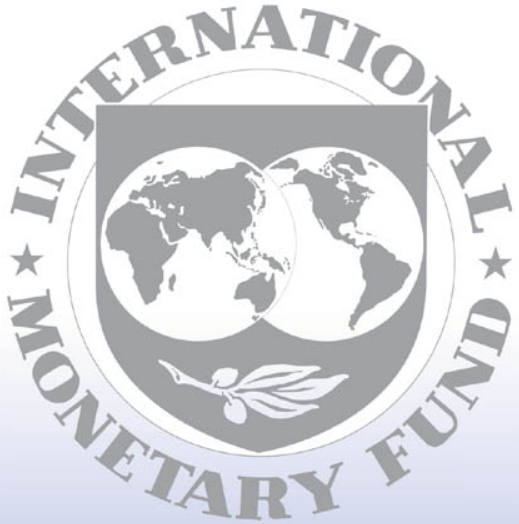

Staff

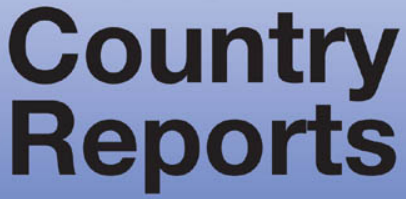




\section{Tanzania: Poverty Reduction Strategy Paper Progress Report}

Poverty Reduction Strategy Papers (PRSPs) are prepared by member countries in broad consultation with stakeholders and development partners, including the staffs of the World Bank and the IMF. Updated every three years with annual progress reports, they describe the country's macroeconomic, structural, and social policies in support of growth and poverty reduction, as well as associated external financing needs and major sources of financing. This country document for Tanzania, dated April 2004, is being made available on the IMF website by agreement with the member country as a service to users of the IMF website.

To assist the IMF in evaluating the publication policy, reader comments are invited and may be sent by e-mail to publicationpolicy@imf.org.

Copies of this report are available to the public from

International Monetary Fund • Publication Services

$70019^{\text {th }}$ Street, N.W. • Washington, D.C. 20431

Telephone: (202) 623-7430 • Telefax: (202) 623-7201

E-mail: publications@imf.org • Internet: http://www.imf.org

Price: $\$ 15.00$ a copy

\section{International Monetary Fund \\ Washington, D.C.}


This page intentionally left blank 


\section{THE UNITED REPUBLIC OF TANZANIA}

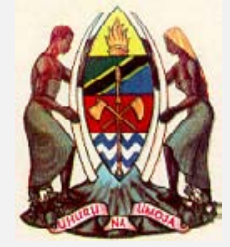

POVERTY REDUCTION STRATEGY

THE THIRD PROGRESS REPORT 2002/03

DAR ES SALAAM

April 2004

CInternational Monetary Fund. Not for Redistribution 


\section{LIST OF ABBREVIATIONS AND ACRONYMS}

\begin{tabular}{|c|c|c|}
\hline $\mathrm{ADB}$ & - & African Development Bank \\
\hline $\mathrm{ADF}$ & - & African Development Fund \\
\hline ADR & - & Alternative Dispute Resolution \\
\hline AGOA & - & African Growth Opportunity Act \\
\hline ASDP & - & Agriculture Sector Development Program \\
\hline ASDS & - & Agriculture Sector Development Strategy \\
\hline ASLM & - & Agriculture Sector Lead Ministries \\
\hline ATC & - & Air Tanzania Corporation \\
\hline ATIP & - & Accountability, Transparency and Integrated Project \\
\hline BOT & - & Bank of Tanzania \\
\hline BSE & - & Basic Statistics on Education \\
\hline CAP & - & Country Action Program \\
\hline CBOs & - & Community Based Organizations \\
\hline $\mathrm{CEF}$ & - & Community Education Fund Program \\
\hline CFAA & - & Country Financial Accountability Assessment \\
\hline CFS & - & Child Friendly School Program \\
\hline $\mathrm{CHF}$ & - & Community Health Fund \\
\hline COBET & - & Complimentary Basic Education in Tanzania \\
\hline CPI & - & Consumer Price Index \\
\hline CSOs & - & Civil Society Organizations \\
\hline $\mathrm{DAC}$ & - & Donor Aid Coordination \\
\hline DAWASA & - & Dar es Salaam Water and Sewerage Authority \\
\hline DBSPE & - & District Based Support to Primary Education \\
\hline DFID & - & Department for International Development \\
\hline DHS & - & Demographic and Health Survey \\
\hline DPT & - & Diptheria Pectusis Tetanus \\
\hline DRF & - & Drug Revolving Fund \\
\hline DSA & - & Dissemination, Sensitization and Advocacy \\
\hline EAC & - & East African Community \\
\hline $\mathrm{EPZ}$ & - & Export Processing Zones \\
\hline ESDP & - & Education Sector Development Program \\
\hline ETP & - & Education and Training Policy \\
\hline EU & - & European Union \\
\hline FDI & - & Foreign Direct Investment \\
\hline FDTF & - & Fiscal Decentralization Task Force \\
\hline GATT & - & General Agreement on Trade and Tariffs \\
\hline GDP & - & Gross Domestic Product \\
\hline GER & - & Gross Enrolment Rate \\
\hline GFS & - & Government Financial Statistics \\
\hline GGCU & - & Good Governance Coordination Unit \\
\hline GOT & - & Government of Tanzania \\
\hline HBS & - & Household Budget Survey \\
\hline HIPC & - & Highly Indebted Poor Countries \\
\hline HIV/AIDS & - & Human Immuno-deficiency Virus/Acquired Immune Deficiency Syndrome \\
\hline HMIS & - & Health Management Information System \\
\hline HSR & - & Health Sector Reforms \\
\hline ICBAE & - & Integrated Community Based Adult Education \\
\hline ICT & - & Information and Community Technology \\
\hline IFAD & - & International Fund for Agricultural Development \\
\hline
\end{tabular}




\begin{tabular}{|c|c|c|}
\hline IFEM & - & Inter-Bank Foreign Exchange Market \\
\hline IFMS & - & Integrated Financial Management System \\
\hline ILFS & - & Integrated Labor Force Survey \\
\hline INSET & - & In-Service Training Program \\
\hline IRP & - & Integrated Roads Program \\
\hline ITN & - & Insecticide Treated Nets \\
\hline LGA & - & Local Government Authorities \\
\hline LGRP & - & Local Government Reform Program \\
\hline MAFS & - & Ministry of Agriculture and Food Security \\
\hline $\mathrm{MCM}$ & - & Ministry of Cooperatives and Marketing \\
\hline MDA & - & Ministries, Departments and Agencies \\
\hline MDG & - & Millennium Development Goals \\
\hline MDT & - & Millennium Development Targets \\
\hline MIS & - & Management Information System \\
\hline MOEC & - & Ministry of Education and Culture \\
\hline MWLD & - & Ministry of Water and Livestock Development \\
\hline NACP & - & National Aids Control Program \\
\hline NACSAP & - & National Anti-Corruption Strategy and Action Plan \\
\hline $\mathrm{NAO}$ & - & National Audit Office \\
\hline NDS & & National Debt Strategy \\
\hline NER & - & Net Enrolment Rate \\
\hline NFE & - & Non-Formal Education \\
\hline NGOs & - & Non-Governmental Organizations \\
\hline OCAG & - & Office of the Controller and Auditor General \\
\hline PASS & - & Private Agribusiness Sector Support \\
\hline PCB & - & Prevention of Corruption Bureau \\
\hline PEDP & - & Primary Education Development Program \\
\hline PER & - & Public Expenditure Review \\
\hline PHDR & - & Poverty and Human Development Report \\
\hline PMMP & - & Poverty Monitoring Master Plan \\
\hline PMS & - & Poverty Monitoring System \\
\hline PORALG & - & President's Office, Regional Administration and Local Government \\
\hline PPA & - & Participatory Poverty Assessment \\
\hline PRBS & - & Poverty Reduction Budget Support \\
\hline PRS & - & Poverty Reduction Strategy \\
\hline PRSC & - & Poverty Reduction Support Credit \\
\hline PRSP & - & Poverty Reduction Strategy Paper \\
\hline PSLE & - & Primary School Leaving Examination \\
\hline PSRP & - & Parastatal Sector Reform Program \\
\hline QSP & - & Quick Start Project \\
\hline RDS & - & Rural Development Strategy \\
\hline REPOA & - & Research on Poverty Alleviation \\
\hline SADC & - & Southern Africa Development Community \\
\hline SEDP & - & Secondary Education Development Program \\
\hline SMEs & - & Small and Medium Enterprises \\
\hline STI & - & Sexually Transmitted Infections \\
\hline TACAIDS & - & Tanzania Commission on Aids \\
\hline TAS & - & Tanzania Assistance Strategy \\
\hline TB & - & Tuberculosis \\
\hline TCCIA & - & Tanzania Chamber of Commerce, Industries and Agriculture \\
\hline TEDP & - & Teacher Education Development Program \\
\hline
\end{tabular}


TIC

TNBC

TRC

TSED

URRP

VAT

VPO

VTTP

WABEM

WSDP

WSDS

WSIS
Tanzania Investment Center

- Tanzania National Business Council

- Tanzania Railways Corporation

- Tanzania Socio-Economic Database

- $\quad$ Urgent Roads Rehabilitation Programs

- $\quad$ Value Added Tax

- $\quad$ Vice President's Office

- $\quad$ Village Travel and Transport Program

- Ward Based Education Management Program

- Whole School Development Program

- $\quad$ Water Sector Development Strategy

- World Summit on Information Society 
Table of Contents

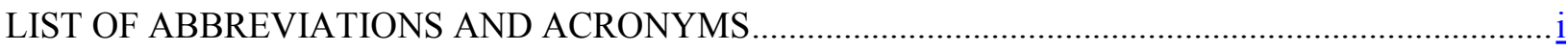

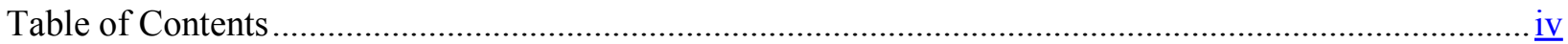

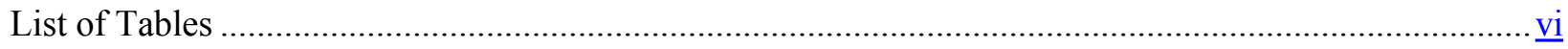

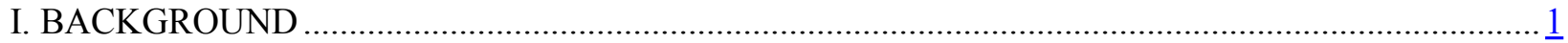

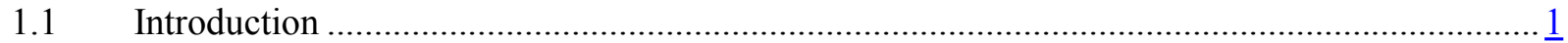

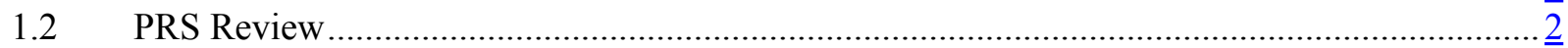

II. THE STATUS OF POVERTY ........................................................................................... 4

$2.1 \quad$ Income poverty: Growth, Employment and Roads ........................................................

2.2 Non-Income Poverty: Human Capabilities, Survival, Extreme Vulnerability ..........................

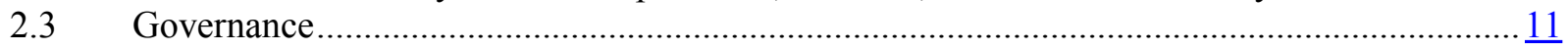

$2.4 \quad$ Prospects of Monitoring Poverty Reduction...................................................................... $\frac{12}{14}$

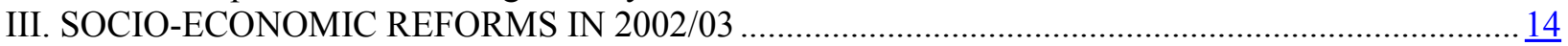

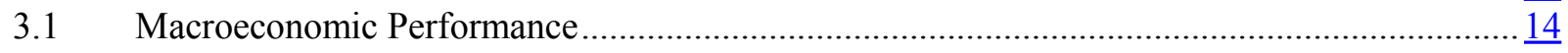

3.2 Structural Reforms and Private Sector Development .....................................................

3.3 Poverty Orientation of the 2003/04 Budget..................................................................... $\frac{17}{18}$

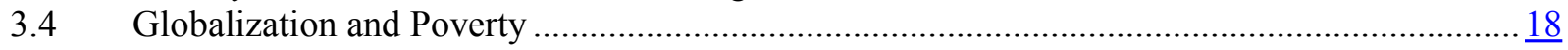

3.5. Public Debt Developments and Management.................................................................. $\frac{19}{20}$

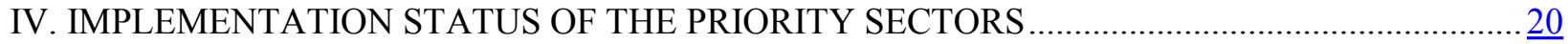

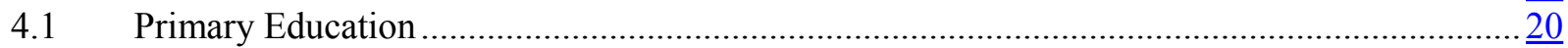

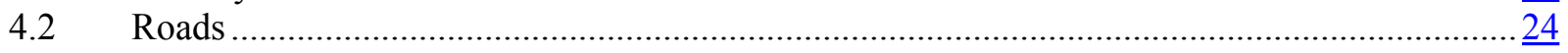

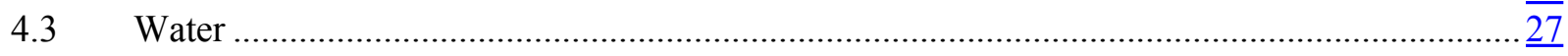

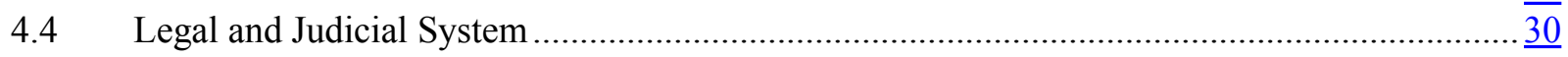

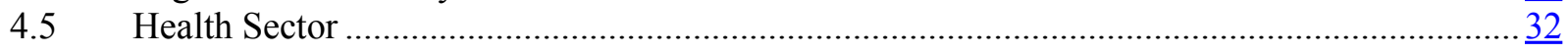

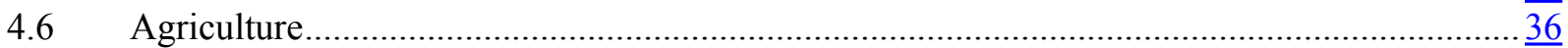

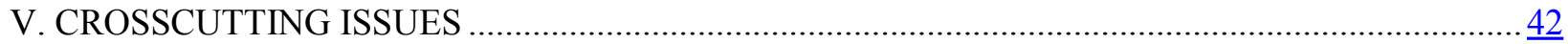

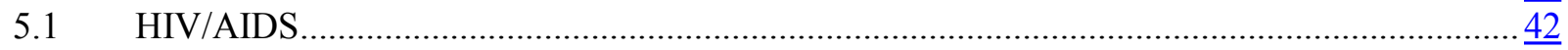

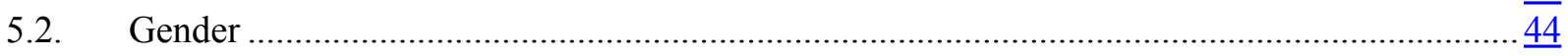

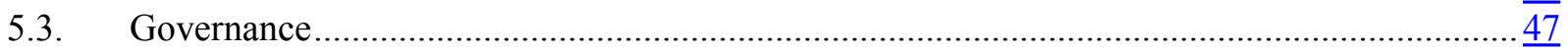

5.4. Local Government Reform Program ........................................................................ $\frac{48}{51}$

5.5 Human Capital Development ................................................................................ $\frac{51}{51}$

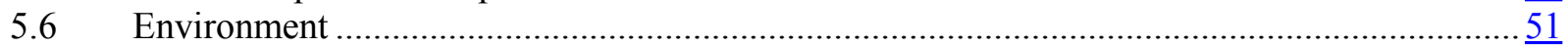

VI. BUDGET FRAMEWORK FOR POVERTY REDUCTION PROGRAMS .................................... $\frac{55}{55}$

6.1. Resource envelope: A macroeconomic perspective ................................................ $\frac{55}{56}$

6.2 Budget frame consideration for financing of priority sectors.......................................... $\frac{56}{59}$

6.3 Public Expenditure Management in the Medium Term................................................... $\frac{59}{60}$

VII. POVERTY MONITORING AND EVALUATION ............................................................. $\frac{60}{60}$

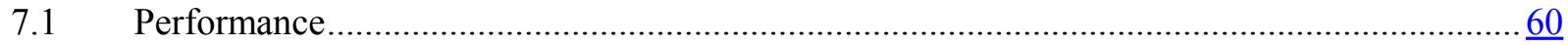

7.2 Operationalization of pooled fund mechanism for the PMS ............................................ $\frac{61}{61}$

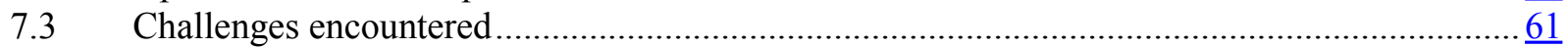

Annexes: Policy Matrix for Poverty Reduction Strategy ............................................................. $\frac{62}{62}$

A.I: Macroeconomic, Good Governance and Private Sector Development .................................... $\underline{62}$

A.II: Poverty Monitoring System .......................................................................................... $\frac{63}{63}$

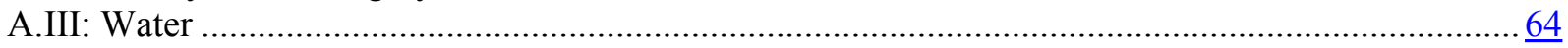

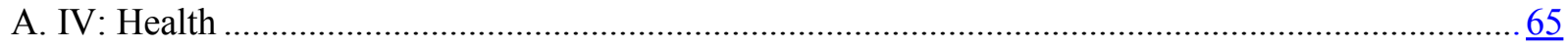

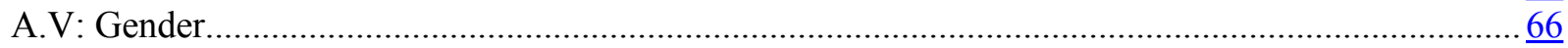

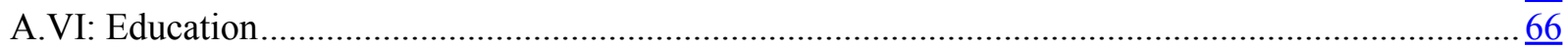

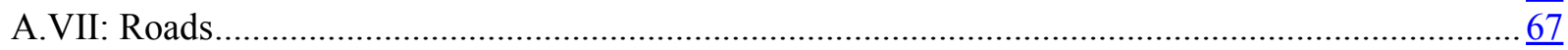

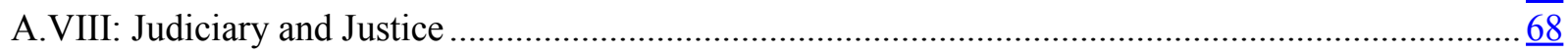

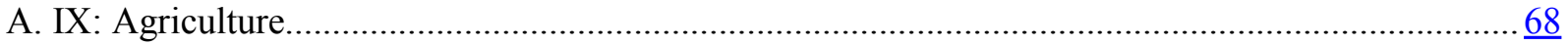


A.X: HIV/AIDS

69

A.XI: Employment

A.XII: Environment. 


\section{List of Tables}

Table.1: Income poverty indicators, baseline and targets .......................................................... 4

Table 2: Education Indicators, Base line and Targets .............................................................. 7

Table 3: Health Outcome and Nutrition Indicators, Base line and Targets ......................................... 8

Table 4: Health Service Indicators, Base line and Targets ....................................................... 10

Table 5: Tanzania: Selected macroeconomic indicators ................................................................... 14

Table 6: Priority Expenditures within Priority Sectors, 2000/01 - 2006/07 (Jul-Jun) (in billions TShs) ... 15

Table 7: Highlights for the 2003/04 Budget Measures .................................................................. 17

Table 8a: Gross and Net Enrolment Ratio (GER and NER) By Sex and Region, 2002 ..........................2 21

Table 8b: Gross and Net Enrolment Ratio (GER and NER) by Sex and Region, 2003 .........................2 21

Table 9: Education Units Inspected 2002 ....................................................................................22

Table 10: Estimated Financing Requirements for the ESDP 2002/03 - 2005/06 (in million Tshs.) ........ 23

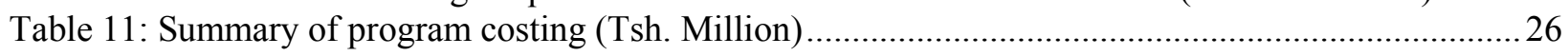

Table 12: Financing of the water sector Program, 2003/2004 - 2005/2006 (billion Tshs) ........................30

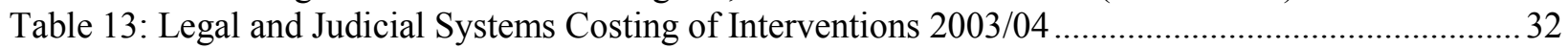

Table 14: Financing of Priority Health Interventions, 2003/04 - 2005/06 (July-June) TShs billion .......... 35

Table 15: Summary of costing of sector programs 2003/04 - 2005/06 (Tshs. 'Millions) ........................40

Table 16: Costing of Mid-Term Plan of the LGRP........................................................................50

Table 17: Central Government Expenditure, 1998/99-2003/04 (billion TShs) .......................................56

Table 18: Budget Framework 2003/04-2006/07 (in million TShs) .................................................58 


\section{BACKGROUND}

\subsection{Introduction}

This is the third PRS Progress Report (July 2002-June 2003) that closes the three-year cycle of the implementation of the first PRSP, which was formulated in the year 2000. While it marks the end of the first cycle it also provides a bridge to the review process leading to the formulation of the second cycle PRSP II. The PRS review process was launched during the Poverty Policy Week in October 2003, the consultative process of which is stipulated in the "Guide for the Poverty Reduction Strategy Review."

There are successes recorded due to the implementation of the first PRSP in macroeconomic performance and in reforms in various areas including financial sector, public service and local government. Distinct effort has been made to improve delivery of social services such as education, health and water. However, more effort is still needed in virtually all areas. Challenges due to unmet development needs emanate from various angles. There is insufficient translation of macro level achievements to the micro level hence the need for closer analytical work on growth-poverty linkages and how growth could better benefit the poor. Greater attention also has to be paid to quality and equity issues in the delivery of social services, like education and health; combating the spread of HIV/AIDS and commitment to governance issues.

The report highlights what Government did during the past year in terms of policy developments, an assessment of the achievements and challenges, including the monitoring system. Unlike the earlier two reports that pointed out intervention areas for the following year in terms of next steps, this report only updates the Policy Matrix and takes the year ahead as the planning year to inform the next PRSP. The first cycle PRS had process activities, some of which have been finalized, while others will continue and be better informed by the PRS review. Cases in point are the Rural Development Strategy (RDS), mainstreaming of gender, environment and governance issues.

Experience during the preparation of the last two progress reports and this one reveals that the reporting quality of progress on both outcome and impact indicators requires improvement. This includes all PRS sectors and thematic areas. Further, reporting on progress towards poverty reduction in terms of incidence and correlates can only be made if new data sets are generated. Government will strengthen the reporting capacity of sectors and thematic areas during the PRS review and in the next PRS cycle. Among other things, Government will strengthen the capacity of the PRS Technical Committee and Secretariat and harmonize and synchronize various reporting instruments e.g. PHDR, PER and sector reviews.

In relation to the Poverty Monitoring System (PMS) the challenge is how to hold the entire "machinery" together and avoid duplication of activities without further stretching available capacity and existing 
institutional set up. This occupies center stage as we plan for the PRS review. Capacity constraints may hinder consolidation of the PRS gains and poverty monitoring. Duplication of activities and failure to define a point of convergence will add to the transaction costs and put additional strain on the already stretched capacity. Thus addressing PMS capacity concerns and harmonization of activities will certainly be critical to the implementation of the next PRS cycle and to the management of the PRS review process.

\subsection{PRS Review}

Overall, the purpose of the review is to update the current PRS by making it more comprehensive and pro-poor. Also, the review will broaden and deepen interventions to reduce poverty and raise awareness on the PRS and MDGs. While it is intended to undertake a comprehensive review it is necessary to be strategic and prioritize issues the review will focus on, and avoid trying to do everything. Specifically the review will:

- Be set in the context of the country's long-term strategies (e.g. NPES and Vision 2025). The PRS is seen as a means to achieve these long-term goals set out in these strategies, visions and MDGs.

- Use existing and recent data and analyses including the last (three) PRS progress reports, PPA, PER studies and reports, PHDR, Poverty Week Reports, Labor Force and Child Labor Survey, HBS 2000/01 and Census findings, Agriculture Survey, Policy and Service Satisfaction Survey (PSSS) and other reports. However, since the findings of these reports will be used in the review process, it is not necessary for this report to highlight them.

- Identify knowledge gaps and commission few critical new studies e.g. growth and trade, growth and employment (jobs) creation, raising returns to smallholder agriculture, examining macro-meso-micro linkages and integration of cross-cutting issues - HIV/AIDS, gender and environment.

- Scale up ownership and awareness of PRS within and across government; strengthen government leadership and foster participation of key stakeholder with a clear focus on community participation in PRS formulation, implementation and monitoring.

- Improve harmonization of key processes around the PRS, PMS, PER and the budgeting cycle to ensure most effective utilization of government resources in line with its poverty reduction efforts.

The PRS review provides an opportunity to explore and discuss what is working and what is not. The review has to address the current limitations of the PRS and PMS and amplify the complementing contributions of sectors by examining the inter-sector linkages. Capacity constraints in key institutional bodies of the PRS and PMS, including Local Government will be examined. A PRS Communication Strategy to support the PRS/MDGs and the PMS will be prepared. 
As part of the review, a consultative meeting of stakeholders was held in January 2004 in Dar es Salaam to clarify PRS Review issues and launch the preparation of a country-wide Consultation Process on a range of poverty and policy concerns for the next cycle PRS. Stakeholders came from first-PRS priority sector and cross-cutting issues ministries, government departments and civil society. Government and development partners have contributed financial resources to support the country-wide consultations which are now underway. Reports from the consultations are beginning to flow in. They will be analysed so that key messages can be incorporated in the new PRS document. It is expected that work on the first draft of the PRS will start in April and that there will be further rounds of consultation - in June for the first draft and September for the second draft. Poverty Policy Week is scheduled for October and finalization and publication activities on the document will take place between October and December 2004.

Details on the PRS review are available in the guide document which can be accessed through http://www.tzonline and poverty website - http://www.povertymonitoring.go.tz 


\section{THE STATUS OF POVERTY}

This chapter presents the status of poverty based on the original PRSP indicators and the revised set of indicators that were extended and modified in 2002. The chapter builds on 2001/02 Progress Report Status chapter, adding on new data where available and explaining trends in the selected indicators. It also assesses whether the targets are likely to be achieved, highlights strategic policy direction and prospects of monitoring poverty reduction. In-depth analysis of poverty status is contained in the PHDR 2003. Section 1 addresses income poverty including GDP growth, agriculture and employment. Section 2 looks at non-income poverty dimensions. Section 3 reviews governance and related gender indicators. Section 4 highlights medium-term prospects for improving monitoring of poverty.

\subsection{Income poverty: Growth, Employment and Roads}

The PRS underpins sustained economic growth as a precondition for poverty reduction, grounded in sound macroeconomic management, increased investment and improvements in productivity. Agriculture, improvements to the road network and other pro-poor sectors are prioritized.

The performance indicators identified in the PRS were revised in 2002. The agriculture indicators were extended, food price inflation was added, unemployment indicators were included to reflect the extent of economic opportunities, and the road indicators were modified to reflect available data. Targets for new indicators will be set during the PRS review; a baseline is available in many cases. The resulting indicators are presented in Table 1 . The poverty targets have been adjusted to reflect the revised poverty estimates that were produced after the publication of the PRSP.

Table.1: Income poverty indicators, baseline and targets

\begin{tabular}{|l|l|l|l|l|l|}
\hline Indicator & Baseline & \multicolumn{2}{l|}{ Actual } & Targets \\
\hline & Estimate & Year [Source] & $\mathbf{2 0 0 3 *}$ & $\mathbf{2 0 0 3}$ & $\mathbf{2 0 1 0}$ \\
\hline \% of the population below the basic needs poverty line & 36 & $2000-01[1]$ & - & 30 & 17.8 \\
\hline \% of the population below the food poverty line & 18.7 & $2000-01[1]$ & - & 16 & 9.3 \\
\hline GDP growth rate (\%) & 4.9 & $2000[1]$ & 5.5 & 6.3 & \\
\hline Agricultural growth rate (\%) & 3.4 & $2000[1]$ & 3.3 & 5 & \\
\hline Food price inflation in urban areas (\%) & 6.8 & $2000[1]$ & & & \\
\hline$\%$ of working age population not currently employed & 5 & $2000-01[1]$ & - & & \\
\hline $\begin{array}{l}\text { \% of 15-24 years old not currently employed in urban } \\
\text { areas }\end{array}$ & 28 & $2000-01[1]$ & - & & \\
\hline
\end{tabular}

Note: For actual 2003, most of the socio-economic indicators in this section have not been worked out. The information is obtained from HBS and the latest is the 2000/01 HBS.

Sources: - National Bureau of Statistics

Other indicators that future reports will consider due to their relation to growth and employment include number of kilometers of roads under periodic / routine maintenance, percentage of roads that are only seasonally accessible), percentage of working age population not currently employed percentage of 15-24 
years old not currently employed in urban areas. Indicators for investment and business climate will also be considered.

There is no information on trends in household income poverty since 2000. The current Household Budget Survey 2000/01 provides the most current information on trends in income poverty between 1991/92 and 2000/01, showing very limited declines in income poverty levels over the 1990s. Estimates of household consumption levels are not produced annually.

The rest of this section focuses on macroeconomic and sector indicators that have an impact on income poverty. Note, however, except for a few macroeconomic variables, data on performance of most social indicators are not readily available for the current progress report. Subsequent report will carry those for which analyses from the various surveys will have been completed. In addition, possibilities of having similar indicators for contributions of the private sector in social sectors where the sector has grown in importance following liberalization will be considered in later reporting.

\section{Economic Growth}

While in the early 1990s GDP annual growth rates were often lower than population growth rate, economic growth has, since the mid-1990s, risen more steadily and overtaken the population growth rate (2.9\% for 1988-2002). In 2002, GDP growth rate registered 6.2\%, surpassing the PRSP target of $6.0 \%$; sliding back to $5.5 \%$ for 2003 (provisional estimates). Overall the performance reflects the positive impact of the economic and fiscal reforms undertaken since mid-1990s. The sticky issue, however, is how far this growth can translate into poverty reduction over the coming years. Related to this, is the question of how the gains from growth can be distributed among households for the benefits to reach the poor. Government is grappling with these issues through broadening sources of growth, expediting implementation of agricultural sector and rural development programs, facilitating increased private investment, promoting micro financing and Small and Medium Enterprises (SMEs), and developing the infrastructure, especially supporting agriculture.

Agriculture and Food Security: Being the mainstay of the economy, agriculture must grow well above the population growth. PRS agriculture growth target of 5\% was achieved in 2001 and 2002, largely due to good weather conditions. The growth rate for 2003 is provisionally set at $3.3 \%$. This is due to poor rains. The forthcoming agricultural survey will provide a baseline for 2003, thus reducing data limitations on production, access to credit, access to market and extension services.

Employment and Unemployment: The ILFS 2000/01 shows that overall unemployment increased substantially and that it is higher amongst women than men in urban areas. Also, unemployment is particularly high amongst young people, making them more vulnerable. The Integrated Labor Force and 
Child Labor surveys, 2000/01 (launched in April 2003) indicated that 39.6\% of children aged from 5 to 17 years old are economically active and $21.3 \%$ of them are child laborers working more than 4 hours a day often in worst forms of child labor. Government is addressing employment creation through policy actions on private sector development, SMEs, agricultural and rural development, micro financing and EPZs. Such efforts include measures to enhance productivity through job and business management skills, access to flexible loans and market support for poor women and their families. There are also measures to curb child labour under the "Time Bound Programme on Worst Forms of Child Labour" coordinated by the Ministry of Labour, Youth Development and Sports.

Roads: PRS envisaged a rehabilitation of 4,500 $\mathrm{km}$ of rural roads in twelve of the poorest regions by 2003. It also aimed at undertaking routine and periodic maintenance on all rural roads, with a focus on community involvement. Only $51 \%$ of the planned rural roads had routine spot improvement and periodic maintenance. The condition of most roads is classed "poor".

\section{$\square$ Challenges and Strategic Policy direction and monitoring}

The overriding concern is to ensure attainment of sustained high economic growth and ensuring such growth benefits the poor particularly in the rural areas. Constraints facing agriculture require expeditious actions with regard to financing mechanisms, investment and provision of support services. Regional diversity and inequality would be addressed through appropriate budgetary allocation mechanisms as well as provision of enabling environment for domestic and foreign investment. The forthcoming agriculture survey offers an opportunity to revisit and establish concrete indicators for monitoring agriculture and rural development. More concrete approach of measuring will be designed to capture both rural and urban dimensions. As part of the PRS updates, attention will be paid to the income and employment impacts of agriculture, with increasing returns to agriculture at the center.

For the roads, more effective coordination machinery between the central and local governments in the maintenance of the road stock will be developed. The coordination machinery will clearly assign responsibilities.

The capacity of Government and relevant NGOs at national and sub-national levels, both human and resources will be strengthened to meet the challenges of efficiently implementing the "Time Bound Program on the Worst Forms of Child Labor." 


\subsection{Non-Income Poverty: Human Capabilities, Survival, Extreme Vulnerability Education}

The past three years have registered substantial achievement, particularly in primary school enrolment. Enrolment grew by $50 \%$ from 4.4 million in 2000 to 6.6 million in 2003 . Both net and gross enrolments have increased by about 30\%. This increase is attributed to the abolition of UPE levy and other mandatory contributions. Apparently, 2003 PRS and PEDP targets for GER and NER have been surpassed. Regarding gender parity, despite encouraging signs of near equality in the entry of 7 year olds, there are concerns that PRS and MDG target for parity in the overall enrolment of girls and boys by 2005 may be adversely affected by over-age girls facing more difficulties to start school than their male counterparts. There are also vast disparities in enrolment rates across regions.

Table 2: Education Indicators, Base line and Targets

\begin{tabular}{|l|l|l|l|l|}
\hline & \multicolumn{2}{|l|}{ Baseline } & \multicolumn{2}{l|}{ Targets } \\
\hline & Estimate & Year [Source] & $\mathbf{2 0 0 3}$ & $\mathbf{2 0 1 0}$ \\
\hline Primary net enrolment ratio (\%) & 59 & $2000[1]$ & 90 & 100 \\
\hline Primary gross enrolment ratio (\%) & 78 & $2000[1]$ & 100 & \\
\hline Ratio of girls/boys in primary & 0.98 & $2000[1]$ & 1.00 & \\
\hline Ratio of girls/boys in secondary & 0.85 & $2000[1]$ & 0.90 & \\
\hline \% of cohort completing std 7 & 70 & $2000[1]$ & & \\
\hline Primary dropout rate (\%) & 6 & $2000[1]$ & 3 & \\
\hline \% students passing PSLE & 22 & $2000[1]$ & 50 & \\
\hline Transition rate std 7 to form 1 (\%) & 16 & $2000[1]$ & 28 & \\
\hline Literacy rate of pop aged 15+ & 71 & $2000-01[2]$ & & 100 \\
\hline Literacy rate of pop aged 15-24 & 82 & $2000-01[2]$ & & \\
\hline
\end{tabular}

Note: $\quad$ Targets for 2003 are the revised values given in the Second PRS Progress Report (2000-01), where different from the PRSP

Sources: 1- MoEC Basic Statistics Education (BSE)

2- Household Budget Survey 2000-01

Many of the out-of-school children were registered for complementary basic education programs in 2002 but actual enrolment in non-formal education is still low. To rectify this situation, Government is implementing its new strategy for adult and non-formal education beginning 2003/04.

In the past two years, there has been some improvement in the pass rates in the primary school leaving examination, with a peak pass rate of $29 \%$ in 2001 . However, a call for further quality improvement is still in order. Achievement of the PRS target of a 50\% PSLE pass rate by 2005 seems to be unlikely. Transition rate from primary to secondary school has increased from 16\% during the late 1990s to about $20 \%$ largely due to the 50\% expansion of secondary school places between 1997 and 2003 . Nonetheless, the absolute level of transition remains low. Overall gender gap in secondary enrolment is still large. This is attributed to the poorer performance of girls in PSLE. Selection for secondary school places takes into account both gender and academic performance. 
Another challenge is eliminating illiteracy by 2010, particularly for rural women, the population with the highest incidence of illiteracy. The recently launched Adult and NFE Strategy is a necessary and important initiative in addressing the challenges towards achieving PRS/MDGs targets.

\section{$\square$ Challenges and Strategic Policy direction and monitoring}

The tempo for attaining significant achievement in education will be enhanced. The focus will be on:

- improving infrastructure and quality in teaching,

- $\quad$ provision of pedagogical inputs, and incentives;

- supporting vulnerable children,

- reviewing curriculum to provide knowledge and skills useful to graduates in the labor market,

- provision of non-formal education for older out-of-school children and illiterate adults; and

- continued expansion of secondary schooling, with enhanced government-private sector partnership.

\section{Survival, Nutrition and Health}

Because of lack of data the maternal mortality ratio was removed from the PRS indicator list and replaced by births attended by skilled health worker. As the national estimates after 2000 are not available, the general assessment in this section is based on the demographic and health surveys of the 1990s and sentinel surveillance sites. Table 3 shows health and nutrition indicators and targets.

Table 3: Health Outcome and Nutrition Indicators, Base line and Targets

\begin{tabular}{|l|l|l|l|l|l|}
\hline \multirow{2}{*}{ PRS indicator } & \multicolumn{3}{l|}{ Base line } & \multicolumn{2}{l|}{ Targets } \\
\cline { 2 - 6 } & estimate & Year & $\mathbf{2 0 0 3}$ & $\mathbf{2 0 1 0}$ & $\mathbf{2 0 2 5}$ \\
\hline Total fertility rate & 5.6 & $1997[1]$ & & & \\
\hline Infant mortality rate & 99 & $19971]$ & 85 & 50 & 20 \\
\hline $\begin{array}{l}\text { Ratio of the IMR of the poorest quintile } \\
\text { to the IMR of the richest }\end{array}$ & 1.25 & $1999[1]$ & & & \\
\hline Under-five mortality rate (MDG) & 147 & $1997[1]$ & 127 & 79 & \\
\hline HIV prevalence in age group 15-24 (\%) & $\begin{array}{l}\text { Male: } 8 \\
\text { Fem: } 13\end{array}$ & $2000[2]$ & & & \\
\hline \% of children born to HIV+ mothers who & & & & & \\
\hline Life expectancy at birth & 52 & $1988[3]$ & & 52 & \\
\hline Nutrition in the under fives: & & & & & \\
\hline Stunting (moderate-severe, \%) & 44 & $1999[1]$ & & 20 & \\
\hline Wasting (moderate-severe, \%) & 5 & $1999[1]$ & & 2 & \\
\hline Under-weight (mod.-severe,\%) & 29 & $1999[1]$ & & & \\
\hline
\end{tabular}

$\%$ change in mortality attributable to malaria in under-fives - to be added in later reports / analyses

Source: 1 - Tanzania Reproductive and Child Health Survey 1999; 2 - National AIDS Control Program, 2002; and 3 - National Population Census, 1988

Infant and Child mortality: There have been no significant changes in infant mortality and prevalence of fever in children under five during the 1990s. Sentinel site surveillance shows little net change in the 
importance of malaria as a cause of child deaths, though there is some year-on-year fluctuations and differences between sites.

HIV and AIDS: Data from blood donors show steady increases in HIV prevalence since 1996. Despite widespread knowledge of HIV and some successful local initiatives in its prevention and control, there is no significant improvement. In general prevalence is higher in women than in men and the gap between male and female infection rates has increased. Prevalence in blood donors replaced prevalence in antenatal clinic attendees as an indicator because of weakness in the ANC sentinel surveillance system. The national HIV/AIDS survey being conducted in 2003 will provide a baseline against future trends.

Life Expectancy: Based on the 1988 census, life expectancy at birth was 52 years. Life expectancy is expected to be lower now due to the effect of HIV. The forthcoming analysis of 2002 Census will provide a definitive picture on trends and differentials in life expectancy.

Nutrition: There has not been much improvement in the nutrition status of the under-fives. Child malnutrition is much worse in rural than urban areas and much higher in the poorest quintiles. About 16\% of children have a birth weight below 2,500 grams as a result of early pregnancies, illness and poor nutrition status of pregnant women. Apparently, food insecurity and HIV/AIDS in under-fives will also worsen the nutritional status of children.

\section{Health Service Delivery}

The number of outpatient visits has increased enormously since 1999, showing a 47\% increase in absolute numbers between 2000 and 2002. Indicators of the proportion of births attended by skilled health worker and proportion of institutional deliveries showed a decline over the 1990s. Rural-urban disparities in skilled attendance at birth are large, mainly due to shortage of adequately trained staff in rural areas. Both urban-rural disparities and between poorest and richest increased during the 1990s. There has been continuous improvement in DPT3 and measles coverage. DTP3 reached almost 90\% coverage in 2002, well above the targets for 2003 (Table 4). 
Table 4: Health Service Indicators, Base line and Targets

\begin{tabular}{|c|c|c|c|c|c|c|}
\hline \multirow[t]{2}{*}{ PRS indicator } & \multicolumn{2}{|l|}{ Base line } & \multirow{2}{*}{\begin{tabular}{|l|} 
Actual \\
2003 \\
\end{tabular}} & \multicolumn{3}{|c|}{ Targets } \\
\hline & Estimate & Year & & 2003 & 2010 & 2025 \\
\hline Annual no. of outpatient visits per capita & \begin{tabular}{|l|} 
Gov 1.3 \\
All 2.3 \\
\end{tabular} & \begin{tabular}{|l|}
$2000-01$ \\
{$[3]$}
\end{tabular} & - & & & \\
\hline Health facility users' satisfaction (\%) & $\begin{array}{l}\text { Gov. } 66 \\
\text { All } 71\end{array}$ & $\begin{array}{l}2000- \\
01[3]\end{array}$ & - & & & \\
\hline Total number of family planning acceptors (new and old users) & & & - & & & \\
\hline Births attended by doctor, nurse or skilled midwife (\%) (MDG) & 36 & $1999[2]$ & - & & 80 & \\
\hline Births taking place in govt health facility (\%) & 44 & $1999[2]$ & - & & & \\
\hline$\overline{\mathrm{DTP}}(\mathrm{Hb}) 3$ immunization coverage $(\%)$ & $\begin{array}{l}\text { DHS 81 } \\
\text { MoH 76 }\end{array}$ & \begin{tabular}{|l|}
$1999[2]$ \\
$1999[1]$
\end{tabular} & $\approx 90(2002)$ & 85 & & \\
\hline TB treatment completion $(\%)$ & 78 & $2000[1]$ & - & & & \\
\hline
\end{tabular}

Sources: 1 - Ministry of Health 2002; 2 - Tanzania Reproductive and Child Health Survey 1999 3 - Household Budget Survey 2000-01

\section{$\square$ Challenges and Strategic Policy direction and monitoring}

Analysis of 2002 Census and the forthcoming DHS in 2004 will provide more robust recent estimates for many of the indicators of survival, nutrition status and health. Improvement in routine data system will also provide a regular source for assessing trends in health service outputs. Government will focus on ensuring that health services are accessible to the rural population and the poor through the provision of adequate facilities and quality services. As part of the PRS review, further reflection will be made on the application of user fees at primary level facilities to ensure universal access.

Government will scale up efforts in prioritizing measures to reduce transmission of HIV and its impact on the welfare of those affected.

\section{Water and Sanitation}

Increasing access to clean and safe drinking water for the rural population is among the PRS priorities. The target is to improve coverage to $55 \%$ of rural inhabitants by 2003 . During 1990 s there was noticeable improvement in the coverage in rural areas, although the rate of improvement is unlikely to reach the 2003 target. The time it takes to collect water has increased in urban areas, probably as a result of increased pressure on water points due to increased urban growth rates, implying substantial time costs on those who collect water, mostly women and children. No specific targets for sanitation were set.

\section{$\square$ Challenges and Strategic Policy direction and monitoring}

The greatest concern is on the weakness of routine data system from collection, production and analysis to dissemination at district, regional and national levels. Government is in the process of developing a single, highly accessible monitoring system that contains all of the necessary data to be used by the district, councils, regional secretariats and central government. 


\section{Extreme Vulnerability}

The PRS recognizes vulnerable groups that require special attention, including AIDS sufferers, orphaned children who most likely would get into the child labor market and its worst forms, the disabled, the very old and refugees. There is no new information on trends of the five indicators for monitoring extreme vulnerability. However, trends over the 1990s are known only for orphanhood that increased during the decade, largely as a consequence of HIV/AIDS pandemic. The Participatory Poverty Assessment (PPA) carried out in 2002 has brought up more qualitative information on various dimensions of vulnerability conceptualization, the most vulnerable social groups, impoverishing forces, and protection and risk management programs.

\section{$\square$ Challenges and Strategic Policy direction and monitoring}

The current indicators on extreme vulnerability cover a disparate set of areas and do not appear to have been selected within a common conceptual and policy framework. The PPA will assist in refining indicators for vulnerability in sectors that are already monitored. It provides also a basis for the development of additional indicators. During the PRS review process the PPA will be used to concretize Government policy towards vulnerability and to develop appropriate social protection programs.

\subsection{Governance}

The major challenges have been to identify and prioritize the key aspects of governance most linked to poverty reduction. So far, governance has been addressed through the legal, judicial, and public expenditure management systems and in checking corruption. The percentage of councils with clean audit report reflects the proper use and accountability of government funds by local authorities. The number of corruption cases reported is an indicator of the readiness of the population to report corruption and willingness to combat it, while the number of convictions shows the promptness and effectiveness of prosecution of cases.

In recent years, the coverage of the audit services has been increased, i.e. covering more local authorities, Most local authorities have been audited annually since 1998 . However, only $10 \%$ of councils were awarded a clean certificate, which shows weak accountability at the local level.

The number of corruption cases lodged increased from 33 in 2000 to 129 in 2002 . However, the number of convictions is low, recoding 6 in 2000 and 12 in 2002, attributed to the long delay in processing cases before a conviction or acquittal is obtained.

The proportion of women among civil servants has remained steady at 39\% over the past 3 years, with a small rise to $40 \%$ in 2003 , and when women teachers are excluded, the proportion of women falls to about one third. Programs to enhance productivity and promotion of good industrial relations at the 
workplace have been implemented in collaboration with workers and employers organizations. These include workers education, women workers rights, occupational safety and health, social dialogue and HIV/AIDS interventions. Social welfare services were promoted in tea plantations through renovation and creation of day care centers. Women's role in Parliament is still wanting, occupying only $27 \%$ of all seats, despite constituting about half of population. However, the current situation represents an improvement from the previous Parliament, in which women held only $18 \%$ of seats.

\section{$\square$ Challenges and Strategic Policy direction and monitoring}

More urgent actions will be undertaken to increase the proportion of district councils given clean auditing certificates. Faster processing of corruption cases is required to retain public confidence and engagement. More robust actions will be undertaken to increase women's representation and involvement in Government and Parliament.

\subsection{Prospects of Monitoring Poverty Reduction}

One of the most substantial changes in the PMS since 2002 has been the revision of the list of poverty monitoring indicators in response to the monitoring requirements of Poverty Reduction Budget Support (PRBS), Poverty Reduction Support Credit (PRSC) and Millennium Development Goals (MDGs). The indicators in the Poverty Monitoring Master Plan (PMMP) were revised and supplemented in preference to establishing an additional, parallel monitoring mechanism.

The focus of PRS/MDG indicators and the PHDR is to assess whether welfare has improved rather than to report on progress in implementing the policies. Most outcomes and impact indicators are expected to take some time to respond to policy changes, and they change only slowly once they respond. The PMMP prioritized the selection of indicators including a number of slow moving impact indicators for balance. It is appropriate that the PMMP define indicators that can be used to monitor poverty beyond the short-term perspective of the PRS e.g. MDGs indicators; but it is then necessary to identify the indicators that can reasonably be used for monitoring over the short term.

A number of important data collection and analysis activities are currently being undertaken and will provide additional poverty monitoring data in the near future. Foremost amongst these is the analysis of the Population and Housing Census 2002. Preliminary tabulations of population by district have already been produced and more detailed analysis is ongoing. The census will provide updated information on a series of poverty indicators including literacy, school enrolment and the level of schooling attained, child and adult mortality, fertility, source of drinking water and unemployment. It will also provide information on population by age group, improving the denominator used for many of the indicators based on routine data, which can then be recalculated. This will be particularly important in education, where it will help to 
resolve current uncertainties about enrolment rates. A particular benefit of the census is that data can be highly disaggregated - down to district and below.

The Agriculture Survey conducted in 2003 will provide information on agricultural production that can be used to update GDP figures and that will allow the calculation of three of the agriculture indicators for the first time. This survey will be the first to use the 'core poverty module' that standardizes the measurements of basic socioeconomic characteristics across surveys, particularly those that are useful for the prediction of consumption and poverty status.

The review and re-basing of the GDP and CPI series undertaken in 2003 is also noteworthy. It is essential that both be based on recent data and on a sound and transparent methodology.

The national HIV/AIDS survey being conducted during 2003/04 will provide national seroprevalence estimates, linked with information on knowledge and behavior. In addition, the report of the 2002/03 Tanzania Participatory Poverty Assessment finalized in 2003 provides an insight into vulnerability and the processes by which households and individuals may become impoverished.

The Policy and Service Satisfaction Survey (PSSS) that was undertaken as part of the introduction of performance management system into the civil service is currently being analyzed. It will give quantitative information on people's knowledge of, and satisfaction with, government policies and basic services, including health, education, water, roads and agriculture. This will provide a baseline for assessing whether services are perceived to have improved or not. 


\section{SOCIO-ECONOMIC REFORMS IN 2002/03}

\subsection{Macroeconomic Performance}

Tanzania has continued to experience steady economic growth over the last 4-5 years. During 2002 GDP growth rate rose to $6.2 \%$ from $5.7 \%$ in 2001 . The main sources of this growth were agriculture $(5.0 \%)$, mining (15\% from $13.5 \%$ in 2001), wholesale and retail trade including tourism ( $7 \%$ from $6.7 \%$ in 2001 ) and manufacturing ( $8 \%$ from 5\% in 2001). Per capita GDP grew by $3.4 \%$ compared to $2.8 \%$ in 2001 .

By the end of December 2002, the rate of inflation was at 4.4\%, sliding further to 4.2\% by March 2003. The decline in inflation is attributed to improvement in the food supply situation in the country, following good food crop harvests, coupled with steady implementation of prudent fiscal policies, supported with a cautious monetary policy. However, in the 2002/03 season adverse weather conditions led to higher food prices taking the headline inflation up to $4.6 \%$ by end-November 2003 . Table 5 shows trends in selected macroeconomic indicators.

Table 5: Tanzania: Selected macroeconomic indicators

\begin{tabular}{|c|c|c|c|c|c|c|c|}
\hline Indicator/Year & 1997 & 1998 & 1999 & 2000 & 2001 & 2002 & $2003 *$ \\
\hline Real GDP growth rate $(\%)$ & 3.3 & 4.0 & 4.7 & 4.9 & 5.7 & 6.2 & 5.5 \\
\hline Real per capita income (US\$) & 240.2 & 256.9 & 259.4 & 261.2 & 264.1 & 265.3 & $\ldots$ \\
\hline Real growth of agriculture (\%) & 2.4 & 1.9 & 4.1 & 3.4 & 5.5 & 5.0 & 3.5 \\
\hline Real growth of manufacturing (\%) & 5 & 8 & 3.6 & 4.8 & 5 & 8 & 8.5 \\
\hline Real growth of mining and quarrying (\&) & 17.1 & 27.4 & 9.1 & 13.9 & 13.5 & 15 & 15.1 \\
\hline Inflation - annual average CPI (\%) & 16.1 & 12.9 & 7.8 & 6 & 5.2 & 4.5 & $\begin{array}{l}4.6 \\
\text { November }\end{array}$ \\
\hline Current account balance (US\$) & -403.5 & -921.3 & -860.1 & -469.6 & -479.5 & -325.4 & \\
\hline Merchandise exports (US\$ m) & 752.6 & 588.5 & 543.3 & 663.3 & 776.4 & 902.5 & \\
\hline Export/Import ratio (goods) & 65.6 & 43.1 & 38.1 & 49.6 & 52.1 & 59.7 & \\
\hline Foreign Direct Investment (mil. US\$)** & 157.8 & 172.2 & 516.7 & 463.4 & 327.4 & 240.4 & \\
\hline Foreign exchange reserves (months of imports) & 3.8 & 3 & 4.1 & 5.6 & 6.3 & 8.9 & \\
\hline Exchange rate (annual average, TShs/US\$1) & 612.1 & 664.7 & 744.8 & 808.4 & 876.4 & 978.9 & \\
\hline Investment/GDP (\%) & 14.9 & 15 & 15.2 & 16 & 17.2 & & \\
\hline External debt service/exports (\%) & 36.9 & 36.4 & 27.2 & 28.6 & 21.6 & & \\
\hline Fiscal year & $97 / 98$ & 98/99 & $99 / 00$ & $00 / 01$ & $01 / 02$ & $02 / 03$ & $03 / 04$ \\
\hline Domestic revenue (excl. grants)/GDP (\%) & 12.6 & 12.5 & 11.3 & 12.2 & 12.1 & 12.8 & 13.3 \\
\hline Total Govt expenditure/GDP at market prices & 14.8 & 14.8 & 17.1 & 16.8 & 17.6 & 20.8 & 24.9 \\
\hline Fiscal deficit before grants/GDP (\%) & -2.3 & -2.3 & -5.8 & -4.5 & -6.6 & -4.1 & \\
\hline Growth of money supply (M2) (\%) & 11 & 11.1 & 15 & 12.5 & 12.3 & 13 & \\
\hline Average deposit interest rate $(\%)$ & 10 & 7.9 & 7.1 & 4.2 & 3.5 & 3.1 & \\
\hline Average lending interest rate & 24 & 24.5 & 22.1 & 19.6 & 16.4 & 15.7 & \\
\hline
\end{tabular}

*projections 
Government revenue effort has continued to improve, with collection now reaching Tshs. 100 billion per month. During fiscal year 2002/03 total revenue amounted to Tshs. 1,217.5 billion. Tax revenue for 2002/03 stood at Tshs 1,105.7 billion compared to Tshs 938.5 billion in 2001/02. Non-tax revenue was Tshs 111.8 billion in 2002/03. Improved performance is attributed to high collections on income tax, customs duty and VAT on domestic goods and services.

Government spending continues to be guided by the priorities set out in the PRS. Trends in actual recurrent expenditures in the priority sectors and projections are shown in table 6 (Table 18 includes data on development expenditures to priority sectors).

Table 6: Priority Expenditures within Priority Sectors, FY 2001/02 - 2004/05 (Jul-Jun) (in billions TShs)

\begin{tabular}{|l|r|r|r|r|}
\hline & \multicolumn{1}{|c|}{$2001 / 02$} & \multicolumn{1}{c|}{$2002 / 03$} & \multicolumn{1}{c|}{$2003 / 04$} & \multicolumn{1}{c|}{$2004 / 05$} \\
\hline & \multicolumn{1}{|c|}{ Actual } & \multicolumn{1}{c|}{ Actual } & \multicolumn{1}{c|}{ Budget } & \multicolumn{1}{c|}{ Proj. } \\
\hline Education & 344.9 & 436.2 & 502.3 & 564.7 \\
\hline Basic Education & 116.6 & 171.3 & 371.3 & 417.4 \\
\hline Health & 142.1 & 186.7 & 214.3 & 284.9 \\
\hline Primary Health & 101.0 & 113.3 & 124.4 & 165.4 \\
\hline Water & 32.5 & 51.9 & 64.4 & 87.7 \\
\hline Roads & 179.6 & 190.2 & 236.0 & 289.5 \\
\hline Rural Roads & 21.5 & 22.8 & 57.0 & 69.9 \\
\hline Judiciary & 18.8 & 23.2 & 32.7 & 46.0 \\
\hline Agriculture and Food Security & 31.9 & 60.2 & 93.1 & 112.3 \\
\hline TACAIDS & 4.0 & 5.3 & 21.2 & 58.7 \\
\hline Total Priority Sectors & 753.8 & 953.7 & $1,164.0$ & $1,443.9$ \\
\hline Total Priority Items & 261.9 & 335.9 & 606.6 & 757.5 \\
\hline Source: Mins
\end{tabular}

Source: Ministry of Finance

\subsection{Structural Reforms and Private Sector Development}

Government has continued to demonstrate commitment to develop a liberalized private sector-led economy. Considerable progress has been made in the implementation of privatization policy as a whole. As a result 259 public enterprise companies (comprising of two third of all public enterprises) and 210 non-core assets were placed in the hands of the private sector by June 2002. Out of the 259 privatized enterprises 135 have been acquired $100 \%$ by Tanzanian investors. Out of 210 non-core assets divested, Tanzanians acquired 180 through an open competitive tender system.

The Parastatal Sector Reform Program (PSRP) continues to make progress. Focus now is on privatization of large utilities organizations and banks, including the Tanzania Electric Supply Company (TANESCO), Tanzania Railways Corporation (TRC), the Tanzania Harbors Authority (THA), and the National Microfinance Bank (NMB). Divesture of Air Tanzania Corporation (ATC) and Dar es Salaam Water and 
Sewerage Authority (DAWASA) were concluded in December 2002 and February 2003 respectively. The process of unbundling TANESCO into autonomous commercial entities is ongoing. A private management company, which took over in April 2002 has begun to improve the finances of TANESCO.

\section{Employment creation}

The structural reforms undertaken by Government have had short-term implications in terms of job losses. This has compounded the problem of unemployment mainly in urban centers. However, private sector development is seen in the medium to longer term as a sustainable employment creation mechanism. Government is supporting private sector investment so that it can create employment opportunities and raise incomes. These initiatives have already started to bear fruits. For instance, in 2002 TIC approved 311 private sector investment projects in the manufacturing sector worth TShs 1, 024,536 million. These investment projects have the potential to employ 33,132 people. Government, through its Time Bound program, is also creating skill training for 2000 families and 7,500 youth who are already in worst forms of child labor or at risk of getting into it, with the budget of US\$1,230,000 (200405).

Government is creating an enabling environment for employment (jobs) creation through revisions of employment laws, labor relations, dispute prevention and settlement and the regulatory framework. It has established a Labor Exchange Center (LEC) to match skills of job seekers and job qualifications and implemented a demand-driven skills training to promote self-employment in formal and informal sectors.

\section{Government-private sector consultation mechanism}

A formal consultative mechanism with the private sector has been established through the formation of the Tanzania National Business Council (TNBC). The objective is to enhance private sector participation in development. Issues emerging from dialogue between Government and private sector that have been acted upon during the period under the review include:

i) Establishment of the Export Credit Guarantee Scheme.

ii) A comprehensive review of the micro credit schemes.

iii) Involving the private sector in the negotiations for the East African Community and the SADC trade agreements.

iv) Nuisance taxes have been abolished.

v) Views from various stakeholders on inadequacies in the Land Act of 1999, including collateralization are being processed for possible revision of the Act.

The Business Environment Strengthening in Tanzania (BEST) that has been approved aims at improving the effectiveness of government/private sector partnership. The program is geared to provide better 
policy, administrative, legal, regulatory and judicial environment for private sector development. Other actions relate to the financial sector development in respect of improvements in the payments systems, stronger insurance supervisory regime, and of the financial institutions such as the National Insurance Corporation, Tanzania Postal Bank, Tanzania Investment Bank etc

\subsection{Poverty Orientation of the 2003/04 Budget}

Table 7 provides in brief the focus and orientation of the 2003/04 Budget; clearly showing increased attention to poverty reducing measures.

Table 7: Highlights for the 2003/04 Budget Measures

\begin{tabular}{|c|c|}
\hline SECTOR & MEASURE \\
\hline Health. & $\begin{array}{l}\text { Increased resource allocation to the sector } \\
\text { - Inclusion of ambulances in item } 5 \text { to The Third Schedule of the VAT Act since they are also } \\
\text { part of medical equipment. }\end{array}$ \\
\hline Water & $\begin{array}{l}\text { - Introduction of Customs duty exemption on water drilling machines and equipment. } \\
\text { - Increased resource allocation to the sector }\end{array}$ \\
\hline Education. & $\begin{array}{l}\text { The } 2003 / 04 \text { budget has set aside additional resources for the education fund to support } \\
\text { children with academic ability but whose parents fail to pay schools fees due to poverty. } \\
\text { - Increased resource allocation to the sector }\end{array}$ \\
\hline Roads & - Increased resource allocation to the sector \\
\hline Lands & - Earmarking and advertising land for commercial farming so as to attract investors; \\
\hline HIV/AIDS & - Increased resource allocation to the sector \\
\hline $\begin{array}{l}\text { Legal and } \\
\text { Judicial System }\end{array}$ & - Increased resource allocation to the sector \\
\hline $\begin{array}{l}\text { Agriculture } \\
\text { sector }\end{array}$ & $\begin{array}{l}\text { - Introduction of simplified and transparent procedures for business activities in the districts; } \\
\text { - Reduction of withholding tax on sale of fish from the current } 2 \% \text { to } 1 \% \text {. } \\
\text { - Increased resource allocation to the sector } \\
\text { - Shifting of milk packaging from Second Schedule of the VAT Act of } 1997 \text { to the Third } \\
\text { - Schedule of the same Act, because it was misplaced in the Second Schedule. } \\
\text { - Improve access to credit through established export credit guarantee scheme that guaranteed } \\
\text { cooperative unions. } \\
\text { - Improve access to credit through guaranteeing micro-credit to small-scale farmers, small scale } \\
\text { fishermen, small scale livestock keepers, small scale manufactures; } \\
\text { - Provision of modern superior seeds to farmers at affordable prices. } \\
\text { - Provision of subsidized fertilizers for Rukwa, Mbeya, Iringa and Ruvuma regions so as to } \\
\text { boost maize production and eliminate the risk of famine in the country; } \\
\text { - Government is working on plans to start a bank that will cater for the requirements of large and } \\
\text { medium scale fishermen, livestock keepers and farmers; } \\
\text { - Government has introduced a fund to cater for livestock development starting with this budget. } \\
\text { - Government has allocated more resources to the Export Credit Guarantee Scheme }\end{array}$ \\
\hline $\begin{array}{l}\text { Structural } \\
\text { Reform }\end{array}$ & $\begin{array}{l}\text { The privatization Trust has been established to enable many people especially those with low } \\
\text { incomes, to participate in the privatization of state parastatals; } \\
\text { - Government has set aside Shs } 4,000 \text { million for payment of terminal benefits to employees } \\
\text { who will be retrenched in certain key parastatal organizations under privatization, and } \\
\text { employees who will be retrenched from District Councils. }\end{array}$ \\
\hline $\begin{array}{l}\text { Private Sector } \\
\text { Development }\end{array}$ & $\begin{array}{l}\text { - Government has allocated funds in the } 2003 / 04 \text { budget to guarantee loans for SMEs } \\
\text { - The current Income Tax Act No.33 of } 1973 \text { will be reviewed with a view to putting in place a } \\
\text { new law to cater for the modern economic and business environment. }\end{array}$ \\
\hline Employment & $\begin{array}{l}\text { - The Government has allocated funds for special projects focusing on economic growth, } \\
\text { employment creation, and exports. }\end{array}$ \\
\hline
\end{tabular}




\begin{tabular}{|l|l|}
\hline Governance & Abolish a number of levies and fees charged by Local Governments and remain with very few \\
of them which are beneficial to the people in rural and urban areas. \\
- The 2003/04 budget has made a special allocation for salary reviews, that will also include \\
salary adjustments for Government institutions \\
- The Government, with effect from January, 2004 will start paying salaries to Village \\
Government and Ward officials \\
- The budget for 2003/04 has set aside Shs 5,000 million to start construction work of the new \\
National Assembly Hall. \\
The 2003/04 budget has increased allocation to security agencies to enable them to confront all \\
sorts of crimes. \\
Government has raised the minimum pension entitlement to Shs 20,000 per month \\
- In order to enable the District Commissioners to execute their duties more efficiently, allocated \\
funds, with effect from next financial year are channeled directly to their respective districts \\
and not through the Regional Administrative Secretaries.
\end{tabular}

\subsection{Globalization and Poverty}

It is important that the country positions itself to cope with the globalization process so as to benefit from it in the context of the Development Vision 2025 and the PRS. Increased trade liberalization at global level and growing regional integration pose great challenges for economic growth and sustainable development that are critical for poverty reduction. Among measures undertaken in responding to the challenges of globalization include:

- Diversification of exports and processing of agricultural produce so as to add value, improving efficiency in production, processing and marketing of current and potential export commodities;

- Initiatives to establish the Export Processing Zones (EPZ) have been undertaken to promote exports.

- Developing strong financial systems, financial markets and sound economic policies, e.g. enhancing participation of SMEs in the global arena. The SME Development Policy approved in 2003.

- Putting in place sound, consistent and stable investment policies to encourage development and promote investment, technology and the export sector.

- Reviewing aid relationships between Tanzania and development partners to create local ownership through the implementation of Tanzania Assistance Strategy (TAS).

- Being proactive in furthering intra-regional trade and other forms of regional cooperation.

- Increased investment in education, research and health sectors and IT as prerequisites for gaining from integration into the world economy.

- Enhancement of private sector development through implementation of BEST program. 
- Participation in the "Development Round of Trade Talks" with an objective to urge rich nations to make the WTO Doha Development Agenda a reality and agree to remove trade barriers.

- Push for a common position among and within developing countries to allow for removal or lower trade barriers between themselves and hence foster better access to each other's markets.

- Tanzania is also in the process of creating more awareness to the community and address globalization issues in a more holistic approach.

\subsection{Public Debt Developments and Management}

With the objective of strengthening debt management (both external and domestic) Government launched the National Debt Strategy in August 2002. Since then the following measures have been implemented:

(i) The legal and regulatory framework has been strengthened by the amendment of the Loan, Securities and Grants Act of 1974.

(ii) The amendment has vested all powers of debt contraction and management with the Minister for Finance based upon advice of the National Debt Management Committee.

Debt relief under the enhanced HIPC initiative received a boost from the cancellation of debt by all the Paris Club members except for Brazil and Japan under the Paris Club VII agreements. Government will continue to strive for further debt cancellation from these two members as well as the Non-Paris Club and commercial creditors on the same terms. Government introduced a 10-year Treasury bond in October 2002 in addition to the 2-year, 5-year Treasury bonds. Government has gained flexibility in restructuring and extending the term of domestic debt that was previously heavily front-loaded. Implementation of the recommendations of the NDS is expected to reinforce these initiatives. 


\section{IMPLEMENTATION STATUS OF THE PRIORITY SECTORS}

This chapter presents the performance of priority sectors in relation to the identified priority activities in each of the sectors including (i) primary education (ii) rural roads (iii) water and sanitation (iv) legal and judicial systems (v) primary health care and (vi) agriculture. The next steps or planned actions for all PRS sectors and crosscutting issues are included in the policy matrix.

\subsection{Primary Education Overview}

During 2002/03 the Government with support from development partners continued to implement the second year of the five-year Primary Education Development Program (PEDP), which is one of the first components of the Education Sector Development Program (ESDP). The aim has been to sustain the PRS targets for 2003 focusing on expansion of enrolment, improvement of quality, capacity building and improvement in management and strengthening the institutional arrangements.

\section{Progress and Achievements}

Progress towards the PRS targets identified in PEDP is given below:

- In $20031,475,889$ pupils were enrolled as against a target of $1,600,000$. The enrolment target was not met because most of eligible children were enrolled in the first year of PEDP implementation. Standard One enrolment for 2003 is above the PRS target of $85 \%$ of school age children.

- School mapping exercise coverage expanded from 82 districts in June 2002 to 98 by June 2003 of which 53 districts were micro-planned. An additional 16 districts were to be micro-planned by December 2003.

- The Gross Enrolment Ratio (GER) in year 2003 is $105.3 \%$ compared to $100.4 \%$ in year 2002 .

- The Net Enrolment Ratio (NER) (Age 7-13) has risen from $80.7 \%$ in year 2002 to $88.5 \%$ in 2003 . This increase is attributed to the abolition of school fees and other enrolment related contributions from parents. PRS target of raising NER to $77 \%$ by 2003 has thus been surpassed (Tables $8 \mathrm{a}$ and 8 b).

- The transition rate from primary to secondary education has risen by $0.7 \%$ from $21 \%$ in 2001 to $21.7 \%$ in 2002 . The small rise in the transition rate is attributed to the increase in the number of secondary schools from 937 (2001) to 1,024 (2002).

- Dropout rate in primary schools stands at $4.7 \%$ in 2003 as opposed to $6.6 \%$ (2000). However, the achievement is still low compared to the target of reducing the dropout rate to $3.0 \%$ by year 2003 . 
Table 8a: Gross and Net Enrolment Ratio (GER and NER) By Sex and Region, 2002

\begin{tabular}{|c|c|c|c|c|c|c|}
\hline \multirow{3}{*}{ Region } & Male & Female & Total & Male & Female & Total \\
\hline & GER & GER & GER & NER & NER & NER \\
\hline & 2002 & 2002 & 2002 & 2002 & 2002 & 2002 \\
\hline Arusha & 99.8 & 96.5 & 98.2 & 79.5 & 77.3 & 78.4 \\
\hline Dar es Salaam & 104.3 & 103.0 & 103.6 & 86.7 & 88.6 & 87.6 \\
\hline Dodoma & 87.9 & 85.0 & 86.5 & 68.2 & 67.2 & 67.7 \\
\hline Iringa & 103.2 & 103.2 & 103.2 & 85.2 & 86.1 & 85.7 \\
\hline Kagera & 105.3 & 102.6 & 104.0 & 85.3 & 84.1 & 84.7 \\
\hline Kigoma & 108.9 & 96.8 & 102.8 & 88.5 & 79.9 & 84.2 \\
\hline Kilimanjaro & 103.1 & 99.3 & 101.2 & 85.9 & 83.7 & 84.8 \\
\hline Lindi & 84.4 & 77.0 & 81.0 & 70.4 & 65.0 & 67.6 \\
\hline Mara & 115.1 & 105.0 & 110.0 & 93.0 & 86.5 & 89.7 \\
\hline Mbeya & 103.9 & 101.8 & 102.8 & 84.9 & 84.9 & 84.9 \\
\hline Morogoro & 103.9 & 98.0 & 10.9 & 80.5 & 78.7 & 79.6 \\
\hline Mtwara & 91.0 & 90.5 & 90.8 & 76.7 & 76.2 & 76.4 \\
\hline Mwanza & 109.9 & 102.0 & 105.9 & 91.4 & 86.6 & 89.0 \\
\hline Pwani & 114.7 & 102.9 & 108.7 & 92.5 & 86.0 & 89.2 \\
\hline Rukwa & 93.9 & 86.0 & 89.9 & 74.1 & 70.0 & 72.0 \\
\hline Ruvuma & 101.8 & 98.7 & 100.2 & 81.3 & 80.1 & 80.7 \\
\hline Shinyanga & 93.5 & 86.7 & 90.1 & 74.8 & 70.9 & 72.8 \\
\hline Singida & 103.0 & 100.3 & 101.7 & 76.6 & 76.5 & 76.5 \\
\hline Tabora & 88.4 & 79.2 & 83.8 & 73.1 & 66.9 & 70.0 \\
\hline Tanga & 101.7 & 96.0 & 98.8 & 84.6 & 80.2 & 82.4 \\
\hline Grand Total & 101.2 & 96.1 & 98.6 & 82.1 & 79.3 & 80.7 \\
\hline
\end{tabular}

Table 8b: Gross and Net Enrolment Ratio (GER and NER) by Sex and Region, 2003

\begin{tabular}{|c|c|c|c|c|c|c|}
\hline Region & $\begin{array}{c}\text { Male GER } \\
2003\end{array}$ & \begin{tabular}{c|} 
Female \\
GER 2003
\end{tabular} & $\begin{array}{c}\text { Total GER } \\
2003\end{array}$ & $\begin{array}{c}\text { Male NER } \\
2003\end{array}$ & \begin{tabular}{cc|}
\multicolumn{2}{c|}{ Female } \\
NER $\quad 2003$
\end{tabular} & $\begin{array}{c}\text { Total NER } \\
2003\end{array}$ \\
\hline Arusha & 106.3 & 100.4 & 103.4 & 89.5 & 85.6 & 87.5 \\
\hline Dar es Salaam & 110.7 & 109.5 & 110.1 & 93.7 & 96.4 & 95.0 \\
\hline Dodoma & 89.2 & 85.8 & 87.5 & 72.7 & 70.7 & 71.7 \\
\hline Iringa & 111.5 & 108.5 & 110.0 & 94.0 & 93.1 & 93.5 \\
\hline Kagera & 110.7 & 106.8 & 108.7 & 91.1 & 90.4 & 90.7 \\
\hline Kigoma & 117.3 & 107.0 & \begin{tabular}{|l|}
112.1 \\
\end{tabular} & 96.4 & 89.1 & 92.7 \\
\hline Kilimanjaro & 107.0 & 101.5 & 104.2 & \begin{tabular}{|l|}
91.9 \\
\end{tabular} & \begin{tabular}{l|l|}
88.2 \\
\end{tabular} & 90.1 \\
\hline Lindi & 89.5 & 80.9 & \begin{tabular}{l|l}
85.2 \\
\end{tabular} & 75.7 & 69.2 & 72.4 \\
\hline Manyara & 109.2 & 103.6 & 106.5 & 85.5 & 81.7 & 83.6 \\
\hline Mara & 125.3 & 115.5 & 120.4 & 103.1 & 97.7 & 100.4 \\
\hline Mbeya & 112.1 & 107.7 & 109.9 & 96.5 & \begin{tabular}{l|l|}
94.3 \\
\end{tabular} & 95.4 \\
\hline Morogoro & 107.2 & 100.0 & 103.5 & 85.0 & 82.5 & 83.8 \\
\hline Mtwara & 98.3 & 93.3 & 95.8 & 84.4 & 80.5 & 82.5 \\
\hline Mwanza & 120.9 & 113.0 & 116.9 & 102.1 & 97.7 & 99.9 \\
\hline Pwani & 120.9 & 107.3 & 114.0 & 98.7 & 89.8 & 94.2 \\
\hline Rukwa & 102.4 & 91.2 & 96.7 & 83.2 & 76.7 & 80.0 \\
\hline Ruvuma & 107.4 & 102.7 & 105.0 & 89.2 & 86.5 & 87.8 \\
\hline Shinyanga & 104.3 & 95.7 & 100.0 & 86.5 & 81.2 & 83.8 \\
\hline Singida & 111.5 & 106.6 & 109.1 & 86.0 & 84.5 & 85.3 \\
\hline Tabora & 93.2 & 82.5 & 87.8 & 78.9 & 71.5 & 75.1 \\
\hline Tanga & 112.5 & 105.3 & 108.9 & 95.7 & 90.2 & 92.9 \\
\hline Grand Total & 108.6 & 102.1 & 105.3 & $\begin{array}{l}90.4 \\
\end{array}$ & 86.7 & 88.5 \\
\hline
\end{tabular}


- To enhance quality of teaching and learning and to reduce the shortage of teachers across schools and regions, the government recruited 10,719 new Grade “A” teachers out of the targeted 11,651 by May 2003. This is $92 \%$ of the target. The failure to employ in some districts is a result of unattractive working environment including, among other things, poor housing conditions for teachers.

- In order to meet the increased demand for teachers, the government increased the number of trainees in teacher training colleges. The pre-service teachers training enrolment expanded from 9,728 in 2002 to 15,285 in 2003.

- In-service training of teachers is also being conducted through Teacher Resource Centers (TRCs) and distance learning. In 2002, a total of 149 (86 male and 63 female) in-service grade A teachers were admitted in Teacher Training Colleges and in 2003, 484 (234 male and 250 female) teachers were enrolled. Training of 763 facilitators to upgrade 50,000 grades " $\mathrm{C} / \mathrm{B}$ " teachers to grade A was conducted. In-service and pre-service teacher professional development programs have been developed to integrate In-Service Training Program (INSET) into PEDP. These programs aim at enhancing the quality of the learning environment.

- The pass rate in standard 7 examinations has increased from 24.9\% (2001) to 27.1\% (2002). The recruitment of qualified teachers, improvement of school inspection service and provision of quality teaching and learning materials are undertaken to attain the pass rate of $50 \%$ by year 2005 .

- The gender enrolment parity ratio in Primary Schools was 1:1 in 2002 and is still maintained while in secondary schools the gender parity ratio has increased from 1:0.87 (2002) to 1:0.93 (2003).

- For the implementation of national application of USD 10 (Tshs 10,000/=) capitation grant per pupil, a total of Tshs 32.19 million was disbursed to councils for 6,536,798 pupils in 2002/03. This is equivalent to USD 4.9 per pupil.

- To enhance teaching and learning processes and improve the quality of education. The inspectorate system inspected various education units in 2002. The results are shown in Table 9. In all categories of education units the targets were met or exceeded.

Table 9: Education Units Inspected 2002

\begin{tabular}{|l|r|r|r|}
\hline Education Unit & \multicolumn{1}{|l|}{ Target } & Inspected & \multicolumn{1}{c|}{$\%$} \\
\hline Pre-primary Schools & 2,879 & 3,918 & 136.1 \\
\hline Primary & 6,402 & 7,043 & 110.0 \\
\hline Special Education Schools & 118 & 121 & 102.5 \\
\hline Adult Education Center & 6,402 & 6,726 & 105.1 \\
\hline Secondary & 506 & 529 & 104.5 \\
\hline Teachers Training Colleges & 42 & 42 & 100.0 \\
\hline
\end{tabular}

Source: MOEC Budget Speech (2003) 
- The enrolment rate in secondary schools (Form I-IV) increased by 8\% (2003). Therefore the PRS target of $7 \%$ by 2003 has been reached.

\section{Lessons and Challenges}

- Some of the Councils have shown weakness in the use of funds as per action plan. This weakness delays the release of funds by donors for the quarter that follows. Other councils do not adhere to the specified standards for construction of classrooms and teachers' houses nor do they follow criteria for the management of primary schools.

- Some of the Councils' Directors and District Education Officers do not inform Head Teachers and School Committees about the amount of funds released by the central government. As a result Head Teachers, School Committees and the society are unable to follow up, or participate fully in the implementation of PEDP activities.

\section{Costing of interventions}

Table 10: Estimated Financing Requirements for the ESDP 2002/03 - 2005/06 (in million Tshs.)

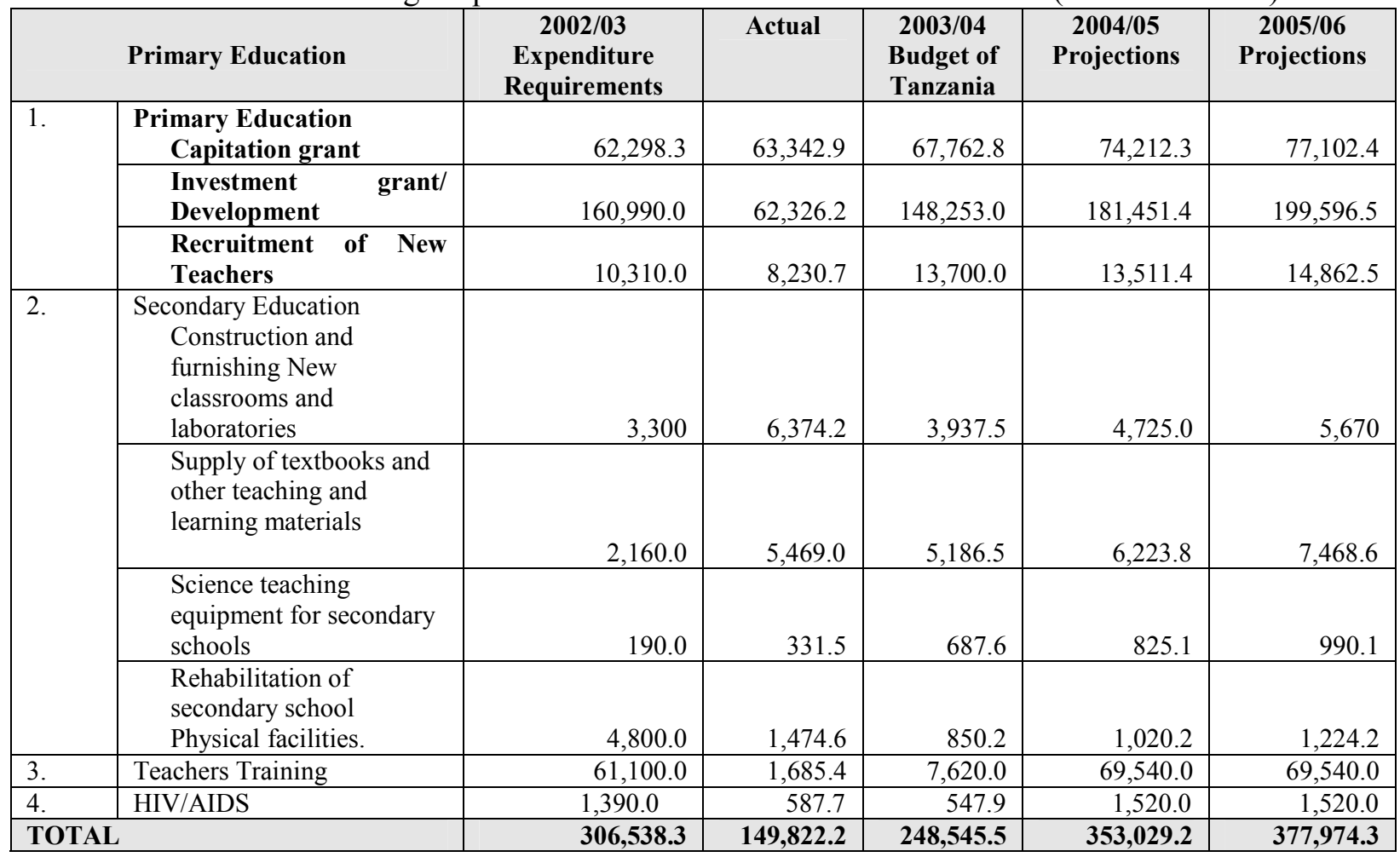

Source: 1. MoF and PO-PP Budget Guidelines (2003/04 - 2005/06)

2. 2001/02 and 2002/03 Budget books 


\subsection{Roads}

\section{Overview}

Overall road network improvement in the past three PRS years has increased the accessibility of rural areas, thus improving the flow of people and commodities. Agricultural, forest and fisheries products can more easily reach urban and rural market centers. Manufactured goods such as household goods and farm implements more easily flow into rural areas. However, increased number of accidents due to overspeeding raises concern. Measures taken to address the concern include road user education campaigns, enforcement of traffic regulations and construction of speed humps on some highways.

During the financial year 2002/2003 the following planned actions were to be implemented by the government in order to improve the road network conditions taking into consideration the poorest regions.

- The Government to continue allocating Tshs. 1.84 billion monthly to improve transport link to the northwestern and southern regions of the country.

- To increase normal budget allocations to rehabilitate feeder, district and regional road network in the poorest eight regions.

- To give special attention to footpaths, tracks and trails and to mobilize communities in carrying out needed improvement

- To carry out routine maintenance, emergency repair and spot improvement in all districts to ensure uninterrupted use of the roads.

- Develop and prepare a program similar to the "Urgent Road Rehabilitation Program" (URRP) for the districts, feeder and urban roads.

- Improve the capacity of district engineers to manage execution of road maintenance works at district level.

\section{Progress and Achievement}

\section{The use of the Tshs. 1.84 billion per month (Special Project).}

The Government allocated funds for the improvement of the transport link to the Northern-Western and Southern regions of the country by upgrading to bitumen standard some road sections on the Southern Corridor namely Dar es Salaam-Lindi-Mingoyo and Central Corridor namely Dar es Salaam-DodomaSingida. The rehabilitation work is going on, which will cover a total of $468 \mathrm{~km}$. A total of Tshs 25.36 billion has already been spent. 


\section{Three year Program on rehabilitation of regional roads}

This involves road works on $923 \mathrm{~km}$ of road network in four regions (Kagera, Dodoma, Singida and Tabora), which are under $\mathrm{ADB}$ and GoT financing, and regional network rehabilitation program involving about $320 \mathrm{~km}$ under OPEC and GoT financing for Lindi and Kigoma regions.

\section{Maintenance Works}

Government continues to address capacity requirements for District Engineers to manage the execution of road works, both maintenance and construction.

\section{Improvement of district and feeder roads, footpaths, track and trails, and use of IMT.}

During 2002/03, a program similar to the "Urgent Road Rehabilitation Program" (URRP) for the districts, feeder and urban roads was developed. The District Roads Management System is now being considered for rolling out to the 92 District Councils, which were not in the pilot scheme. At the same time a total network under PORALG of 7,049 km of rural roads (51.4\%), of the planned 13,727 km received routine, spot improvement and periodic maintenance. The expenditure for the work amounts to $63.4 \%$ of the planned budget of Tshs 13,854 million. A number of bridges, culverts and drifts were also repaired and maintained at a cost of Tshs 1,961.2 million. The reason for achieving only $65 \%$ of the planned works is inadequate capacity at district level, lack of competent contractors in some Councils and late release of Road Fund allocation by Road Fund Board. Tshs 4,927 million earmarked for PORALG for rehabilitation /construction from the development budget for year 2002/2003 was not released thus making it difficult to rehabilitate the $4,500 \mathrm{~km}$ originally planned.

\section{Promotion of Labor Based Technology}

The Ministry is currently promoting use of labor-intensive technology in rehabilitation of the road network. More than 700 people (mostly laborers) are employed at the Chalinze-Melela roads rehabilitation project. Out of these about $12 \%$ are women. The Makuyuni-Ngorongoro road that is being upgraded to bitumen standard employs about 500 people (mostly laborers). $2 \%$ of them are women. In the Southern Highland zone, several petty contracts were awarded to village contractors and communities. Promotion of labor-intensive technology helps to generate income to local communities, which ultimately contributes to poverty reduction in the country.

\section{Lessons learned and Challenges}

- One of the major challenges is to enhance the capacity of local government authorities to manage district, urban and feeder roads. The ongoing Local Government reforms need to go further to establish a mechanism that will ensure that the road networks under their jurisdiction are managed 
properly by local authorities. Strengthening local government capability through training and allocation of skilled manpower remains critical for the achievement of planned work.

- The Ministry has planned for the Urgent Road Rehabilitation Program (URRP), under the Trunk and Regional Roads Network and the Ten Year Road Sector Rehabilitation Program (10YSRP). For districts and feeder roads, the District Roads Management System (DROMAS) has been developed, which needs to be rolled out to more districts.

- Given the scope of work needed to raise the condition of the road network and ensure proper maintenance, the financial resources available prove to be insufficient implying a need to go beyond the Road Fund Resources.

- Only $17 \%$ of the District road network is in good condition (requiring recurrent maintenance). The rest are in fair and poor condition, which require development budget.

- More efforts need to be directed towards establishment and reinforcement of technical departments with the required personnel, tools and equipments, and enhance accountability and transparency.

\section{Cost of Interventions}

Table 11 shows the summary of program costing for the road sector.

Table 11: Summary of program costing (Tsh. Million)

\begin{tabular}{|c|c|c|c|c|}
\hline Road Sector & $2002 / 03$ & $2003 / 04$ & $2004 / 05$ & $2005 / 06$ \\
\hline Total Sector Requirement $^{1}$ & 260,170 & 299,274 & 344,255 & 395,997 \\
\hline Allocation & 208,415 & 258,655 & 321,005 & 369,156 \\
\hline Gap & 51,755 & 40,619 & 23,250 & 26,484 \\
\hline \multicolumn{5}{|l|}{ Breakdown between Trunk and rural Roads } \\
\hline \multicolumn{5}{|l|}{ Trunk Roads \& Regional Roads } \\
\hline Construction (Budgeted) & 133,483 & 167,631 & 227,856 & 262,034 \\
\hline Maintenance & 50,700 & 45,157 & 59,177 & 68,014 \\
\hline TOTAL & 184,183 & 212,788 & 287,033 & 330,048 \\
\hline Gap & 31,457 & 24,689 & 13,150 & 16,341 \\
\hline \multicolumn{5}{|l|}{ Rural Roads $^{2}$} \\
\hline Construction & 4,927 & 3,945 & 8,606 & 9,244 \\
\hline Maintenance & 19,305 & 21,545 & 25,366 & 29,864 \\
\hline TOTAL & 24,232 & 25,490 & 33,972 & 39,108 \\
\hline Gap & 20,298 & 15,930 & 10,100 & 10,143 \\
\hline
\end{tabular}

1. Total Sector Requirement is the overall road sector including the construction costs for trunk and regional, district, urban and feeder roads

2. Rural Roads in this table means the road network under the Regional Administration and Local Government 


\subsection{Water}

\section{Overview}

Availability of adequate water supply with good quality reduces time spent in fetching water, increases health standards, and ensures a favorable environment for increased children's school attendance. The economic use of water for irrigation is also an important consideration especially in drought prone areas. Water is a fundamental natural resource for socio economic development. For example, the poor suffer most during water shortages as they usually pay more per liter from informal water suppliers than their affluent neighbors with water connections, putting their health at risk.

\section{Progress and Achievements}

Urban Water Supply and Sewerage service was fairly good compared to Rural Water Supply and Sanitation during the period under review (2000/01-2002/03) due to donor commitments favoring urban areas especially during the first two years of PRS implementation. Rural water supply service coverage increased from $48.5 \%$ in 2000 to $53 \%$ in 2003 , failing to hit the PRS target of $55 \%$ by 2003 . During 2002/03 the sector recorded the following achievements:

(i) The sector has maintained coverage of access to water in urban centers at $73 \%$ for the second consecutive year and has raised the sewerage service coverage in the two cities (Dar es Salaam and Mwanza) and seven municipalities (Arusha, Moshi, Tanga, Morogoro, Dodoma, Tabora and Iringa) from $10 \%$ in June 2002 to $17 \%$ in June 2003. This has been made possible because of the following interventions:

- Rehabilitation and expansion of urban water supply systems in Songea, Kigoma, Musoma, Bukoba, Sumbawanga, Shinyanga, Mtwara (where 11 pumping stations were strengthened) and Lindi town (where 10 deep boreholes were built for production of 4.2 million liters per day),

- $80 \%$ progress in implementation of the 2 nd phase of expansion of water supply systems in Tanga, Moshi and Arusha,

- Installation of 2,300 water meters which increased installed meters to $50 \%$ of all customers in the 18 UWSAs,

(ii) Rural water supply coverage has increased from 50\% in June 2002 to $53 \%$ in June 2003. Measures behind this increase include:

- Rehabilitation and expansion of 28 rural water schemes in 24 Districts and rehabilitation of 14 water pumps in 14 pumped schemes. 
- Completion of the Chalinze Water supply pumped scheme project that covers one small town and 21 villages with 105,000 beneficiaries.

- Over $90 \%$ progress in the implementation of the East Kilimanjaro and Hai District rural water supply projects that involves construction of the 8 large gravity water supply schemes for 779,958 beneficiaries in Rombo, Moshi rural and Hai districts in Kilimanjaro region.

- Completion of impact evaluation of the Rural Water Supply Project that covered 15 Districts in Iringa, Ruvuma and Mbeya Regions. The project serves 902,000 people.

- Completion of impact evaluation of the Health through Sanitation and Water Project (HESAWA) that covered 17 districts in 3 regions ( 5 in Kagera, 8 in Mwanza and 4 in Mara). The project serves $3,248,000$ rural inhabitants. This coverage is equivalent to $61 \%$ of the total population.

- Construction of 328 water wells in rural areas and 100 water wells in selected peri-urban areas.

- Adequate project design manuals have been prepared and disseminated to District Water Engineers for enhancing community and private sector participation in water service delivery.

(iii) Government launched the National Water Policy of 2002 in March 2003. The new policy underlines issues of sustainable management of water resources with emphasis on equitable allocation and environmental conservation, private/public sector partnerships, community participation through demand responsive approaches, inter-sectoral coordination, collaboration and information sharing, gender awareness and mainstreaming, use of appropriate technologies, promotion of rainwaterharvesting technologies, and appropriate institutional and regulatory framework.

(iv) In reinforcing legal and institutional involvement of local communities and the private sector in developing water supply schemes, Government continues to sensitize communities, private sector and Local Government Authorities to participate in developing water schemes, protect water sources and enact by-laws to protect water sources in their respective areas.

(v) Divestiture of DAWASA has been completed. City Water Services Ltd has taken over DAWASA and undertakes to improve technical efficiency of existing water and sewerage systems and ensure reliable services to about 3 million beneficiaries in Dar es Salaam city, Kibaha and Bagamoyo.

\section{Lessons learnt and challenges}

- Capacity building of village water funds management is very important for enhancing community ownership of water schemes through meeting their operation and maintenance costs and developing new sources of water in the same areas. A legal framework to govern the operations and management 
of the Village Water Funds to ensure transparency and avoid mismanagement and particularly misappropriation of these funds is being worked out through the ongoing review of water legislation.

- Water users and Local Authorities need further sensitization for increased participation with ultimate goal of reducing donor dependency.

- Sector financing is still fragmented into different major, medium and small projects based on bilateral agreements. The sector recognizes the need for a coordinated approach through a Sector wide approach in planning,

- Capacity at Local Government Authorities, which are central organs in implementation of water sector activities need to be strengthened through merit recruitments and training of personnel.

- Water Sector PRS indicators are ambitious, especially the possibility of reaching the $85 \%$ by 2010 , and therefore needs to be reviewed through a consultative process during the comprehensive PRS review. At the same time, Water Sector co-ordination and steering of the sector reform process continues to be strengthened.

- Implementation, monitoring and evaluation of sanitation activities continues to be challenging due to a stretch of uncoordinated obligations amongst three main implementing agencies (MoWLD, $\mathrm{MoH}$ and PORALG). This challenge will be addressed through a consultative process during the PRS review so as to determine clear and harmonized targets.

\section{Costing of Interventions}

During 2002/03 and 2003/05, the Development Budget share to Rural Water Supply rose by $100 \%$ as indicated in Table 12, compared to about 30\% decline in investment financing for urban water and sewerage. Government believes that increased direct allocation for the water sector to district councils to implement rural priority schemes will enhance capacities for managing increased expenditures and raise service coverage of water supply in rural areas. The financing position for 2002/03 and 2003/04 in the table below reflects budget ceilings. Following the Public Expenditure Review (PER 2003 Water Sector), budget allocations for investment in rural water supply have almost doubled as shown in Table 12: 
Table 12: Financing of the water sector Program, 2003/2004 - 2005/2006 (billion Tshs)

\begin{tabular}{|c|c|c|c|c|}
\hline \multicolumn{5}{|c|}{ (June-Julv) } \\
\hline & $\begin{array}{l}2002 / 03 \\
\text { Budget }\end{array}$ & $\begin{array}{c}\text { 2003/04 } \\
\text { Budget }\end{array}$ & $\begin{array}{c}2004 / 05 \\
\text { Projection }\end{array}$ & $\begin{array}{l}2005 / 2006 \\
\text { Projection }\end{array}$ \\
\hline Recurrent expenditure & 16.9 & $\mathbf{1 7 . 5}$ & 28.7 & 29.0 \\
\hline Salaries and wages & 5.2 & 4.8 & 8.8 & 9.0 \\
\hline Other charges & 11.7 & 12.7 & 19.9 & 20.0 \\
\hline Administration & 1.6 & 2.7 & 2.9 & 3.5 \\
\hline Electricity & 7.2 & 2.9 & 9.8 & 8.0 \\
\hline Operation and maintenance & 1.6 & 4.8 & 4.6 & 5.2 \\
\hline Capacity building & 1.3 & 2.3 & 2.6 & 3.3 \\
\hline Investment/Development & 41.7 & 46.1 & 89.4 & 97.2 \\
\hline Rural water supply infrastructure & 9.3 & 20.3 & 22.2 & 25.2 \\
\hline Urban water and sewerage & 26.2 & 18.5 & 48.5 & 48.5 \\
\hline $\begin{array}{l}\text { Water research, management, } \\
\text { Planning and Training }\end{array}$ & 5.9 & 4.4 & 6.7 & 10.0 \\
\hline *Others & 0.3 & 2.9 & 12.0 & 13.5 \\
\hline **Total expenditure & 58.6 & 63.6 & 118.1 & 126.2 \\
\hline
\end{tabular}

* "Others" means the Development budget shares going to Regions and the Local Government. This allocation has a very strong bias in financing rural water supply schemes.

** Projections for 2004/2005 and 2005/2006 consider a change in sector planning through introduction of the sector SWAP that incorporates LGA's planned sector requirements and donor commitments for rural and urban sub sectors respectively.

The sector is planning the WSDS that will be in place by June 2004. This strategy is expected to guide sector programs, implementation and financing modalities that will capture aid-financed spending that is currently off-budget.

\subsection{Legal and Judicial System}

The Government is currently implementing the Legal Sector Reform Program. The Medium Term Strategy and Action Plan 2000-2005 was reviewed in March 2003. Its implementation will enhance timely and accessible justice for all, in line with basic human rights focusing on personal safety, access to justice, overall efficiency, fairness, and transparency of the administrative system. Government financing reflects this commitment.

\section{Progress and Achievements}

Various initiatives were undertaken in the year 2002/03 to improve efficiency and fairness in delivery of legal and judicial services. These were:

- A move by Parliament to open the legislative process to participation by civil society organization as part of the legal reform process;

- Recruitment of two Judges of Court of Appeal, 6 Judges of the High Court, 7 Resident Magistrates, 84 Primary Court Magistrates and 36 State Attorneys was undertaken in fiscal year 2002/03; 
- The introduction of the Alternative Dispute Resolution (ADR) system which has contributed to a significant reduction in the backlog of pending civil cases in the High Court and Resident Magistrate Courts. Government extended this system to all Resident Magistrates and District Courts in April 2002;

- Training of 600 Primary Court Magistrates, 300 Resident Magistrates and 34 Judges of Court of Appeal and High Court;

- Establishment of the Human Rights and Good Governance Commission in March 2002, now operational;

- The preparations for Tanzania Accountability, Transparency and Integrity (ATIP) are being finalized as part of the reform program. It has the objective of strengthening good governance;

- Preliminary preparation of a comprehensive program for the rehabilitation of buildings and other facilities of primary courts has started.

\section{Lessons learned and challenges}

Despite these achievements the sector continues to face the following challenges:

- Formulation of the Legal Sector Policy;

- Mainstreaming gender and HIV/AIDS issues in the legal sector, policy, plans and budget.

- The changing social cultures of the people arising from urbanizations and expanding and intensifying interaction with other cultures calling for an appropriate legal framework.

- The new pluralistic democratic political environment coupled with the movement towards participatory management of legal and social economic development;

- The rapid expanding and institutionally complex private sector-led market economy and globalization;

- The vast growing electronic (e)-commerce. E-commerce raises many new legal issues including those relating to regulation, taxation, contact, liability, patent, data protection, etc; and

- The need to create a legal framework to cater for the needs of the National Development Vision and Long term Development Strategy (Vision 2025). 


\section{Costing of Interventions}

Table 13: Legal and Judicial Systems Costing of Interventions 2003/04

\begin{tabular}{|l|l|c|c|r|r|}
\hline ACTIVITY & \multirow{2}{*}{$\begin{array}{l}\text { SOURCE } \\
\text { OF FUNDS }\end{array}$} & \multicolumn{3}{|c|}{ TOTAL COST (IN TSHS. MILLION) } \\
\cline { 4 - 6 } & VOTE 40 & VOTE 41 & VOTE 59 & TOTAL \\
\hline Reducing the backlog of pending cases & GoT & $4,580.7$ & $2,125.24$ & - & $6,705.94$ \\
\hline Enhancing supervision, division of work & GoT/QST & $1,717.57$ & $1,012.76$ & - & $2,730.33$ \\
\hline Updating legal framework and legal & GoT/QST & - & $1,049.25$ & 42.34 & $1,091.59$ \\
\hline Improvement of civil registration & GoT & - & 268.36 & - & 268.36 \\
\hline Training & GoT/QST & 998.64 & 355.73 & 66.08 & $1,765.45$ \\
\hline Improvement of accommodation & GoT/QST & $1,700.00$ & 65.00 & - & $1,420.45$ \\
\hline Transfers & GoT & $1,613.62$ & 25.00 & - & $1,638.62$ \\
\hline Establishment of new Divisions/ Institutions & GoT & 431.67 & - & - & 431.67 \\
\hline Legal Sector Reform Program & GoT & - & $2,841.22$ & - & $2,841.22$ \\
\hline TOTAL & Basket Fund & $11,042.2$ & $7,742.56$ & 108.42 & $18,893.18$ \\
\hline
\end{tabular}

\subsection{Health Sector}

\section{Overview}

According to HBS 2000/01 about $91.4 \%$ of the population are less than $10 \mathrm{~km}$ from a health facility and $75.4 \%$ are less than $6 \mathrm{~km}$. Essential drugs and services are now available at all levels and the target is to continue to improve the district health services. However, provision of quality health services is constrained by dilapidated infrastructure, shortage of trained staff and limited management capacity.

Malaria continues to be number one killer disease, accounting for $17 \%$ of all deaths and approximately $30 \%$ of all hospital visits. Other diseases are Acute Respiratory Infections, waterborne diseases, skin conditions and increasing chronic diseases such as hypertension and diabetes. HIV/AIDS continues to threaten and has mostly affected the productive work force.

In $2003 \mathrm{MoH}$ conducted a review of the health sector performance, which was preceded by a technical review on district health services. The technical review was used as an input into the new Health Sector Strategic Plan (HSSP), which was completed in April 2003. The new HSSP is expected to be a key step towards the implementation of the second PRS. The new strategy aims at improving quality of health services and client satisfaction at a cost the individuals and community can afford.

The new strategy integrates nine other strategies into three components; (i) District Health Services (ii) Hospital Services and (iii) Central Level, and spells out their roles:

- The district health services component focuses on quality service delivery within the context of comprehensive district health planning. 
- The hospital component provides referral services. Regions will assure availability of supervisory and technical support to councils; and ensure adherence to policy and guidelines.

- The central ministry will be responsible for development of necessary policies and regulatory framework, tracking policy implementation, reform management, monitoring and quality control.

The strategic plan highlights (i) greater integration of health services, (ii) the importance of human resources, skill mix, and deployment and retention, (iii) the importance of Public Sector Reform process and the role of Public Service Management Office and issues of pay reform and staffing levels, and (iv) the role of PO-RALG in overseeing the proper functioning of the various levels in the health system; the regional and district hospitals, health centers, dispensaries and communities. Furthermore having the correct number of competent staff with the appropriate skills in the Regional Secretariat is emphasized.

\section{Progress and Achievements}

(i) In order to create the necessary linkages and adopt a common frame the PRS was mainstreamed in the revised health policy and in the Health Sector Strategic Plan 2003-2008.

(ii) The Health Sector HIV/AIDS strategy 2003-2006 was developed and accepted by all stakeholders and translated into MTEF activities for HIV/AIDS. It aims at integrating HIV/AIDS in the functions of all the structures of Ministry of Health. Plans for introducing antiretroviral therapy are at an advanced stage.

(iii) Births attended by trained personnel were sustained at $80 \%$. Furthermore $\mathrm{MoH}$ is seeking to improve the quality of work delivered by TBAs. A policy guideline on TBA activities was developed and distributed.

(iv) Vaccination coverage rose to $88 \%$ for BCG, $89 \%$ for measles and $83 \%$ for DPT3 (EPI 2002 ).

(v) Malaria program is being strengthened through the Roll Back Malaria approach with vector control, drug supplies and management protocols including intensification of research.

(vi) MoH has introduced a voucher system whereby all pregnant mothers will be provided with a voucher, which will subsidize the purchase of an insect-treated bed net. In the Household Budget Survey it is reported that $37.1 \%$ of all households are in possession of a mosquito net.

(vii) All 113 districts have been included in the HSR Program.

(viii) A resources allocation formula for basket funds was developed and accepted by the Basket Finance Committee. This formula aims at redirecting resources to main priorities in the health sector, with a special focus to areas where the majority of poor and vulnerable groups live. 
(ix) The Health Boards are being rolled out to all 113 LGAs and the district hospitals. At lower level in the health system Health Facility Committees are being established. Health Boards have been established in 16 districts and 76 districts have been sensitized.

(x) CHF has been introduced in 23 districts. 72 districts have been sensitized and are ready to start the CHF Program.

(xi) Accreditation of more private facilities is being undertaken by National Health Insurance Fund and it is expected to strengthen service delivery.

(xii) Essential Reproductive and Child Health Package document was developed and distributed.

(xiii) Hepatitis B vaccine immunization was introduced countrywide.

(xiv) 47 new councils were trained in IMCI, community strategy for IMCI was developed, Kiswahili versions of IMCI modules are now available and IMCI indicators have been developed.

(xv) The National Food and Nutrition policy Guidelines on Community-Based Nutrition has been reviewed. Micronutrient supplementation on Vitamin A, Iron-folate and Iodine are going on. Vitamin A supplementation coverage was over $90 \%$ in 2002 compared to around $22 \%$ in 1999.

(xvi) Information, Education and Communication materials that are tailored to meet requirements of different level of health delivery were developed and distributed to all health facilities.

(xvii) 61,606 TB cases were reported in 2001 (MTUHA 2002). The TB and Leprosy unit reported that the completion rate in 2001 of DOTS was $81 \%$ and the cure rate was $76.3 \%$.

\section{Lessons and Challenges}

- The health sector is still under-funded. The target for MoH has been set at US\$ 9 per capita, although according to the World Development Report (1993) US\$ 12 is an absolute minimum to ensure sufficient resource allocation to priority areas such as malaria, TB and HIV/AIDS. In the PER 2003 the allocation was USD 6.3 per capita. The current level of funding is approximately US\$6 per capita, leaving a gap of US\$ 3 per capita from the target of US\$ 9 per capita.

- The sectoral allocation to health is increasing very slowly, from $7.5 \%$ in FY00 to $8.7 \%$ in FY03. A Financing Task Force has been established with an aim of negotiating with MoF and donors to increase the resources envelope.

- HIV/AIDS and related diseases are a huge burden on the health care system. More than $30 \%$ of the resources are spent on diseases related to HIV/AIDS. Surveillance on HIV among antenatal clinic 
enrollees (2001-2002) showed prevalence of 9.6\% (NSS). HIV/AIDS interventions are still not sufficiently funded.

- HSR needs a high degree of coordination with other ministries, donors and communities.

- Inadequacy of staff in terms of numbers and skill mix: It will be necessary to look at deployment, development, motivation, incentives and retention schemes

- The information systems in the health sector need to be improved and coordinated. A Task Force on information systems and performance measurement has been established. Routine data are not readily available which makes it difficult to track progress in health sector outcome and impact.

- Run-down and dilapidated health units due to lack of rehabilitation or repair need urgent attention.

- Delays in disbursement of basket fund are still a problem.

\section{Costing of Interventions}

The MoH is every year preparing a PER and MTEF. The resources for 2003/04 are 6.6 USD per capita. The budget for the year 2003/04 for the health sector is TShs. 141.08 billion. Table 14 shows the breakdown of the costs of priority interventions.

Table 14: Financing of Priority Health Interventions, 2003/04 - 2005/06 (July-June) TShs billion

\begin{tabular}{|c|c|c|c|c|}
\hline $\mathbf{S} / \mathbf{N}$ & Priority Areas for PRS & $\begin{array}{c}2003 / 04 \\
\text { Budget }\end{array}$ & $\begin{array}{r}2004 / 05 \\
\text { Projections }\end{array}$ & $\begin{array}{r}2005 / 06 \\
\text { Projections } \\
\end{array}$ \\
\hline 1 & Drugs & 22.60 & 36.40 & 39.31 \\
\hline 2 & Essential Medical Supplies & 9.80 & 12.50 & 13.50 \\
\hline 3 & Strengthening of referral hospitals & 20.70 & 35.90 & 38.77 \\
\hline 4 & Malaria Prevention and Control & 8.50 & 9.90 & 10.69 \\
\hline 5 & Human Resources Development & 5.40 & 15.07 & 16.28 \\
\hline 6 & Immunization Services (EPI) & 10.90 & 13.25 & 14.31 \\
\hline 7 & Control of TB/Leprosy & 2.20 & 5.14 & 5.55 \\
\hline 8 & Improvement of District health Services & 2.60 & 5.15 & 5.56 \\
\hline 9 & Reproductive Health Care, IMCI and Contraceptive (Depo- & 8.00 & 10.70 & 11.56 \\
\hline 10 & Nutrition & 1.40 & 1.81 & 1.95 \\
\hline 11 & Environment Health Hygiene and Sanitation & 0.13 & 0.29 & 0.31 \\
\hline 12 & Improve health services to Voluntary Agencies and DDH & 7.30 & 7.30 & 7.88 \\
\hline 13 & HIV/AIDS Awareness Program & 11.20 & 11.19 & 12.09 \\
\hline \multirow[t]{2}{*}{14} & Public Health Research Services & 14.10 & 3.53 & 3.81 \\
\hline & Total recurrent expenditure & 124.83 & 168.13 & 181.58 \\
\hline \multirow[t]{2}{*}{15} & Development expenditure (rehabilitation of facilities and & 16.25 & 20.31 & 21.94 \\
\hline & Grand Total & 141.08 & 188.44 & 203.51 \\
\hline
\end{tabular}

Source (PRS- PB 2002 - updated) MoH 


\subsection{Agriculture}

\section{Overview}

The Agricultural Sector Development Program (ASDP) is an instrument for achieving the PRS objectives in the Sector. The program spells out priority areas for investment in the context of the PRS. The broad objective of the ASDP is to create an enabling environment for improving productivity and profitability in agriculture, improve farm income and ensure household food security. Through the ASDP, the sector has designed and is strengthening a system involving districts and wards and participatory approaches in the design of DADPs. The DADPs act as a focal point for identifying priority areas for poverty reduction in the rural areas. Through these teams, a community-based monitoring system will be strengthened for the community to provide feedback on the outcome and impact on the agriculture interventions.

Available statistics show that during the implementation of the PRS, yield levels for major cereals such as maize and paddy have increased due to improved adoption rates in the use of better seeds, better farming practices and general increase in area under irrigation. As a result household incomes and food security have improved.

\section{Progress and achievements}

During the fiscal year 2002/2003 priority has been to improve the productive capacity of smallholder farmers and livestock keepers and the provision of favorable legal and institutional framework, aiming to accelerate private sector investment. During the year the following progress and achievements were made in the agriculture sector:

\section{A. Sector Level}

- Initiated detailed formulation of key ASDP sub-programs (Phase II), including issuance of guidelines for preparation of District Agricultural Development Plans (DADPs).

- The local government taxes and levies were harmonized. Non-core (nuisance) taxes that have negative impact on agricultural growth have been eliminated.

- Private Agribusiness Sector Support (PASS) was implemented. As a result 77 gender balanced farmers groups were organized. They received assistance on contract farming, input supply, producerprice negotiations and advisory services. 78 businesses received financial linkage and 75 credit guarantees were issued for agriculture investments.

- A review of the role and funding arrangements of Crop Boards is underway in collaboration with the Ministry of Cooperatives and Marketing 


\section{B. Crop Sub-Sector}

Achievements made under crop sub-sector include:

\section{Irrigation development:}

- For the year $2002 / 03$ land under irrigation farming increased by 8,995 ha thus totaling to 200,895 ha compared to 191,000ha under irrigation in 2001/2002.

- Advisory, Research, Training and Regulatory Services Support

\section{Extension services and Training:}

- Achievements made during 2002/03 include training of 6,688 farmers and 1,130 village extension staff on participatory methodologies and broadcasting of 104 radio programs with regard to crop production and distribution of 6 leaflets on agricultural technologies to farmers

- Training to technical staff and farmers at the agricultural institutes continued focusing on commercial farming. 6,031 farmers (2,524 female and 3,507 male) received formal training in Oxen plough farming, crop processing and sugar cane production. The number of farmers trained during the year increased by $59 \%$ compared to 3,803 farmers trained in $2001 / 02$. An increase was attributed to an increase in Ministry budgetary allocation to farmer training. In addition 1,079 farmers, of whom 491 were women, attended a special course on irrigation for paddy production in KATC Moshi.

\section{Crop research services:}

- Nine (9) new breeder seeds for paddy, sorghum, beans, pigeon peas, soya, wheat, wheat potatoes and UK 91 were generated from research institutions.

\section{Improved Seeds:}

- For $2002 / 03$, actual availability of improved seeds was 10,426 tons, equivalent to $35 \%$ of total requirement. Seed production was carried out in both government seed farms, smallholder farms and private seed production companies contributing $1 \%, 2 \%$ and $32 \%$ of the total requirements respectively.

\section{Agricultural Equipment:}

- For the year 2002/03 achievement made include:

○ 274 big tractors, 75 power tillers, 19,319 oxen-ploughs and 2,107,550 hand hoes were imported.

- 83 hand small tractors were distributed to farmers. 
○ Oxenization centers were rehabilitated in 16 regions and about 520 extension staff and 8,717 farmers were trained on this aspect.

\section{Crop pests:}

- It is estimated $30 \%$ of crops in the country is lost annually due to pests and disease outbreaks.

- The Ministry in collaboration with district councils, farmers and other institutions managed to fight pests and disease outbreak as the outbreak occurred. Outbreaks experienced include: quelea quelea and parrots, locusts, army warms, rodents and various plant diseases. The outbreaks were contained in 19 out of 21 regions in Tanzania Mainland. The ministry also in collaboration with other stakeholders saved $90 \%$ of crops and grasslands invaded by armyworms.

\section{Inputs credit:}

- The Inputs Trust Fund started to issue fresh loans for importers and input distributors through banking arrangement system in collaboration with district councils.

- Input Trust Fund signed contracts with Exim Bank and Kilimanjaro Cooperative Bank through which loan amounting to Tshs 2.05 billion have been issued for various agricultural inputs.

\section{Livestock Sub sector}

Achievements made in this area include:

\section{Animal Health Services:}

- A total of 39 zoo sanitary checkpoints were equipped to implement its activities and a total of 399 zoo sanitary inspectors were trained

- National Artificial Insemination Center (NAIC) was strengthened and a total of 41,250 doses of semen were produced which is a 9\% increase compared to 38,560 doses of 2001/02.

- Newcastle disease thermo-stable vaccines continue to be produced and distributed. A total of 6.2 million chickens were vaccinated in 145 villages.

- 6 Veterinary Investigation Centers (VICs) continue with the disease investigations and surveillance, out of these 4 VICs Mpwapwa, Mtwara, Tabora and Arusha were rehabilitated and equipped with laboratory equipments.

- A total of 60,000 doses of rabies vaccines were procured and distributed to 30 districts, which reported rabies. Also, a total of 3,000 leaflets on rabies and 15,000 leaflets on modern livestock 
keeping, pasture and range management, poultry, beef production and control of diseases were produced and distributed.

- The production and testing of the I-2 Newcastle vaccine continued. More than 13 million doses were produced and most of it sold. The vaccine was distributed all over the country. The thermo stability of the vaccine under different storage conditions was tested and the results suggested that the vaccine can be kept under room temperature for about 1 month, 6 months in the refrigerator and for some years when frozen.

\section{Dairy production services}

- 4,494 in-calf heifers were produced and distributed to smallholder livestock keepers, 3,880 were distributed by NGOs and 614 were obtained from Government Livestock Multiplication Farms.

- Introduction of Mpwapwa cattle breed at the smallholder farms resulted into increased milk production in the central zone ranging from $4-6$ liters/day with average production of 5 lts/day. This excludes the amount sucked by the calves. An increase of about 4 extra liters is an achievement compared to the local breeds that are producing hardly a liter per day.

\section{Cooperative and Marketing Sub-sector}

Achievements made in this area include:

\section{Cooperative development:}

- Interested groups of people were sensitized to form Cooperative Societies in regions comprising of disadvantaged group such as women, youth and people with disabilities: 150 Cooperative Societies were formed in total.

- 123 SACCOS were registered whose memberships include farmers, fishermen, workers, women, youth, groups and small traders. Also 16 SACCOS in Mbeya, Dodoma, Morogoro and Dar es Salaam regions were monitored, evaluated and provided with management advisory services.

\section{Marketing development services:}

- The Ministry, in collaboration with PORALG, is coordinating two projects dealing with construction and rehabilitation of rural agricultural marketing infrastructure, Agricultural Marketing Service Development Project (AMSDP). These projects are: Morogoro and Kongwa Rural Agricultural Marketing Project funded by the French government which is expected to build a market center at Kibaigwa in 2003 and Agricultural Marketing System Development Program funded by ADF/IFAD. This program is implemented in 36 districts of Rukwa, Mbeya, Ruvuma, Iringa, Tanga, Kilimanjaro 
and Manyara. In collaboration with other stakeholders, the Ministry is preparing the Agricultural Marketing Policy.

\section{Lessons and Challenges}

- Low use of agricultural inputs (such as improved seeds, farm machinery, agro-chemicals, fertilizers) resulting into low production and productivity.

- Unreliable crop and livestock marketing caused by poor marketing infrastructure - acting as disincentive to producers.

- Dependence on rain-fed agriculture and low use of technology by smallholder farmers and livestock keepers leading into unreliable food production to satisfy both domestic demand and foreign market.

- Inadequate extension services (technology dissemination) causing low adoption of agriculture technologies by farmers.

- Low crop product quality resulting into low prices and market uncertainty.

- Inadequate capacity in managing agricultural projects and programs at district level.

- Low level of investment from both public and private sector leading into low growth rate in the sector.

\section{Costing of interventions}

Table 15: Summary of costing of sector programs 2003/04 - 2005/06 (Tshs. 'Millions)

\begin{tabular}{|c|c|c|c|}
\hline Priority Area for PRS & $\begin{array}{l}\text { 2003/04 } \\
\text { Budget }\end{array}$ & $\begin{array}{l}2004 / 05 \\
\text { Projections }\end{array}$ & $\begin{array}{l}\text { 2005/06 } \\
\text { Projections }\end{array}$ \\
\hline \multicolumn{4}{|l|}{ Crop sub sector } \\
\hline Strengthening Agriculture Extension Services & 541.5 & 920.5 & $1,196.7$ \\
\hline Promote Client-oriented Agricultural Research & 588.3 & $1,029.5$ & $1,801.6$ \\
\hline Irrigation Development & $2,663.3$ & $3,062.8$ & $3,522.2$ \\
\hline Control crop pests and diseases outbreak & 908.9 & $1,045.3$ & $1,202.1$ \\
\hline Agriculture Mechanization and land use & 782.5 & 899.9 & $1,034.9$ \\
\hline Strengthening Agriculture Input Trust Fund ( AGTIF) & $3,600.0$ & $4,680.0$ & $6,084.0$ \\
\hline Strengthening strategic Grain Reserve (SGR) & $3,026.5$ & $3,480.4$ & $4,002.5$ \\
\hline Support to Post harvest and Agro processing & 553 & 635.9 & 731.3 \\
\hline Strengthen Sub sector Policy, Regulatory and Institutional Capacity & $1,093.7$ & $1,257.8$ & $1,446.4$ \\
\hline Support to Internal and External Subventions & $3,121.8$ & $5,904.7$ & $7,263.9$ \\
\hline Sub-total Recurrent & $16,292.0$ & $21,240.4$ & $26,425.7$ \\
\hline \multicolumn{4}{|l|}{ Development expenditure } \\
\hline Constructions of irrigation structures & 520.0 & 600.0 & $1,000.0$ \\
\hline Research and Agriculture extension and training center rehabilitation & $1,690.0$ & $1,710.0$ & $2,000.0$ \\
\hline District Agricultural Development Program & $4,000.0$ & $7,000.0$ & $13,000.0$ \\
\hline Total Development & $6,210.0$ & $9,310.0$ & $16,000.0$ \\
\hline \multicolumn{4}{|l|}{ Livestock-Sub-sector } \\
\hline $\begin{array}{l}\text { Develop and introduce livestock of high genetic potential as well as } \\
\text { formulation of feasible feeding packages in beef and milk production } \\
\text { (from } 1600 \text { lts to 2000lts of milk yield/lactation and from } 100 \mathrm{~kg} \text { to } \\
250 \mathrm{kgs}\end{array}$ & 290.8 & 392.5 & 529.9 \\
\hline Strengthen Veterinary Investigation Centers (VICS) to carry out effective & & 305.6 & 412.6 \\
\hline
\end{tabular}




\begin{tabular}{|c|c|c|c|}
\hline $\begin{array}{l}\text { disease surveillance and early warning system, analyze, process animal } \\
\text { disease data. }\end{array}$ & 226.4 & & \\
\hline $\begin{array}{l}\text { Strengthen livestock production, input and regulatory services in order } \\
\text { to achieve quality assurance }\end{array}$ & 70.0 & 94.5 & 127.5 \\
\hline $\begin{array}{l}\text { Facilitate LMU in production of 1,000 heifers pending privatizations } \\
\text { aiming to increase the productivity }\end{array}$ & 170.9 & 230.7 & 311.4 \\
\hline $\begin{array}{l}\text { Strengthen rangeland management development in } 50 \text { local authorities } \\
\text { and provide water for livestock in drought prone regions. }\end{array}$ & 592.3 & 799.6 & $1,079.4$ \\
\hline $\begin{array}{l}\text { Develop and strengthen the existing extension packages to be delivered } \\
\text { to the Districts aiming to improve small holder's performance on animal } \\
\text { production, diseases, control, management, book keeping and husbands }\end{array}$ & 197.1 & 266.0 & 359.2 \\
\hline $\begin{array}{l}\text { To control and eradicate other zoonoses in particular tuberculosis and } \\
\text { other brucelosis. }\end{array}$ & 154.2 & 208.1 & 281.0 \\
\hline $\begin{array}{l}\text { Improve livestock, products, markets and other infrastructures to } \\
\text { increase the off-take rates of livestock. }\end{array}$ & 123.6 & 166.8 & 225.2 \\
\hline $\begin{array}{l}\text { Control and arrest the spread of trans boundary diseases such as } \\
\text { Contagious Bovine Pleuroneumonia (CBPP), African Swine Fever } \\
(A S F), \text { New castle disease (ND) etc in the country. }\end{array}$ & 427.7 & 577.3 & 779.4 \\
\hline $\begin{array}{l}\text { Strengthen and formulating ticks and tick-board disease control (dip } \\
\text { rehabilitation/constructions) and raise community awareness of tsetse } \\
\text { and tyrpanosomiasis control techniques }\end{array}$ & 89.2 & 120.4 & 162.5 \\
\hline Cooperative and Marketing Sub-sector & & & \\
\hline Establishment and strengthening of SACCOS & 7.0 & 10.3 & 13.9 \\
\hline Members Empowerment Program & 110.0 & 148.5 & 200.4 \\
\hline $\begin{array}{l}\text { Capacity building Cooperative Society through Export Credit Guarantee } \\
\text { Scheme (ECGS) }\end{array}$ & 9.4 & 12.7 & 17.1 \\
\hline Inspection and Supervision Districts & 112.7 & 152.1 & 205.4 \\
\hline Special Investigation and Enquiries & 12.9 & 17.5 & 23.6 \\
\hline Promotion and Establishment of Cooperative Banks & 61.6 & 83.1 & 112.2 \\
\hline $\begin{array}{l}\text { Review of } 1991 \text { Cooperative Act (Code of Conduct for Cooperative } \\
\text { Management }\end{array}$ & 9.0 & 121.5 & 164.0 \\
\hline $\begin{array}{l}\text { Formulation and operationalization of enabling Agricultural Marketing } \\
\text { Policy by year 2004; }\end{array}$ & 25.1 & 33.8 & 45.7 \\
\hline Monitoring and evaluation of Marketing projects (AMSDP) & 14.8 & 20.1 & 27.1 \\
\hline Establishment of marketing development center by June, 2004 & 7.7 & 10.5 & 14.1 \\
\hline $\begin{array}{l}\text { To expand and promote market potentials of non traditional crops (e.g. } \\
\text { cassava and millet) }\end{array}$ & 20.5 & 27.7 & 37.4 \\
\hline Total - Sector & $25,822.40$ & $36,026.10$ & $49,414.60$ \\
\hline
\end{tabular}




\section{CROSSCUTTING ISSUES}

\subsection{HIV/AIDS}

\section{Overview}

In an effort to intensify the fight against the HIV/AIDS pandemic, the institutional framework for the national response has been transformed from National AIDS Control Program (NACP) under the Ministry of Health $(\mathrm{MoH})$ to the centrally placed Tanzania Commission for AIDS (TACAIDS) under the Prime Minister's Office. This transformation is meant to provide strategic leadership and multi-sectoral coordination, advocacy, resource mobilization, monitoring and evaluation of the national response. The commission has strong representation from the civil society. It has a fully staffed Secretariat since January 2003.

\section{The Multi-Sectoral Strategic Framework (NMSF) on HIV/AIDS}

The Prime Minister officially launched the Multi-sectoral Strategic Framework (NMSF) on HIV/AIDS on 10 May 2003. The framework translates the National Policy on HIV/AIDS by providing strategic guidance to the planning of programs, projects and interventions by various stakeholders in the fight against HIV/AIDS. It identifies goals, objectives and strategies in line with international commitments by the Government of Tanzania as incorporated in the Millennium Development Goals (2000) and the Declaration of Commitment of the United Nations General Assembly Special Session on HIV/AIDS (UNGASS) of June 2001. The framework also attempts to address the national aspirations with respect to the Vision 2025, poverty eradication as outlined in the Poverty Reduction Strategy.

\section{National Response}

Although there are encouraging signs of increasing awareness and interventions from different parts of the country by various public and private institutions and civil society organizations, more serious and targeted interventions are necessary to have an impact on slowing down the rate of new infections and protect the $85-90 \%$ of HIV free people in the community. Emphasis in the national response is therefore directed towards increasing individual and community awareness on the risk of HIV infection of the individual and families and its serious implications on the individual, the family and community. Attention to HIV/AIDS in the workplace would also be an entry point to upscale national efforts. Measures being taken include the following:

- Government Ministries, Departments and Agencies are developing plans for mainstreaming HIV/AIDS intervention into routine activities including workplace interventions and integrating HIV/AIDS control activities in the ministry's MTEF. Many private enterprises have workplace 
HIV/AIDS interventions including provision of anti retroviral treatment. There is much potential for more involvement of the private sector in the national response to the epidemic.

- In order to ensure that communities at the grassroots level have sustained HIV/AIDS interventions, local government authorities are being supported in developing comprehensive HIV/AIDS programs that involve all stakeholders. Regional Facilitating Agencies (RFAs) will provide technical assistance to local government authorities and civil society organizations to empower communities in rural and urban areas in responding to the epidemic. Guidelines for the establishment of District AIDS Committees have been disseminated to all local government authorities aimed at facilitating more community mobilization and involvement in the fight against HIV/AIDS. Modules for training members of the District AIDS Committees and technical functionaries have been developed and training was expected to start in November 2003.

- Efforts to mainstreaming HIV/AIDS in the planning/budgeting process in the public sector have been initiated. This is aimed at ensuring regular budgetary allocations for the sectors HIV/AIDS activities. Codes for tracking HIV/AIDS related activities have been developed and will be applied in the fiscal year 2004/05. Medium Term Expenditure Review (MTEF) for 2003/04 - 2005/06 for TACAIDS has been developed and TACAIDS now operates own vote.

- National monitoring and evaluation framework for the national response has been developed and core team of trainers has been trained. A protocol for Tanzania HIV Indicator Survey (THIS) has been developed and will be carried out in November 2003. This study will provide information on HIV prevalence in the community.

- The process of developing National Advocacy Strategy is ongoing. A draft outline has been developed. An advocacy forum for religious leaders from all Christian and Muslim denominations was held in March 2002. The leaders unanimously agreed to use their strategic leadership in the communities to further promote awareness, care and support and impact mitigation in the fight against the epidemic in line with their religious ethics.

\section{Partnership}

The national response initiative enjoys good partnership with Development Partners, civil society organizations, the private sector and faith-based organizations. In recognition of the existing partnership and transparency in the national response initiatives, Development Partners and Government signed a Memorandum of Understanding (MoU) to reaffirm their joint commitment and support to the National Multisectoral Strategic Framework on HIV/AIDS. The main thrust of the MoU is to enhance and harmonize partnership between the GOT and Development Partners in the implementation of the national 
multi-sectoral strategic framework on HIV/AIDS through a common program of work for planning, management, resource mobilization and allocation and monitoring and evaluation. The Global Fund Country Coordinating Mechanism (GFCCM) that brings together some 28 members from all sectors is a good example of multi-sectoral coordination. Consultations are ongoing to expand the mandate of this forum to other global and international multi-sectoral programs.

The Global Fund Grant Agreement for scaling up effective district response focusing on communities, primary schools and the informal sector in Tanzania was signed on 3 July 2003, for USD 5.4 million for one year. The World Bank funded TMAP agreement was signed on 27 August 2003 for providing USD 65 million and USD 5 million for Tanzania Mainland and Zanzibar respectively for the next five years. Rapid Funding Envelope that has mobilized over USD 2.5 million from willing partners to finance short term quick impact projects by civil society organizations and institutions is one of the innovative approaches in the national response.

Collaboration with civil society organizations in the national response is being strengthened. A network of AIDS service organizations has been formed (TANASO). Also, people living with HIV/AIDS (PLHAs) are in the process of forming their Council to cater for the welfare of all PLHAs regardless of their organizations.

\section{Care and Treatment for people living with HIV/AIDS}

Government and the Clinton Foundation have formulated a draft Care and Treatment Program that aims at providing care and treatment to about 400,000 people living with HIV/AIDs in five years at an estimated cost of about US\$535 million. The policy, financial and human resources implications are being addressed. To ensure sustainability and continuity, the program will be integrated into the existing systems. A second five-year program will be developed in the course of implementation of the program.

\subsection{Gender}

\section{Overview}

In 2002/03 Government, together with other stakeholders, continued to mainstream gender within the Poverty Reduction Strategy (PRS) particularly the MTEF/PER processes, and within the sectors so as to address the gender specific issues and constraints related to poverty reduction. Government continues to address the gender disparities in employment and income between women and men and conditions that will reduce child labor.

The focal ministries in this process were the Vice-President's Office, Poverty Eradication Division; the MCDGC and the Ministry of Finance. The responsibility of gender mainstreaming within the line ministries was left with the concerned sectors. A number of CSOs were involved in these efforts. The 
MCDGC, with its special responsibility for promoting gender equity, prepared a 3-year master plan with the overall objective of formulating a Gender Policy (2000). This plan and the ongoing PRS review will integrate CSOs' efforts and their participation in PRS implementation and monitoring. The Ministry has also initiated a detailed computerized gender disaggregated monitoring system that will supplement NBS database and will enable the ministry to report fully on CEDAW, the Beijing Platform of Action and the MDGs.

In 2002 the GOT published the results of two key surveys: the Household Budget Survey (HBS) and the Integrated Labor Force Survey (ILFS) that included a special survey of children. Data from these surveys show that gender disparities still persist. These findings have increased the recognition of the need to mainstream gender in the PRS Monitoring System. Recent analyses such as the Poverty and Human Development Reports for 2002, 2003 have paid considerable attention to the gender specific aspects of the performance of all priority sectors. For further understanding of gender disparities within PRS monitoring further detailed studies were conducted on African Gender Development Indicators (AGDI) and the Female Headed Households (FHHs).

\section{Progress and achievements}

For 2002/2003, specific activities were planned in the context of the PRS and the following progress was made towards achieving them.

\section{Gender focal points}

- To institutionalize gender in central and local government PRS priority sectors, gender focal points were appointed. A plan for providing such persons with the appropriate training and tools to carry out gender mainstreaming was developed and will be discussed by the relevant stakeholders.

\section{Reform of Laws that are Discriminatory towards Women}

- The reform of laws that are discriminatory towards women is ongoing within the Law Reform Commission. In order to strengthen the implementation of the Law against Sexual Offences and Physical Abuse (SOSPA), the MCDGC organized a workshop to discuss a National Plan of Action for Combating Violence against Women. Meanwhile, NGOs have been working on creating awareness about other discriminatory laws such as the Inheritance Law and the Land Law. The Legal Reform Commission is working on the findings.

\section{Capacity Building}

As part of its attempts to promote gender within the sectors, the MCDGC held a Workshop for Permanent Secretaries and Regional Administrative Secretaries in early 2003 on the need for mainstreaming gender within the sectors and the LGA's. It also supported the training of gender trainers for Tengeru College to 
enhance the mainstreaming of gender in the curriculum of this college that trains community development officers. In order to develop an appropriate tools and training package for mainstreaming gender in the public finance management modules, a study on gender budgeting status in Tanzania was undertaken.

\section{Women's Empowerment}

- In order to enable women to disseminate information about their products and to link them up with prospective markets within and outside Tanzania, MCDGC in collaboration with NGOs supported women entrepreneurs to participate in the Dar es Salaam International Trade Fair and other trade displays. A survey is needed to see the effectiveness of such efforts.

- The MCDGC has completed a study on the feasibility to set up a "Business Incubator" for women entrepreneurs. A business incubator is a facility established to help entrepreneurs to launch or to expand business, which in turn creates value and jobs. An effort will be made to find ways of integrating this initiative in the PRS framework.

- Women workers engaged in hazardous and low paying jobs have been assisted to form women economic groups and have their capacities enhanced in organizational skills, job skills, business management and marketing skills, savings and credit. 731 women workers have been organized into 14 economic groups to mobilize group saving. Jobs skills including mushroom farming, poultry keeping, food processing and handcraft have been given to women. 1,026 child laborers have been withdrawn from child labor. They were provided with alternatives for primary education and vocational training.

\section{Lessons learned/Challenges}

- There is a mistaken assumption that gender mainstreaming and monitoring is solely the responsibility of the MCDGC. The MCDGC cannot do it alone; all sectors and programs at all levels need to give gender a center stage. This is particularly necessary at the local government level where implementation of most activities related to PRS takes place.

- The importance of gender mainstreaming is beginning to be accepted but still not fully understood as a development issue. There is need to have more gender disaggregated data and analysis to show the role of men and women in household food security, incomes, and the provision of the other needs for social reproduction to fully appreciate the role of gender in development.

- Cultural beliefs about the role of men and women in society still persist in-spite of several workshops, sensitization programs, and media coverage of gender specific constraints by females at all ages. 
- There is as yet no systematic modality to obtain information about the activities carried out by sectors, NGO's and CBO's to mainstream gender. Some very significant activities are thus not reported in the PRS Progress Reports. This will be taken care of during the PRS review process.

\subsection{Governance}

\section{Progress and Achievement}

During the financial year 2002/2003 Government continued with its efforts to promote good governance in the public service delivery by implementing a number of macro-economic reform Programs aiming at improving financial management and accountability, strengthening of the judicial system, reduction of poverty and reduction of corruption. Specific undertakings during the year include:-

- Specialized government agencies e.g. the Ethics Secretariat, the Commission of Human Rights and Good Governance and the Prevention of Corruption Bureau (PCB), have continued to report quarterly on matters brought to their attention.

- The PCB conducted four researches on strategic sectors, which are proven to have high degree of corrupt incidences. The researches involved are:

- Corrupt practices in the importation of veterinary drugs

- Corruption in local government's income and expenditure

- Detailed study on the operations of the National Housing Corporation, and

- Corruption loopholes in the fish industry in the Lake Zone.

- The PCB has been strengthened by increasing its budget and by decentralizing from zones to regional and district offices. In the financial year 2002/2003, the Bureau opened 38 offices in districts.

- The commission for Human Rights and Good Governance conducted meetings with government Ministries and Leaders to enlighten them on the workings of the commission. It has also met the Civil Society Organizations that are engaged in the promotion of human rights.

- The Labor Law Reform Task Force which comprised of representatives from the government, employers, workers, civil society, academia and the private sector, finished phase one of its work and presented to the government its report with two proposed Bills: on Employment and Labor Relations; and Labor Institutions. These Bills seek to:-

- Promote employment and labor standards in line with present socio-economic realities and in compliance with Tanzania's obligation under international law. 
- Create new institutions in the labor sector to promote social dialogue by involving all the important actors: the government, workers' and employers' organizations; create new institutions and labor relations to promote social dialogue that would in turn pave way for industrial peace needed to accelerate economic growth, employment, and poverty eradication

- Operational procedures particularly the financial guidelines to the Local Authorities are now in place.

- The Mass Media have been given a crucial role in Anti-Corruption Strategy. PCB in conjunction with Transparency International, Tanzania chapter and Development Partners carried out seminars on the role of vibrant media in exposing corruption. Courses of an investigative journalism were provided to improve the performance of journalists.

- A workshop for all Members of Parliament was conducted. The workshop looked at the state of corruption in the country.

- Government continues with the exercise of improving salaries of public servants, i.e., pay increases were implemented for the year under the Public Service Reform Program.

- The National Anti-Corruption Strategy and Action Plans of MDAs have been revised and printed.

- Efforts are underway to promote participatory democracy and planning in which people plan their own development through participatory rural appraised and decision making through the Tanzania Social Action Fund (TASAF). Through the Fund 54 community service and infrastructure projects have been completed in overt 30 districts of 13 regions in Tanzania mainland and Zanzibar. 690 projects are still under implementation.

- The government has established the National Integrity Fund (NIF) to support the implementation of Anti-Corruption activities and plans developed by MDAs. Tshs 800 million was apportioned for this purpose in the financial year 2002/2003.

\subsection{Local Government Reform Program Overview}

The GOT and some of its partners developed a Local Government Reform Agenda 1996 - 2000, which was endorsed by the then Steering Committee for the CSRP. To operationalize the policy and strategy decisions, the Local Government Reform Program (LGRP) was designed and the Action Plan and Budget were prepared for July 1999-June 2004. 
The program implementation began on $1^{\text {st }}$ January 2000 in 38 Phase I Councils. Government and donors formally reviewed implementation experience jointly in June 2001. The review team fully endorsed the policies and strategies of the program and recognized the progress to date. Government, Development Partners and key stakeholders endorsed the review of the reform. It became the starting point for the participatory planning process and culminated in the production of the Medium Term Plan (MTP) and Budget - July 2002 to June 2005. This is the current framework document of the LGRP and the Annual Work Program and budgets are derived from it. Government and Development Partners are financing the program jointly.

\section{Planned Priority Interventions for 2002/03}

Implementation experience has shown that the original overall plan, the Action Plan and Budget (APB) 1999 - 2004, was over ambitious and had unrealistic time horizon. The PSRP shows a series of broad reform phases to 2011 and local government reform should also be seen in this 9-year time frame:

\section{Mid-Term Plan 2002/05}

The concept of phasing of the reforms in LGAs has been fundamentally changed in the current plan. The Government's Policy Paper outlines a phasing strategy, but allows for alteration and different phasing strategies based on experience and changing circumstances. The original APB, 1999- 2004, envisaged the program having three overlapping phases catering for roughly one third of LGAs in each phase across the whole range of reform activities. This plan envisages a different type of phasing, with all LGAs free to implement reforms and central support being provided on a demand basis. In terms of fiscal decentralization, only those LGAs that will meet agreed criteria will qualify in the first instance. However, all LGAs will be assisted to meet the criteria and many reform activities. The activities during the 2002 - 2005 MTP will dwell mainly on development, legal harmonization with sector ministries, and harmonization of Public Act No.8 of 2002 with Staff Regulations 2000, capacity building, and reform coordination with sector reforms.

\section{Progress and Achievements}

The following are some major achievements recorded through the reform process:

- There is a clear policy statement on reform supported by the highest levels of government;

- Legislation to enable the reforms has been enacted;

- Regulations and guidelines to support the reforms have been issues;

- Information on the reforms has been disseminated to all local authorities and to the public; 
- Regional Administration has been restructured in line with its new role;

- 38 LGAs are at an advanced stage in the process of restructuring their organizations;

- Work on improving financial management in LGAs and on fiscal decentralization is underway;

- The work of building capacity in LGAs is underway; and

- Attitude towards reform is slowly changing among government officials and members of the public.

\section{Lessons Learned and Challenges}

Implementation of the reforms to-date has been slow by the benchmarks of the original plans. It is now clear that early expectations were unrealistically high. It is now recognized that the process of reforming the local government system is a major undertaking, which involves changing not just the way central and local governments carry out their business, but also fundamentally changing mind-sets at all levels of government and the public at large. In addition, the following factors, among others, have hindered implementation of the reforms.

- Resistance to change at central and local government levels;

- Lack of implementation capacity at PO-RALG and at LGA levels;

- Weak financial management at LGA level; and

- The sheer magnitude of the task

\section{Costing of Interventions}

Table 16: Costing of Mid-Term Plan of the LGRP

\begin{tabular}{|l|r|r|r|r|}
\hline \multicolumn{1}{|c|}{ Cost Item } & $\begin{array}{c}\mathbf{2 0 0 2 / 0 3} \text { Budget in } \\
\text { Tshs.(000) }\end{array}$ & $\begin{array}{c}\text { 2003/04 Budget } \\
\text { in Tshs.(000) }\end{array}$ & $\begin{array}{c}\text { 2004/05 Budget in } \\
\text { Tshs.(000) }\end{array}$ & $\begin{array}{c}\text { Total in Tshs. } \\
\text { (000) }\end{array}$ \\
\hline Governance & 603,628 & 576,000 & 420,000 & $1,599,629$ \\
\hline Restructuring & $1,708,661$ & $1,565,000$ & $1,315,000$ & $4,588,661$ \\
\hline Finance & $1,614,565$ & $2,160,000$ & $1,390,000$ & $5,164,565$ \\
\hline HRD \& MGT* & $3,676,245$ & $2,365,000$ & $2,140,000$ & $8,181.070$ \\
\hline Legal & 682,435 & 350,000 & 580,000 & $1,612,435$ \\
\hline PO-RALG & 442,764 & 805,000 & 485,000 & $1,732,764$ \\
\hline Reform coordination & 213,999 & 160,000 & 80,000 & 453,999 \\
\hline Program Management & $3,512,285$ & $3,728,000$ & $4,123,000$ & $11,363,285$ \\
\hline Grand Total & $\mathbf{1 2 , 4 5 4 , 5 8 2}$ & $\mathbf{1 1 , 7 0 9 , 0 0 0}$ & $\mathbf{1 0 , 5 3 3 , 0 0 0}$ & $\mathbf{3 4 , 6 9 6 , 5 8 2}$ \\
\hline
\end{tabular}




\subsection{Human Capital Development}

Human capital development is critical for the success of the PRS. The government reports progress on the development of human capital under PRS's crosscutting issues. Focus will continue to be on strengthening leadership and management qualities, meritocracy, and restoration of ethical conduct, gender equality and pay reform. In this context the new Public Service Act No. 8 of 2002 that gives legal backing to the modernization of the public service has been enacted. Performance management systems have been established in 16 ministries and departments so far and will be established in others to ensure that they set service delivery targets against which the public servants will measure their performance.

Several measures were taken to implement the Medium Term Pay Policy including annual enhancement of salaries of public servants and the implementation of job evaluation. Training and capacity building programs to enhance leadership and modern management capabilities in the public service are ongoing. Notable achievements in gender mainstreaming in the public service are reflected in a sizeable increase in the number of women at senior levels, $24 \%$ for Permanent Secretaries, $26 \%$ for Directors and $24 \%$ for Assistant Directors. There has also been establishment of 19 executive agencies as part of Government efforts to improve service delivery for selected functions that are operational in nature. These are ongoing activities that will be continued and tracked under the Public Service Reform Program for the Central Government and the Local Government Reform Program.

The public service and local government reform programs have developed through a consultative process; so also were indicators to monitor progress on capacity building for the central and local government. Progress and achievements in developing and strengthening human capital will then be assessed through use of these indicators and reported in the PRS monitoring framework.

Government recognizes that children and young people are key to sustained future workforce. Specific sectors contribute to improving conditions for children and young people, notably in education and health. Critical cross-sectoral concerns, including the fight against HIV/AIDs, require close attention especially as they relate to children and young people. Government will thus continue its efforts to identify and address specific problems affecting children and young people and particularly facilitate access to skills and vocational training programs.

\subsection{Environment}

\section{Overview}

Tanzania's natural resources and environment are the main source of peoples' livelihoods and the backbone of the country's main productive sectors: agriculture, tourism and mining. Recent research by the Participatory Poverty Assessment has confirmed that most people in the country directly depend on a 
robust, healthy environment to support their income-generating activities and provide them with building and cooking materials, food and medicine. Environment is thus critically linked to poverty at the levels of livelihood, health and vulnerability, and has been identified as a priority cross cutting issue for the PRS.

\section{Progress and Achievements}

Considerable progress has been achieved over the past year to mainstream environment into the PRS process.

A number of steps were highlighted in the last PRS progress report. Progress has been made on all of these and in addition there have been other significant achievements. These include:

- Strengthening institutional framework for environmental management - The Cabinet approved a new institutional framework for environmental management in December 2002.

- Environment framework law - Following approval of the institutional set up the VPO have led on the development of a single environmental framework law with a first draft prepared for consultation in December 2003.

- Launch of Program to Integrate Environment into the PRS process. This program was formally launched on $26^{\text {th }}$ September 2003 and is supported by UNDP, Dry lands Development Center, Poverty Environment Initiative, DANIDA and DFID. This program will be implemented by VPO (PED, DOE), NEMC, NBS and PORALG commencing in the third quarter 2003. Outputs focus on: knowledge on poverty-environment linkages; use of environment data in poverty monitoring system; and, capacity building of government and non-government stakeholders.

- Environment Working Group - a cross-sectoral environment-working group (EWG) has been established. The goal of the EWG is to promote the integration of the environment into the GoT policies, plans to help ensure the sustainable use of Tanzania's environment and natural resources for poverty reduction.

- PER Environment - the first public expenditure review (PER) of the environment has been initiated. This is expected to produce inputs into the medium term expenditure framework (MTEF), and guidelines for sectors to mainstream environment expenditure into their sectoral PERs.

- Utilization of poverty-environment data for use in PRS process - Preliminary poverty-environment indicators were included in the revised indicator list for the poverty monitoring system for use by PRBS/PRSC. Terms of reference of a detailed study on poverty-environment indicators were developed and identification of consultants to undertake study is now underway. This study will also work on improving agricultural indicators for the PMS. 
- Improved knowledge and awareness on poverty - environment linkages - Activities on this have been developed for implementation under the program to integrate environment into PRS process. In addition to this presentations have been given to a number of workshops and meetings attended by government and non-government stakeholders. VPO are now producing a bimonthly newsletter on poverty environment issues, copies of this newsletter will be placed on the VPO website when this is established.

- Integration of environmental management in the sectoral programs. Approval of environment units for sectors, and development of strategic environment assessment (see below).

- Agricultural survey - VPO with NBS worked on the design and questionnaire of the agricultural survey to ensure it included relevant questions on environment sustainability and livelihood issues.

- Sustainable development network - The former environmental champions and think tank have proposed to establish a sustainable development network to give advice on poverty and environment issues. Members of this group have continued to make inputs into the PMS thematic working groups.

- Strategic environment assessment - Study completed on the use of strategic environment assessment and poverty reduction.

- PRSC - Environment sustainability has been explicitly mentioned in the performance action framework for the Poverty Reduction Support Credit.

- Capacity building. Appointment of Poverty Environment Advisor to VPO, and recruitment of Poverty Environment Officer expected to commence work January 2004. Development of capacity building and training program for VPO and other stakeholders for implementation in 2004.

\section{Lessons and Challenges}

A number of lessons and challenges have emerged over the last year as the Government has taken the initiative on environment mainstreaming. These include:

- Mainstreaming environment into PRS has varying understandings and perceptions on the sectors this covers. There is a need to broaden this understanding to cover environment issues such as those related to agriculture, forestry, wildlife and fisheries etc. to include other areas such as environmental health, education, water, tourism, roads, energy and minerals.

- At present attention to crosscutting issues is largely undertaken on an issue-by-issue basis. There is a need for greater attention to how the different cross cutting issues are linked. For example, there are clear links between gender and environment, and also between HIV/AIDs and environment. 
- While engagement with different government sectors and civil society organizations has commenced on poverty and environment issues, involvement with local government and with the private sector still needs to be addressed.

- During the preparation of TOR for environment PER study it appeared that the work in Tanzania is leading the way with few other countries having undertaken such a PER study. Given that it covers a wide range of sectors and levels of government, this has presented a number of methodological challenges that will need to be addressed. 


\section{BUDGET FRAMEWORK FOR POVERTY REDUCTION PROGRAMS}

\subsection{Resource envelope: A macroeconomic perspective}

The budget framework for poverty reduction in the year 2002/03 was based on the assumption of continued sound and stable macroeconomic environment conducive to attaining high levels of domestic savings and investment. While it was targeted that real GDP would grow by $6.3 \%$ in 2003 , preliminary estimates based on the first half actual show that this is likely to stand at 5.5\%. Consistent with the objectives of the Medium Term Plan for Growth and Poverty Reduction for the period 2004/05-2006/07, the macroeconomic policy targets for the period are summarized as follows:

- Attain a real GDP growth of $6.3 \%$ in 2004 , thereafter up to $7 \%$ by 2006 .

- Continued reducing inflation rate to $4.0 \%$ by the end of 2004 . It is expected to level off at $4 \%$ during the 2004/05-2006/07, consistent with our major trading partners;

- Domestic revenue collection is expected to reach $13.3 \%$ of GDP in 2003/04;

- Restricting broad money supply (M2) to levels consistent with GDP growth and inflation rate targets.

- Maintain adequate official foreign reserves of not less than a value equivalent of six months of imports of goods and non-factor services.

- Maintain a freely floating exchange rate, limiting interventions exclusively to smoothening wide fluctuations and for liquidity management purposes.

Government continuing with tax restructuring in some areas so as to improve the entire tax structure and remove nuisance taxes to enhance economic efficiency and reduce the nuisance and burden to producers/tax payers. To expand the revenue base in the medium term Government committed itself to a number of measures:

(i) To review legislations on Export Processing Zones (EPZ) and Income Tax Legislation with a view to rationalizing them and to enhance the tax yield by closing loopholes.

(iii) Completing preparations and rationalizing tax and various fees of local government in order to create conducive environment for the people in their efforts to produce goods and services.

(iv) Review the remaining exemptions with a view of abolishing them in order to expand the tax base.

(v) To review the tax contribution of the high-growth sectors such as mining.

(vi) To improve administration of tax and non-tax revenue and public corporation dividends to check revenue leakages. 


\subsection{Budget frame consideration for financing of priority sectors}

Government expenditure continues to be guided by the priorities set out in the Poverty Reduction Strategy. Table 17 shows trends in actual spending.

Table 17: Central Government Expenditure, 1998/99-2003/04 (billion TShs)

\begin{tabular}{|c|c|c|c|c|c|c|}
\hline & $\begin{array}{l}98 / 99 \\
\text { Actual }\end{array}$ & $\begin{array}{l}99 / 00 \\
\text { Actual }\end{array}$ & $\begin{array}{l}\text { 00/01 } \\
\text { Actual }\end{array}$ & $\begin{array}{l}\mathbf{0 1 / 0 2} \\
\text { Actual }\end{array}$ & $\begin{array}{l}02 / 03 \\
\text { Actual }\end{array}$ & $\begin{array}{l}03 / 04 \\
\text { Proj. }\end{array}$ \\
\hline TOTAL EXPENDITURE (INCLUDING CFS) & 973.8 & $1,191$. & $1,258.50$ & $1,626.50$ & $2,091.10$ & $2,607.20$ \\
\hline TOTAL EXPENDITURE (EXCLUDING CFS) & 748.5 & 925.8 & 954.7 & $1,296.10$ & $\mathbf{1 , 7 8 7 . 4 0}$ & $2,198.60$ \\
\hline Total expenditure in priority sectors & 342.3 & 418.6 & 499.8 & 761.9 & 973.8 & $1,170.01$ \\
\hline Education & 164.9 & 218 & 254.9 & 344.9 & 436.2 & 502.3 \\
\hline Health & 72.5 & 81.2 & 100.7 & 142.1 & 186.7 & 214.3 \\
\hline Water & 14.4 & 14.5 & 18.3 & 32.5 & 51.9 & 64.4 \\
\hline Agriculture & 14.9 & 21.6 & 19.1 & 31.9 & 60.2 & 93.1 \\
\hline Lands & 3.4 & 4.2 & 5.1 & 8.1 & 20.1 & 6.0 \\
\hline Roads & 66.7 & 70.8 & 92.5 & 179.6 & 190.2 & 236.0 \\
\hline Judiciary & 5.5 & 8.3 & 9.2 & 18.8 & 23.2 & 32.7 \\
\hline TACAIDS/HIV AIDS $2 /$ & 0 & 0 & 0 & 4 & 5.3 & 21.2 \\
\hline Total expenditure in non-priority sectors & 406.1 & 507.2 & 455.0 & 534.2 & 813.7 & $1,028.5$ \\
\hline TOTAL RECURRENT EXPENDITURE (LESS & 565.9 & 565.9 & 668.5 & 951.4 & $1,286.50$ & $1,570.3$ \\
\hline Recurrent expenditure in priority sectors & 235.8 & 285.4 & 351.6 & 497.6 & 724.6 & 836.8 \\
\hline Education & 117.6 & 158.9 & 189.2 & 282.1 & 422.9 & 471.1 \\
\hline Health & 50.7 & 53.9 & 70.3 & 90.9 & 149.1 & 177.6 \\
\hline Water & 7.1 & 5.4 & 8.1 & 15.5 & 16.5 & 17.5 \\
\hline Agriculture & 8.6 & 13.7 & 10.3 & 17.2 & 36 & 47.7 \\
\hline Lands & 2.8 & 3.4 & 4.2 & 7.4 & 4.8 & 5.4 \\
\hline Roads & 43.9 & 42.2 & 60.7 & 65.7 & 71.9 & 84.5 \\
\hline Judiciary & 5.2 & 7.9 & 8.8 & 14.8 & 18.9 & 24.9 \\
\hline TACAIDS/HIV AIDS $2 /$ & 0 & 0 & 0 & 4 & 4.5 & 8.1 \\
\hline Recurrent expenditure in non-priority sectors & 330.1 & 280.5 & 316.8 & 453.8 & 561.9 & 733.5 \\
\hline TOTAL DEVELOPMENT EXPENDITURE & 182.6 & 359.9 & 286.2 & 344.6 & 500.9 & 628.3 \\
\hline Development expenditure in priority sectors & 106.5 & 133.2 & 147.9 & 264.3 & 249.1 & 333.2 \\
\hline Education & 47.3 & 59.1 & 65.7 & 62.8 & 13.3 & 31.3 \\
\hline Health & 21.9 & 27.3 & 30.4 & 51.2 & 37.6 & 36.6 \\
\hline Water & 7.3 & 9.1 & 10.1 & 17 & 35.4 & 46.9 \\
\hline Agriculture & 6.3 & 7.9 & 8.7 & 14.7 & 24.2 & 45.4 \\
\hline Lands & 0.7 & 0.8 & 0.9 & 0.7 & 15.3 & 0.6 \\
\hline Roads & 22.8 & 28.6 & 31.7 & 113.9 & 118.3 & 151.5 \\
\hline Judiciary & 0.3 & 0.4 & 0.4 & 4 & 4.2 & 7.8 \\
\hline TACAIDS/HIV AIDS 2/ & 0 & 0 & 0 & 0 & 0.8 & 13.2 \\
\hline Total expenditure in non-priority sectors & 76.1 & 226.7 & 138.3 & 80.4 & 251.8 & 295.0 \\
\hline CONSOLIDATED FUND SERVICE & 225.3 & 266.1 & 303.8 & 330.4 & 303.7 & 408.6 \\
\hline
\end{tabular}

1/ Original approved budget, with foreign development reallocations from energy to health and roads reflected

2/ Basket funds (education and health) are not reflected in development but in recurrent expenditure 3/ TACAIDS is a Government agency formed in 2001 to coordinate AIDS related priority interventions. For fiscal years 1998/99-2002/03, HIV/AIDS expenditure is shown as expenditure made by the TACAIDS Agency, while other HIV/AIDS expenditure was shown under the health sector. However, for fiscal year 2003/04, all HIV/AIDS expenditure is shown as expenditure made by TACAIDS, the Ministry of Health as well as other ministries, depts., regions and local Govts. Source: Ministry of Finance 
Despite the measures presented above, Government has not generated sufficient resources to cover the entire requirements. More measures are going to be taken in the medium term to enhance resource mobilization and allocation for all sectors including non-priority sectors. In the 2003/04 budget the Government put in place new measures to curb tax evasion, to reduce distortions and to eliminate nuisance taxes. The measures also aim at increasing voluntary tax compliance. Noteworthy are measures to reduce smuggling and tax evasion on petroleum products, entering religious NGOs into the Treasury Voucher system, removal of impediments in the fisheries sub-sector and smuggling of fish by reducing the withholding tax on sale of fish from $3 \%$ to $1 \%$. Nuisance taxes, mainly levies and fees at local government level were abolished to encourage development activities. In addition, the Government has adopted TRA's new corporate plan (2003/04-2007/08) which sets a program for strengthening revenue collection through improved efficiency of interface with taxpayers and overall governance so as to induce voluntary compliance. The corporate plan focuses on modernizing its organization and operations, and improving its effectiveness. In particular TRA will continue preparations for implementation of an integrated structure for domestic revenue administration during 2004/05. TRA is in the advanced stage of implementation of a functionbased Large Taxpayers Department (LTD) that integrates VAT and income tax administration and that is adequately resourced. In addition, there are plans for a complete transfer of an additional 100 large taxpayers to the LTD. An integrated computer system for administration of income tax and VAT will also be piloted in the LTD. TRA has also begun to integrate all district offices.

In the area of tax reform, the new Income Tax law was passed by Parliament in April2004. It is based on the principle of self-assessment and addresses a number of sources of revenue leakages, and will become effective from July 2004.

The combination of policy and administration measures is expected to lead to increased domestic revenues, both in absolute and relative to GDP terms. However, the projected resource envelope and expenditure requirements for 2003/04-2005/06 in Table 18(a) \& 18(b), reflect a declining share of domestic revenue in total from $53 \%$ in $2003 / 04$ to $48 \%$ in the $2004 / 05$ Budget. The shortfall will be met through support from development partners. 
Table 18(a): Budget Framework 2003/04-2006/07 (in million TShs)

\begin{tabular}{|l|r|r|r|r|}
\hline \multirow{2}{*}{ TOTAL RESOURCES } & $\begin{array}{r}2003 / 04 \\
\text { Budget }\end{array}$ & $\begin{array}{r}2004 / 05 \\
\text { Ceiling }\end{array}$ & $\begin{array}{r}2005 / 06 \\
\text { Projection }\end{array}$ & $\begin{array}{r}2006 / 07 \\
\text { Projection }\end{array}$ \\
\cline { 2 - 5 } & $\mathbf{2 , 6 0 7 , 2 0 5}$ & $\mathbf{3 , 3 2 8 , 2 3 7}$ & $\mathbf{3 , 3 4 4 , 3 7 2}$ & $\mathbf{3 , 3 0 8 , 5 4 6}$ \\
\hline Domestic revenue & $1,393,026$ & $1,588,392$ & $1,766,453$ & $1,988,546$ \\
\hline Programme loans and grants & 405,047 & 413,266 & 325,899 & 138,489 \\
\hline Project loans and grants & 472,772 & $1,010,648$ & 953,821 & 815,925 \\
\hline Basket support loans & 70,982 & 10,759 & 10,917 & 11,076 \\
\hline Basket support grants & 123,595 & 96,758 & 48,182 & 35,905 \\
\hline Recovery from NBC Bond & - & - & - & - \\
\hline HIPC relief (ADB, IMF, WB) & 103,425 & 83,100 & 85,100 & 85,100 \\
\hline Non-bank borrowing & - & 111,313 & 138,175 & 218,047 \\
\hline Bank borrowing & 21,358 & - & - & - \\
\hline Adjustment to cash & - & - & - & - \\
\hline Privatisation Funds & 17,000 & 14,000 & 14,000 & 14,000 \\
\hline TOTAL EXPENDITURE & $\mathbf{2 , 6 0 7 , 2 0 5}$ & $\mathbf{3 , 3 2 8 , 2 3 7}$ & $\mathbf{3 , 3 4 4 , 3 7 2}$ & $\mathbf{3 , 3 0 8 , 5 4 6}$ \\
\hline Recurrent Expenditure & $1,799,765$ & $2,081,981$ & $2,189,655$ & $2,287,963$ \\
\hline Consolidated Fund Service (CFS) & 408,600 & 395,574 & 381,934 & 371,162 \\
\hline \multicolumn{1}{|c|}{ Debt service } & 323,674 & 302,155 & 288,516 & 277,744 \\
\hline Amortization & 188,867 & 134,200 & 134,200 & 131,700 \\
\hline CFS others & 84,926 & 93,418 & 93,418 & 93,418 \\
\hline Recurrent excl CFS & $1,391,164$ & $1,686,408$ & $1,807,720$ & $1,916,800$ \\
\hline Salaries and wages & 464,061 & 551,159 & 628,205 & 727,077 \\
\hline Designated Items & 18,243 & 207,882 & 213,969 & 203,759 \\
\hline Other charges & 908,860 & 927,367 & 965,546 & 985,964 \\
\hline Payment of arrears & - & - & - & - \\
\hline Contingency & $\mathbf{8 0 7 , 4 4 0}$ & $\mathbf{1 , 2 4 6 , 2 5 6}$ & $\mathbf{1 , 1 5 4 , 7 1 7}$ & $\mathbf{1 , 0 2 0 , 5 8 3}$ \\
\hline DEVELOPMENT EXPENDITURE & 607,440 & $1,246,256$ & $1,154,717$ & $1,020,583$ \\
\hline Projects & 140,091 & 128,091 & 141,797 & 157,678 \\
\hline Local & & $1,118,165$ & $1,012,920$ & 862,905 \\
\hline Foreign & & & \\
\hline & & - & - & \\
\hline
\end{tabular}

Source: President's Office, Planning and Privatization and Ministry of Finance.

Table 18(b): Budget Framework 2003/04-2006/07 (in \% of GDP)

\begin{tabular}{|l|r|r|r|r|}
\hline \multirow{2}{*}{ TOTAL RESOURCES } & $\begin{array}{r}2003 / 04 \\
\text { Budget }\end{array}$ & $\begin{array}{r}2004 / 05 \\
\text { Ceiling }\end{array}$ & $\begin{array}{r}2005 / 06 \\
\text { Projection }\end{array}$ & $\begin{array}{r}2006 / 07 \\
\text { Projection }\end{array}$ \\
\cline { 2 - 5 } & $\mathbf{2 4 . 9 \%}$ & $\mathbf{2 8 . 7 \%}$ & $\mathbf{2 6 . 1 \%}$ & $\mathbf{2 3 . 2 \%}$ \\
\hline Domestic revenue & $13.2 \%$ & $13.7 \%$ & $13.8 \%$ & $14.0 \%$ \\
\hline Programme loans and grants & $3.9 \%$ & $3.6 \%$ & $2.5 \%$ & $1.0 \%$ \\
\hline Project loans and grants & $4.5 \%$ & $8.7 \%$ & $7.4 \%$ & $5.7 \%$ \\
\hline Health Basket Recurrent & $0.7 \%$ & & & \\
\hline Education Basket Recurrent & $1.2 \%$ & & & \\
\hline Recovery from NBC Bond & $0.0 \%$ & & & $0.6 \%$ \\
\hline HIPC relief (ADB, IMF, WB) & $1.0 \%$ & $0.7 \%$ & $0.7 \%$ & $0.02 \%$ \\
\hline Non-bank borrowing & $0.0 \%$ & $1.0 \%$ & $1.1 \%$ & \\
\hline Bank borrowing & $0.2 \%$ & & & \\
\hline
\end{tabular}




\begin{tabular}{|l|r|r|r|r|} 
Adjustment to cash & $0.0 \%$ & & & \\
\hline Privatisation Funds & $0.2 \%$ & $0.1 \%$ & $0.1 \%$ & $0.1 \%$ \\
\hline TOTAL EXPENDITURE & $\mathbf{2 4 . 9 \%}$ & $\mathbf{2 8 . 7 \%}$ & $\mathbf{2 6 . 1 \%}$ & $\mathbf{2 3 . 2 \%}$ \\
\hline Recurrent Expenditure & $17.2 \%$ & $18.0 \%$ & $17.1 \%$ & $16.0 \%$ \\
\hline Consolidated Fund Service (CFS) & $3.9 \%$ & $3.4 \%$ & $3.0 \%$ & $2.6 \%$ \\
\hline Debt service & $3.1 \%$ & $2.6 \%$ & $2.3 \%$ & $1.9 \%$ \\
\hline Amortization & $1.8 \%$ & $1.2 \%$ & $1.0 \%$ & $0.9 \%$ \\
\hline CFS others & $0.8 \%$ & $0.8 \%$ & $0.7 \%$ & $0.7 \%$ \\
\hline Recurrent excl CFS & $13.3 \%$ & $14.6 \%$ & $14.1 \%$ & $13.4 \%$ \\
\hline Salaries and wages & $4.4 \%$ & $4.8 \%$ & $4.9 \%$ & $5.1 \%$ \\
\hline Designated Items & $0.2 \%$ & $1.8 \%$ & $1.7 \%$ & $1.4 \%$ \\
\hline Other charges & $8.7 \%$ & $8.0 \%$ & $7.5 \%$ & $6.9 \%$ \\
\hline Payment of arrears & - & - & - & - \\
\hline Contingency & - & - & - & - \\
\hline DEVELOPMENT EXPENDITURE & $7.7 \%$ & $10.8 \%$ & $9.0 \%$ & $7.2 \%$ \\
\hline Projects & $7.7 \%$ & $10.8 \%$ & $9.0 \%$ & $7.2 \%$ \\
\hline Local & $1.3 \%$ & $1.1 \%$ & $1.1 \%$ & $1.1 \%$ \\
\hline Foreign & $6.4 \%$ & $9.7 \%$ & $7.9 \%$ & $6.1 \%$ \\
\hline
\end{tabular}

\subsection{Public Expenditure Management in the Medium Term}

In the medium term, Government will continue to strengthen management and discipline in Government expenditure in order to ensure sufficient accountability. The Government intends to amend the Public Procurement Act and the associated regulations to enhance accountability by separating the regulatory functions from the supervisory functions, and to strengthen capacity of the implementers. The Government has improved regulations of the Public Finance Act of 2001 and will continue to strengthen the application of the IFMS for preparation of the budget and to effect payments in order to increase efficiency and transparent in the allocation of funds. In the next financial year, the Government will roll out the IFMS to the Offices of the Regional Administrative Secretaries and the National Defence Forces. 


\section{POVERTY MONITORING AND EVALUATION}

This chapter reports for the first time the operationalisation of the Poverty Monitoring Master Plan. The report covers activities of four Technical Working Groups, namely, Census and Survey, Research and Analysis, Routine Data System, and Dissemination, Sensitization and Advocacy. The report highlights progress and achievements in implementing the PMMP during the period under review, drawing also on activities carried out during the previous year.

\subsection{Performance}

Among the major activities performed include: Preparation of the Second PRS Progress Report (2001/02), publishing of the Poverty and Human Development Report (PHDR 2002), dissemination of the Household Budget Survey (HBS2000/01) and Integrated Labor Force Survey (ILFS 2002/01). A Participatory Poverty Assessment (PPA) exercise was carried out throughout the country to gather views from the grassroots level on efforts and challenges encountered in the fight against poverty. The PPA focused on vulnerability. Dialogue between government, CSOs, external development partners and private sector was carried out through consultative meetings.

The dissemination, sensitization and advocacy strategy focused on poverty reduction policies and related issues, including findings from various studies and surveys. The major activities include: a simplified version of PRSP Progress Report (2000/01) in English and Swahili, which were published and widely disseminated to different stakeholders. To enhance understanding of the poverty monitoring master plan, a user guide was prepared and disseminated. Efforts are also underway to establish a Monitoring Website and Documentation Center within the Poverty Eradication Division. This will ease availability of information generated through the poverty monitoring system and other sources to enhance evidencebased decision making and implementation processes.

The Poverty Policy Week was held in September 2002 and October 2003 with the objective of sensitizing people and advocating for change. This provided opportunity for all key stakeholders to reflect on a number of issues including the contents of the PRS Progress Report and PHDR. The deliberations are documented in the Poverty Policy Week Proceedings for 2002 and 2003, and will enrich the policy review process and facilitate the design of more effective intervention measures so as to adequately address the problem of poverty in the country.

A number of workshops were organized and conducted by the Routine Data System Technical working group at national and zonal levels. The objectives of these workshops were to raise awareness among sector ministries, regional secretariats, NGOs, local authorities, academia and other stakeholders on the 
PMS and link it with the local Government Monitoring and Evaluation system. The workshops also provided an opportunity for exchange of experiences in the field of data collection and use.

\subsection{Operationalization of pooled fund mechanism for the PMS}

Pooled Fund partners have made pledges and contributed to the PMS Pooled Fund. The amount of money from Pooled Fund Partners deposited to the holding account in the Bank of Tanzania during financial year 2002/03 was Tsh 408,390,000 deposited at the end of December 2002 by the Danish Embassy. The use of the funds awaited the finalization of financial procedures for utilization of funds. These were finalized in 2003.

The Memorandum of Understanding (MoU) between GOT and Development Partners concerning the pooled fund for poverty monitoring was prepared and signed in March 2003. Also the TWGs and the Secretariat have opened their respective Bank Special accounts to facilitate smooth flow of funds and implementation of the planned activities.

\subsection{Challenges encountered}

Generally the performance of all four Technical Working Group was satisfactory although some activities were not implemented according to plan due to irregular disbursement and shortage of funds. Operationalization of the joint funding mechanism provides for smooth operations. However, Government recognizes the need to make an open assessment of the weaknesses of the system at the operational level. 


\section{Annexes: Policy Matrix for Poverty Reduction Strategy}

\section{A.I: Macroeconomic, Good Governance and Private Sector Development}

\begin{tabular}{|c|c|c|}
\hline OBJECTIVE & PROGRESS TO DATE & PLANNED ACTIONS \\
\hline $\begin{array}{l}\text { Macroeconomic: } \\
\text { - Attain a real growth of } 6.3 \% \text { in } 2004 \text {. } \\
\text { - Reduce inflation to about } 4.0 \% \text { by } \\
2004 \text {. } \\
\text { - Increase revenue efforts to } 13.2 \% \text { of } \\
\text { GDP in } 2004 / 05 \text {. } \\
\text { Good governance: } \\
\text { - Continue to promote good governance } \\
\text { in public service delivery through } \\
\text { improvements in public finance } \\
\text { management and accountability, } \\
\text { strengthening legal and regulatory } \\
\text { framework, poverty reduction } \\
\text { initiatives, and fighting corruption. } \\
\text { Private Sector: } \\
\text { - Creation of friendly and conducive } \\
\text { business environment. }\end{array}$ & $\begin{array}{l}\text { Macroeconomic: } \\
\text { - GDP growth was at } 6.2 \% \text { in } 2002 \text {, and about } 5.5 \% \text { in } \\
2003 \text {. } \\
\text { Good governance: } \\
\text { - The PCB was strengthened by increasing its budgetary } \\
\text { resources and decentralized from zones to district-level. } \\
\text { - There was a substantial increase in the number of } \\
\text { corruption cases lodged, from } 33 \text { in } 2000 \text { to } 129 \text { in } 2002 \text {. } \\
\text { However, the number of convictions is low, recoding } 6 \text { in } \\
2000 \text { and } 12 \text { in } 2002 \text {, attributed to the long delay in } \\
\text { processing cases before a conviction or acquittal is } \\
\text { obtained. } \\
\text { - National Integrity Fund to support the implementation of } \\
\text { anti-corruption activities and plans developed by MDAs } \\
\text { has been established. } \\
\text { Private Sector: } \\
\text { - Land bank draft report completed in } 2003 \text {. } \\
\text { - Labor policy completed. } \\
\text { - Nuisance taxes removed. } \\
\text { - Restructuring and privatization ongoing. }\end{array}$ & $\begin{array}{l}\text { Macroeconomic \& Good governance:: } \\
\text { - Consolidate macroeconomic stability through } \\
\text { promoting broad-based economic growth } \\
\text { strategies. } \\
\text { - Continue with implementation of public sector } \\
\text { reforms. } \\
\text { - Mobilize more revenue and increase resource } \\
\text { allocation to identified pro-poverty reducing } \\
\text { activities. } \\
\text { - Sustenance of peace and security through } \\
\text { combating crime. } \\
\text { - Create employment opportunities through } \\
\text { increased public and private investments. } \\
\text { - Continue with decentralization process. } \\
\text { - Strengthening judicial and justice system. } \\
\text { - Strengthening financial management and control. } \\
\text { - Continue fighting corruption. } \\
\text { Private Sector: } \\
\text { - Finalization of amendments to the Land policy } \\
\text { and establish the land bank. } \\
\text { - Harmonize and rationalize the licensing process. } \\
\text { - Implementation of BEST. } \\
\text { - Provide stable electricity power, water, } \\
\text { telecommunication and transport systems. }\end{array}$ \\
\hline
\end{tabular}




\begin{tabular}{|c|c|c|}
\hline OBJECTIVE & PROGRESS TO DATE & PLANNED ACTIONS \\
\hline $\begin{array}{l}\text { - Provide the decision policy-making } \\
\text { process with evidence-based policy } \\
\text { advice or information. } \\
\text { - Strengthen data collection and } \\
\text { analysis on poverty trends. }\end{array}$ & $\begin{array}{l}\text { - Preparation of the Second PRS Progress Report } \\
(2001 / 02) \text {, publishing of the Poverty and Human } \\
\text { Development Report (PHDR 2002), dissemination of the } \\
\text { Household Budget Survey (HBS2000/01) and Integrated } \\
\text { Labor Force Survey (ILFS 2002/01). } \\
\text { - A Participatory Poverty Assessment (PPA) exercise was } \\
\text { carried out and focused on vulnerability. } \\
\text { - Efforts are also underway to establish a Monitoring } \\
\text { Website and Documentation Center within the Poverty } \\
\text { Eradication Division. } \\
\text { - The Poverty Policy Week was held in September } 2002 \\
\text { and October } 2003 \text { with the objective to sensitize people } \\
\text { and advocate for change. } \\
\text { - A number of workshops were organized and conducted } \\
\text { by the Routine Data System Technical Working Group at } \\
\text { national and zonal levels. The objectives of these } \\
\text { workshops were to raise awareness among sector } \\
\text { ministries, regional secretariats, NGOs, local authorities, } \\
\text { academia and other stakeholders on the PMS and link it } \\
\text { with the local Government Monitoring and Evaluation } \\
\text { system. }\end{array}$ & $\begin{array}{l}\text { - Continue with production of } 2002 \text { census } \\
\text { reports/volumes } \\
\text { - (a) Complete fieldwork of agricultural sample } \\
\text { census - February } \\
\text { (b) Complete fieldwork of HIV/AIDS Indicator } \\
\text { Survey - April } \\
\text { - (a) Initial planning of DHS } \\
\text { (b) Field work - 2004/05 } \\
\text { - Report preparations } \\
\text { (a) Agricultural sample census } \\
\text { (b) HIV/AIDS Indicator Survey } \\
\text { RDS: To strengthen capacity on Routine Data } \\
\text { System - collection at all levels } \\
\text { To Harmonize Routine Data System collection } \\
\text { DSA: To disseminate PMS findings during the PPW } \\
\text { and other dissemination channels in } \\
\text { collaboration with other TWGs } \\
\text { R\&A WG: } \\
\text { - Identify priority research areas } \\
\text { (i) Poverty mapping: depends on inpts from census } \\
\text { and survey } \\
\text { (ii) Impacts of user charges in health sector: access } \\
\text { of poor people to health services } \\
\text { - Dissemination in collaboration with DSA } \\
\text { PHDR 2003 popular version } \\
\text { - Evaluate PPA: to provide lessons for } \\
\text { improvement of future PPA } \\
\text { - Identify research priority areas for the PHDR } \\
\text { 2004 and PRS Review. } \\
\text { - Prepare (PRS Technical Committee) the Second } \\
\text { MDG Report 2004 for Tanzania. }\end{array}$ \\
\hline
\end{tabular}




\begin{tabular}{|c|c|c|}
\hline OBJECTIVE & PROGRESS TO DATE & PLANNED ACTIONS \\
\hline $\begin{array}{l}\text { - Provide adequate, clean and safe } \\
\text { water and sanitation services through } \\
\text { rehabilitation and expansion of } \\
\text { existing rural water schemes and } \\
\text { construction of new water projects } \\
\text { with targets to increase coverage from } \\
53 \% \text { in } 2003 \text { to } 60 \% \text { in } 2006 \text {. }\end{array}$ & $\begin{array}{l}\text { - Rehabilitation and expansion of } 41 \text { rural water schemes, } \\
118 \text { boreholes, and construction of } 2 \text { large dams and } 3 \\
\text { medium size dams is complete. } \\
\text { - The new Chalinze water supply scheme is almost } \\
\text { complete. } \\
\text { - } 37 \text { district town water boards are in place. } \\
\text { - } 1431 \text { underground water areas explored and } 968 \\
\text { boreholes drilled. } \\
\text { - National water Policy } 2002 \text { launched in March } 2003\end{array}$ & $\begin{array}{l}\text { - Rehabilitate and expand } 794 \text { water supply } \\
\text { schemes in rural areas by } 2006 \text {. } \\
\text { - Explore underground water in } 700 \text { areas to ease } \\
\text { construction of new water schemes especially in } \\
\text { dry areas. } \\
\text { - Ensure district town water boards are in place in } \\
\text { all district headquarters by } 2006 \text {. } \\
\text { - Construct Mugumu dam in Serengeti district. } \\
\text { - Replicate rural water supply and sanitation } \\
\text { project to } 50 \text { districts by } 2005 \text {. }\end{array}$ \\
\hline $\begin{array}{l}\text { - Rehabilitation and expansion of urban } \\
\text { water supply to increase service levels } \\
\text { with targets from } 73 \% \text { in } 2003 \text { to } 78 \% \\
\text { in } 2006 \text {. }\end{array}$ & $\begin{array}{l}\text { - The study on pricing policy is in place, service package } \\
\text { for vulnerable groups identified and operational. } \\
\text { - Rehabilitation and expansion of Water supply and } \\
\text { Sewerage Systems in Seven Municipalities and eight } \\
\text { towns is complete. } \\
\text { - Phase II of expansion of urban water supply is } 80 \% \\
\text { complete } \\
10,462 \text { water meters installed. } 50 \% \text { of customers now } \\
\text { installed with meters, } \\
\text { DAWASA privatization is completed. Private operator } \\
\text { operating since August } 2003 \text {. }\end{array}$ & $\begin{array}{l}\text { - Restructure urban water supply pricing by the } \\
\text { - } \text { year } 2004 \\
\text { - Complete phase II of urban water supply by } 2005 \text {. } \\
\text { - ponduct studies, design and implementation of } \\
\text { - Ensure customers are connected with water } \\
\text { meters by } 2005 \text {. }\end{array}$ \\
\hline $\begin{array}{l}\text { - To strengthen water resource } \\
\text { environmental and pollution control } \\
\text { network with targets to reduce } \\
\text { pollution levels from } 20 \% \text { in } 2003 \text { to } \\
10 \% \text { in } 2006\end{array}$ & $\begin{array}{l}\text { - } 1588 \text { water samples were tested for standard amount of } \\
\text { chemicals, and } 1839 \text { water samples were tested for } \\
\text { turbidity and bacteriological parameters, advisory } \\
\text { measures were taken. } \\
\text { - } 78 \text { industries were inspected to control industrial } \\
\text { effluents. }\end{array}$ & $\begin{array}{l}\text { Increase activities for water resource } \\
\text { environmental and pollution control network in } \\
\text { order to reduce pollution levels from } 20 \% \text { to } 10 \% \\
\text { by } 2004 \text {. }\end{array}$ \\
\hline $\begin{array}{l}\text { To improve Management of Water } \\
\text { Resources (RBM), with targets to have } \\
\text { in place water quantity surveillance and } \\
\text { management mechanism in all water } \\
\text { basins by the year } 2006\end{array}$ & $\begin{array}{l}\text { Five water basin offices in five Basins are in place. } \\
\text { - } 176 \text { hydrometric stations were rehabilitated, } 47 \text { data } \\
\text { lodgers installed and one isotopic hydrometric station } \\
\text { was built at Makutopora Sub-basin. }\end{array}$ & $\begin{array}{l}\text { - Put in place basin offices in the remaining four } \\
\text { basins by } 2005 \text {. } \\
\text { - Rehabilitate the existing hydrometric networks } \\
\text { and complete the network in all basins by } 2005 \text {. }\end{array}$ \\
\hline
\end{tabular}




\section{PROGRESS TO DATE}

- Strengthen immunization services, malaria control activities, nutritional programs, reduce maternal and child mortality rates and reduce prevalence of HIV/AIDS.

- Improving environmental sanitation and safe water.

- Promoting curative services at all levels. the health sector program.
- All 113 Local Authorities have developed their comprehensive District health plans, which target to provide quality of health services, inline with PRSP goals.

- 31 districts which were in Phase III of LGRs are now brought on board by January 2003 to accelerate poverty reduction initiative in

- The Health Sector Strategic Plan 2003-2008 was developed as a continuation of the effort to implement Health Sector Reforms.

- The Health Sector Public Expenditure Review that was undertaken in January 2001 has revealed that per capita public health spending has risen from US\$3.4 to US\$5.50 between 1997/98 to 1999/2000, the PER 2002 indicates 6,361 TSh per capita.

- The sectoral allocation to health is only increasing very slowly, from $7.5 \%$ in FY00 to an estimated $8.7 \%$ in FY03.

- In the PER 2003 the spending on preventive health has increased from $41.4 \%$ in FY01 to $47.8 \%$ in FY02.

- A plan of Action of reforming the tertiary and secondary health services to re-orient these services to support the level I health care is well elaborated, and activities towards hospital reforms started with reforming $\mathrm{MMC}$ to $\mathrm{MNH}$.

- The legal framework of restructuring $\mathrm{MMC}$ is in place, the $\mathrm{MNH}$ board and management has been established.

- Private Sector Development and participation in the service provision is promoted through the Health Sector Reform proposals 1994. This is further elaborated in the HSSP 2003-2008.

- 47 new councils were trained in IMCI, community strategy for IMCI was developed, Kiswahili versions of IMCI modules are now available and IMCI indicators have been developed.

- The reproductive and child health unit reports a MMR for 2002 to be $228.3 / 100.000$

- There is continuing increase in the utilization of $\mathrm{MCH}$ services which include reproductive health and family planning.

- Control of common disease conditions are being addressed under different programs e.g. Malaria Control, onchoceriasis control, schistosomiasis control EPI, TB and Leprosy Control. Furthermore the EAC will address this as an EAC issue to contain these diseases.
PLANNED ACTION

- The government will emphasize on the 'Essential Health Package', to maximize the impact of limited resources and to ensure delivery of essential health at all levels to meet the needs of the poor and vulnerable groups.

- Operationalize the Health Sector Strategic Plan 2003-2008 at all levels.

- A Financing Task Force has been established with an aim of negotiation with $\mathrm{MoF}$ and donors to increase the resources envelope

- A new resource allocation formula for the local government health grant is being developed to ensure equity in resources allocation to LG. This formula takes into account population, poverty, mileage traveled by medical vehicles and burden of disease.

- A strategy for rehabilitation of health services is being developed and implementation is expected to start very soon

- Initiate district hospital reforms and thereby improve quality of care and strengthened the district referral system.

- The MoH has established a co-ordination desk for this activity, which include registration of the private sector facilities. The $\mathrm{MoH}, \mathrm{CSSC}$ and faith groups are working out modalities of participation from policy to implementation over and above the current contractual arrangements under DDH, and grants to the NGO's (VA) hospitals.

- Accreditation of more private facilities is being undertaken by NHIF and is expected to strengthen service delivery.

- New figures for IMR and U5MR are expected to come from the NBS by the beginning of 2004

Provide Maternal and Child Health Services, promote adequate nutrition and improve control of communicable and preventable diseases. 


\section{A.V: Gender \\ OBJECTIVE}

Enhance capacity for gender mainstreaming in the PRS/ MTEF/

PER and in sector plans, strategies and programs

\section{PROGRESS TO DATE}

Gender focal persons have been approved and established in the major PRS priority sectors and their training needs defined;

\section{Monitoring gender}

(i) Considerable gender analysis is available in two major poverty-monitoring reports, PHDR 2002, 2003.

(ii) Computerized system for monitoring progress in gender equity has been initiated within MCDGC and will be completed in April 2004.

(iii) A detailed analysis of the HBS data on Female Headed Households has been completed

Legal reform: A National Plan of Action for Combating Violence Against Women has been developed and resources are being sought to make it operational

Capacity Building: MCDGC has enhanced its capacity to promote gender mainstreaming.

Mainstreaming gender in the PRS: VPO and MCDGC held a consultative meeting to mainstream gender in the Planned PRS Review. An Action Plan has been developed to see how the process can be engendered and made more participatory.

Women's economic empowerment: women's participation in trade fairs was facilitated

Elimination of discrimination in employment and occupation: 731 women workers have been assisted to form economic groups and their capacities enhanced with easy access to productive resources including flexible loans.

\section{PLANNED ACTIONS}

---VPO, MCDGC and other stakeholders to

work together to ensure that gender issues and concerns are taken on board in the PRS Review planned for 2003/2004. VPO to coordinate this process

---Sectors and PORALG will carry out capacity building for gender focal points for

mainstreaming gender within the sectors and for improvement in collection and analysis of gender disaggregated data

---MCDGC /VPO will jointly complete the gender database and monitoring system and provide guidelines for sectors and PORALG to collect gender disaggregated data.

---MCDGC/VPO to work out a system to obtain information from sectors, NGOs and private sector on activities related to promoting gender equity and mainstreaming

---MOLYDS/MCDGC will consolidate the achievements and replicate them so that 1,000 more women can participate and benefit from development interventions

\section{A.VI: Education}

\section{OBJECTIVE}

- Raise gross and net enrolment and enhance the quality of basic education.

- Improving access and equity to education at all levels.

- Increasing the number and quality of teaching staff.

- Strengthening and improving the management capacity at all levels of education.

- Controlling the spread of HIV/AIDS

\section{PROGRESS TO - DATE}

- Gross enrolment ratio is at $105.3 \%$ and Net enrolment ratio at $88.5 \%$ in 2003 . Both ratios have increased from $100.4 \%$ and $80.7 \%$ respectively in 2002. Construction of 13,396 classrooms is expected to be completed by November 2003 .

- 98 districts have been school mapped and by the end of November, 2003 the number of micro planned shall add up to 69 districts.

- Training of Trainers of 763 facilitators to upgrade 50,000 grades "C/B" teachers to grade "A" was conducted.

\section{PLANNED ACTIONS}

- Allocate more resources to the sector.

- Construction 14,203 classrooms, 8,197 teacher houses, pit latrines and rain water-harvesting tanks.

- Enrolment of 1,640,969-school age going children, recruit 10,563 new teachers and enroll 11,290 teacher trainees.

- Ensure pupil book ratio of 1:3 for teaching and learning books so as to attain the ratio of $1: 1$ by 2006 .

- Inspect 19,080 Education units to ensure quality Education.

- Improving water supply and sanitation.

- Conducting counseling activities on radio and TV on HIV/AIDS. 


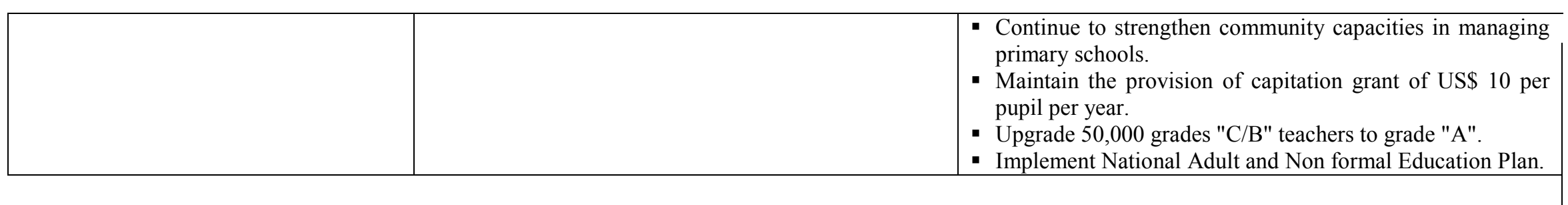

\begin{tabular}{|c|c|c|}
\hline OBJECTIVE & PROGRESS TO DATE & PLANNED ACTIONS \\
\hline $\begin{array}{l}\text { - Improve rural and district and cross } \\
\text { border roads network to enhance } \\
\text { access to farm and agriculture } \\
\text { markets. } \\
\text { - Capacity-building in the LGAs to } \\
\text { enable them manage road networks } \\
\text { effectively. } \\
\text { - Implementation of the EAC-Sub } \\
\text { regional priority road network } \\
\text { program. } \\
\text { - Maintenance of trunk, regional, } \\
\text { urban, district and feeder roads. } \\
\text { - Increasing budget allocation to } \\
\text { financing rehabilitation and } \\
\text { maintenance of using of labor- } \\
\text { intensive technology. }\end{array}$ & $\begin{array}{l}\text { - Somanga-Masaninga including construction of } \\
\text { Matandu bridge, Nangurukuru-Mbwemkulu, } \\
\text { Mbwemkulu-Mingoyo, Dodoma-Manyoni and } \\
\text { Manyoni-Singida road sections: } \\
\text { - Consultants for the supervision of the works } \\
\text { procured. } \\
\text { - } 34 \% \text { increase in budget allocation for FY 2002/03. } \\
\text { - Routine maintenance, emergency repair and spot } \\
\text { improvement carried out in all } 20 \text { regions. } \\
\text { - Rehabilitation of regional roads in progress, } 525 \\
\text { km of regional roads are currently under } \\
\text { rehabilitation. } \\
\text { - Periodic maintenance of } 10,120 \mathrm{kms} \text { of the rural } \\
\text { roads network has been done }\end{array}$ & $\begin{array}{l}\text { - The government will continue to release the allocated } 1.84 \\
\text { billion monthly to improve transport link to the } \\
\text { northwestern and southern regions of the country. } \\
\text { - Advocate the use of Labor Based Technology in } \\
\text { rehabilitation, routine, periodic and sport improvement for } \\
\text { the whole network. } \\
\text { - Develop and prepare a Program similar to } 10 \text { years Road } \\
\text { Sector Development Program for the District, Urban and } \\
\text { Feeder Roads. } \\
\text { - Implementation of the EAC Sub-regional priority road } \\
\text { network program. } \\
\text { - National rollout and dissemination of District Roads } \\
\text { Management System (DROMAS) to District Councils. } \\
\text { - National rollout and dissemination of Urban Roads } \\
\text { Management System (RMMS) to } 21 \text { Town Councils. } \\
\text { National rollout and dissemination of VTTP Program } \\
\text { package tools to } 113 \text { districts (including training, baseline } \\
\text { access study, capacity building, guidance notes etc. } \\
\text { - Undertake maintenance of trunk, regional, district and } \\
\text { feeder roads network, and carry out emergency repair and } \\
\text { spot improvement in all district roads } \\
\text { - Improve the capacity of district engineers to manage } \\
\text { execution of road maintenance works at district level. }\end{array}$ \\
\hline
\end{tabular}


A.VIII: Judiciary and Justice

\section{OBJECTIVE}

- To enhance timely and accessible justice for all, in line with basic human rights focusing on personal safety, access to justice, overall efficiency, fairness, and transparency of the administrative system.

\section{PROGRESS TO DATE}

- Increased appointment and recruitment in the judiciary.

- Enhanced training of magistrates and judges.

- Introduction of the alternative dispute resolution.

- Establishment and operationalization of the Human Rights and Good Governance Commission.

- Enhanced budgetary allocation to the Judiciary, Attorney General's Chambers and Law Reform Commission.

\section{PLANNED ACTIONS}

- Introducing individual Calendar system of managing cases in the High Court and Subordinate Courts;

- Strengthening the Institute of Judicial Administration;

- Strengthening Law Reform Commission of Tanzania through the provision of adequate working tools and materials and training;

- Improving prosecution capacity;

- Initiating measures aimed at reducing crowding of prisons;

- Combating crime and insecurity;

- Establishing and operationalization of Judicial Ethics Committee;

- Continue with rehabilitation of primary courts buildings;

Extension of Commercial Court Sub-Registries in Arusha and Mwanza.

\section{A. IX: Agriculture}

\begin{tabular}{|c|c|c|}
\hline OBJECTIVE & PROGRESS TODATE & PLANNED ACTION \\
\hline $\begin{array}{l}\text { Create an enabling and } \\
\text { conducive environment } \\
\text { profitability of the sector and } \\
\text { ensure food security. } \\
\text { - Increase production and the } \\
\text { processing of agricultural } \\
\text { and livestock outputs. } \\
\text { - Strengthen support services } \\
\text { for agricultural and livestock } \\
\text { growth (research, extension } \\
\text { and technical services). } \\
\text { - Support commercialization } \\
\text { of agriculture. }\end{array}$ & $\begin{array}{l}\text { - Agricultural Sector Development Strategy } \\
\text { Developed in 2001. } \\
\text { - Agriculture Sector Development Program } \\
\text { Framework and process document completed. } \\
\text { - Restrictions on internal trade on agriculture } \\
\text { products removed } \\
\text { - District Agricultural Development Plans } \\
\text { (DADPs) prepared. } \\
\text { - Local government taxes and levies } \\
\text { harmonized. } \\
\text { - Private Agribusiness Sector (PASS) } \\
\text { intensified } \\
\text { - Food Security Policy Formulated. } \\
\text { - Agriculture Survey on going. }\end{array}$ & $\begin{array}{l}\text { - Finalizing detailed formulation of the ASDP sub-program (ASDP) } \\
\text { phase II). } \\
\text { - Continue with the analysis of Agriculture Survey 2003/2004. } \\
\text { - To develop monitoring and evaluation system for ASDP within the } \\
\text { PRS monitoring framework. } \\
\text { - Development of small-scale irrigation schemes including water } \\
\text { harvesting. } \\
\text { - To strengthen extension services and strategic research by } \\
\text { institutionalizing participatory methodologies and district level. } \\
\text { - To strengthen control of crops migratory pest and diseases. } \\
\text { - Review of legal and institutional framework for participation of } \\
\text { private sector in agricultural development. } \\
\text { - To promote agricultural inputs credit systems through support of } \\
\text { AGITF. }\end{array}$ \\
\hline
\end{tabular}




\begin{tabular}{|l|l|l|}
\hline & & $\begin{array}{l}\text { - Strengthen Veterinary Investigation Centers (VICs) to carry out } \\
\text { effective disease surveillance and early warning system, analyze, } \\
\text { process animal disease data. } \\
\text { - Strengthen livestock products, inputs and regulatory services in order } \\
\text { to achieve quality assurance. } \\
\text { - Strengthen rangeland management development in } 50 \text { local authorities } \\
\text { and provide water for livestock in drought prone regions. } \\
\text { Control and arrest the spread of trans-boundary diseases such as } \\
\text { Contagious Bovine Pleuroneumonia (CBPP), African Swine Fever } \\
\text { (ASF), New castle disease (ND) etc in country. }\end{array}$ \\
$\begin{array}{l}\text { Capacity building Cooperative society through Export Credit } \\
\text { Guarantee Scheme (ECGS) }\end{array}$ \\
$\begin{array}{l}\text { Promotion and Establishment of Cooperative Banks. } \\
\text { - Review of 1991 Cooperative Act (Code of Conduct for Cooperative } \\
\text { Management. } \\
\text { - Formulation and operationalization of enabling Agricultural Marketing } \\
\text { Policy by year 2004' } \\
\text { Monitoring and evaluation of Marketing projects (AMSDP) } \\
\text { Establishment of marketing Development center by June, 2004 } \\
\text { - To expand and promote market potentials of non-traditional crops (e.g. } \\
\text { cassava and millet). }\end{array}$
\end{tabular}

\section{A.X: HIV/AIDS}

\section{OBJECTIVE}

- To improve services and reduce HIV/AIDS infection.

- Combating HIV/AIDS in general and preventing the spread of HIV/AIDS infection'

- Care and treatment of PLWHA

- Support to HIV/AIDS affected victims.

\section{PROGRESS TO DATE}

- MDAs are developing plans for mainstreaming HIV/AIDS intervention into routine activities including workplace interventions and MTEF

- Many private enterprises have workplace HIV/AIDS interventions including provision of anti retroviral treatment.

- To ensure that communities at the grassroots have sustained HIV/AIDS interventions, LGAs supported in developing comprehensive HIV/AIDS programs that involve all stakeholders.

- Guidelines for the establishment of District AIDS Committees have been disseminated to all LGAs to facilitate community mobilization and involvement in the fight against HIV/AIDS.

- Modules for training members of the District AIDS Committees and technical functionaries have been developed and training started in November 2003.

- Efforts to mainstream HIV/AIDS in the planning/budgeting process have been initiated and will be applied in the fiscal year 2004/05. Medium Term Expenditure Review (MTEF) for 2003/04 2005/06 for TACAIDS has been developed and TACAIDS now operates own vote.

National monitoring and evaluation framework for the national response has been developed and core team of trainers trained. A protocol for Tanzania HIV Indicator Survey (THIS) has been developed.

\section{PLANNED ACTIONS}

- MDAs to identify HIV/AIDS activities appropriate to the targets.

- Providing costing for identified activities by MDAs.

- Show the linkages between the activities, objectives and priority areas.

- Identify and quantify output by MDAs. 


\begin{tabular}{|c|c|c|}
\hline OBJECTIVE & \begin{tabular}{|l} 
PROGRESS TO DATE \\
\end{tabular} & PLANNED ACTIONS \\
\hline \multirow[t]{4}{*}{$\begin{array}{l}\text { - Enhanced productivity } \\
\text { and competitiveness, } \\
\text { elimination of child } \\
\text { labor and increased } \\
\text { vulnerability of credit } \\
\text { facilities for micro } \\
\text { enterprises. } \\
\text { - Reduce prevalence of } \\
\text { poverty in urban areas }\end{array}$} & $\begin{array}{l}\text { Finalization of policies: } \\
\text { - Two policies are in place i.e. the National Aging Policy and the } \\
\text { National Social Security. } \\
\text { - Two policies are at the stage of being submitted to IMTC i.e. the } \\
\text { National Employment and the National Disability. } \\
\text { - One policy - National Youth Development under revision is ready for } \\
\text { submission to Cabinet Secretariat. } \\
\text { - Child Labor Policy has been replaced by strategies to combat child } \\
\text { labor and its worst forms. The Child labor survey report was } \\
\text { completed and disseminated in 2003. The findings contributed to draft } \\
\text { formulation of child labor strategies. }\end{array}$ & $\begin{array}{l}\text { - Have all policies in place and complete and carry } \\
\text { out policy implementation strategies for these } \\
\text { policies. } \\
\text { - Facilitate formation of the Youth representative } \\
\text { bodies from Village to National level, having in } \\
\text { place National Youth Council as an Apex body. } \\
\text { - The strategies to combat child labor and its worst } \\
\text { forms finalized and linked to the national Child } \\
\text { Development Policy. }\end{array}$ \\
\hline & $\begin{array}{l}\text { Promoting of more and better jobs for women under conditions that } \\
\text { will reduce child labor: } \\
\text { - } 848 \text { poor women workers have been assisted to organize into } \\
\text { economic groups and provided with new skills including mushroom } \\
\text { farming, poultry keeping, handcraft production, vegetable growing } \\
\text { etc. } \\
\text { - } 541 \text { women workers have registered with Akiba Commercial Bank } \\
\text { and are receiving loans } \\
\text { - } 1026(475 \text { girls and } 551 \text { boys) younger and older children have been } \\
\text { withdrawn from child labor and provided with alternatives for basic } \\
\text { education and vocational training } \\
\text { - } 14 \text { daycare attendants have been trained, } 15 \text { daycare centers renovated } \\
\text { and } 1,258 \text { ( } 51 \% \text { girls) smaller children enrolled in the daycare centers } \\
\text { and provided with uniforms, learning and playing materials and a } \\
\text { feeding program. }\end{array}$ & $\begin{array}{l}\text { - Provide loans to } 400 \text { more women workers } \\
\text { - } \text { economize } 1,000 \text { more women workers into } \\
\text { - Remove } 1,000 \text { ( } 50 \% \text { girls) younger and older } \\
\text { children from child labor and provide them with } \\
\text { alternatives for primary education and formal and } \\
\text { non-formal vocational training } \\
\text { - Assist } 400 \text { ( } 50 \% \text { girls) youth withdrawn from } \\
\text { child labor and provided with vocational skills to } \\
\text { set up youth economic groups for income } \\
\text { generation. } \\
\text { Train } 10 \text { more daycare attendants and } \\
\text { rehabilitate/create } 10 \text { daycare centers in project } \\
\text { locations. }\end{array}$ \\
\hline & \begin{tabular}{|l|} 
Creation of employment in municipal services delivery \\
- 2,000 jobs were created in solid waste management services in Dar es \\
Salaam on public-private-partnership approaches
\end{tabular} & $\begin{array}{l}\text { - To up-scale the activity in at least six } \\
\text { municipalities }\end{array}$ \\
\hline & $\begin{array}{l}\text { Promote employment for people with disabilities (pwds) } \\
\text { - } 50 \text { people with disabilities received seed money for income generating } \\
\text { activities. } \\
\text { - } 12 \text { people with disabilities received working tools. } \\
\text { - } 155 \text { people with disabilities were admitted in vocational training } \\
\text { institutions under various skills }\end{array}$ & $\begin{array}{l}\text { - To give seed money and working tools to more } \\
\text { people with disabilities. } \\
\text { - To avail more vacancies to people with } \\
\text { disabilities in vocational training institutions to } \\
\text { more people with disabilities. }\end{array}$ \\
\hline
\end{tabular}




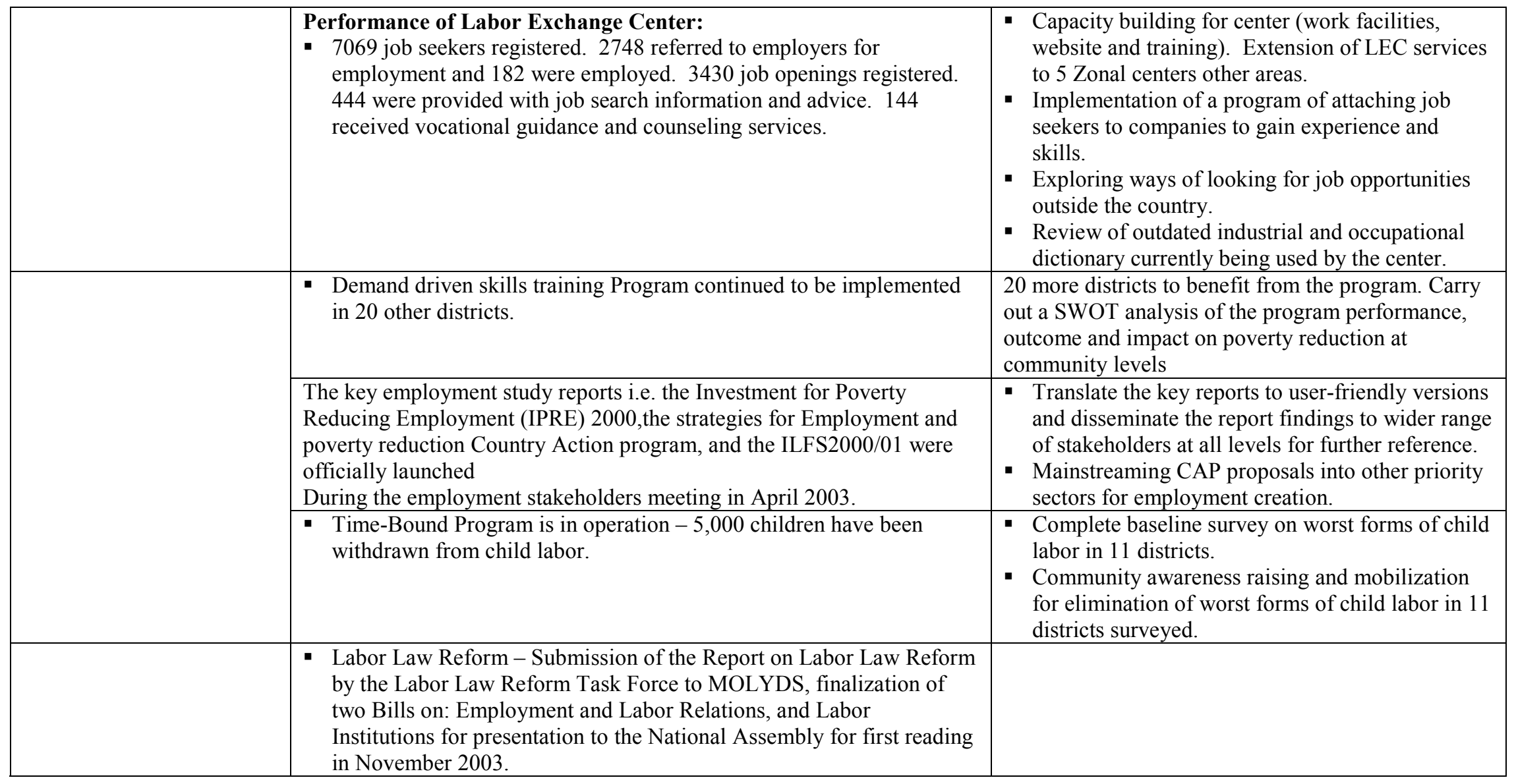

\section{A.XII: Environment}

\begin{tabular}{|l|}
\hline Objective \\
\hline Integrating \\
environment into the \\
PRS process to \\
support sustained \\
economic growth \\
and development
\end{tabular}

\section{Progress to-Date}

Cabinet approved a new institutional framework for environmental management in December 2002.

Environment framework law - Following approval of the institutional set up the VPO have led on the development of a single environmental framework law with a first draft prepared for consultation in December 2003.

Launch of Program to Integrate Environment into the PRS process. Outputs focus on knowledge on poverty-

\section{Planned Actions}

In general implementation of program to integrate environment into PRS process.

Poverty and environment linkages - continue to document on poverty and environment linkages and commission studies as appropriate.

Poverty and environment indicators - Complete study on poverty-environment indicators, and use the results of this to review and amend poverty-environment indicators to strengthen the national 


\begin{tabular}{|c|c|c|}
\hline Objective & Progress to-Date & Planned Actions \\
\hline & $\begin{array}{l}\text { environment linkages, use of environment data in poverty } \\
\text { monitoring system, and capacity building of Government and } \\
\text { non-government stakeholders. } \\
\text { Establishment of Environment Working Group - a } \\
\text { cross-sector environment-working group (EWG) has been } \\
\text { established to promote the integration of the environment into } \\
\text { the GOT policies and plans to help ensure the sustainable use } \\
\text { of Tanzania's environment and natural resources for poverty } \\
\text { reduction. } \\
\text { PER Environment - the first public expenditure } \\
\text { review (PER) of the environment has been initiated and is } \\
\text { expected to produce inputs into MTEF and guidelines to } \\
\text { mainstream environment into their sector PERs. } \\
\text { Utilization of poverty-environment data for use in } \\
\text { PRS process - Preliminary poverty-environment indicators } \\
\text { were included in the revised indicator list for the PMS for use } \\
\text { by PRBS/PRSC. TOR for detailed study on poverty- } \\
\text { environment indicators developed and identification of } \\
\text { consultants to undertake study is underway. } \\
\text { Integration of environmental management in the } \\
\text { sector programs. Approval of environment units for sectors, } \\
\text { and development of SEA (see below). } \\
\text { Agricultural survey - VPO with NBS worked on the } \\
\text { design and questionnaire of the agricultural survey to ensure it } \\
\text { included relevant questions on environment sustainability and } \\
\text { livelihood issues. } \\
\text { Strategic environment assessment - Study completed } \\
\text { on the use of SEA and poverty reduction. }\end{array}$ & $\begin{array}{l}\text { poverty monitoring system. } \\
\text { PRS review - a central element of the coming years activities } \\
\text { will be attention to environment as one of priority cross cutting issues } \\
\text { in the review of PRS. } \\
\text { Cross-cutting issues and mainstreaming - develop links with } \\
\text { groups mainstreaming other cross-cutting issues including gender, to } \\
\text { help ensure effective mainstreaming of these issues and build } \\
\text { knowledge on useful tools for mainstreaming. } \\
\text { Local government - develop with PORALG pilot activities on } \\
\text { mainstreaming environment at the local government level (links with } \\
\text { the implementation of the new institutional structure for environment } \\
\text { management - see below). } \\
\text { Civil Society Organisations - focus work with environment } \\
\text { and conservation non-government organisations to increase their } \\
\text { awareness on poverty and environment issues, and their involvement in } \\
\text { the PRS process. } \\
\text { Private sector - strengthen engagement with private on } \\
\text { poverty and environment issues } \\
\text { Environmental framework law - finalise draft of law for } \\
\text { submission to Parliament following Cabinet approval, and subsequent } \\
\text { to its passing commence development of relevant environment } \\
\text { regulations and guidelines for: (a) integrating EA into sector and } \\
\text { district planning processes; (b) Economic instruments; (c) } \\
\text { environmental standards for monitoring and compliance. } \\
\text { Environment working group - strengthen membership of the } \\
\text { Environment Working Group, and broaden its present work to include } \\
\text { inputs into PRS review and implementation of PRS and engagement } \\
\text { with other sector working groups. } \\
\text { PER Environment - complete 2003/04 PER study and } \\
\text { develop sector guidelines to mainstream environment, and develop } \\
\text { TOR and commission PER study } 2004 / 05 \text { to build on first PER for } \\
\text { environment. } \\
\text { Tanzania Social Economic Database (TSED) - work with } \\
\text { NBS on using existing data collection and analysis of agriculture } \\
\text { survey to complete environment module of TSED. } \\
\text { Capacity building - implementation of capacity building } \\
\text { action plans under the program to integrate environment into the PRS. }\end{array}$ \\
\hline
\end{tabular}

